\title{
EFFECT OF COMMERCIAL FEED ADDITIVES ON PRODUCTION VARIABLES AND METABOLIC MARKERS OF THE PERIPARTURIENT DAIRY COW
}

\author{
A Dissertation \\ presented to
}

the Faculty of the Graduate School

at the University of Missouri-Columbia

In Partial Fulfillment

of the Requirements for the Degree

Doctor of Philosophy

By

NICOLE MARIE BARKLEY

Dr. Matthew R. Waldron, Dissertation Supervisor

DECEMBER 2013 
The undersigned, appointed by the Dean of the Graduate School, have examined the thesis entitled

\section{EFFECT OF COMMERCIAL FEED ADDITIVES ON PRODUCTION VARIABLES AND METABOLIC MARKERS OF THE PERIPARTURIENT DAIRY COW}

presented by Nicole Marie Barkley, a candidate for the degree of Doctor of Philosophy, and hereby certify that in their opinion it is worthy of acceptance.

Dr. Matthew R. Waldron

Dr. Monty S. Kerley

Dr. Duane H. Keisler

Dr. Scott E. Poock 


\section{ACKNOWLEDGEMENTS}

First and foremost, I would like to thank Dr. Matthew Waldron for taking me on as a Ph.D. student. Working for Dr. Waldron over the last five years has been an amazing learning experience. The time spent leading research projects and managing undergraduate students at the university farm have proven to be indispensable. Thank you also to Dr. Monty Kerley. Your support and guidance over the last five years has been greatly appreciated. Additional thanks go to my committee members; Dr. Duane Keisler and Dr. Scott Poock.

A big thank you goes out to all of the dairy farm staff for their time and efforts put towards my research. Individual thanks goes to the following people: Eric Adkins, for his strong work ethic and willingness to assist with daily research tasks and weekly body condition score evaluations. I was always able to count on you to make sure research ran as smoothly as possible. John Denbigh, for assisting with daily research tasks and always sharing your words of wisdom, even when they were neither helpful or scientifically accurate. Joe Ancell, for fixing all of the farm equipment that my undergraduate student workers broke and for always being there to put out the fires; literally.

Thank you to all of the undergraduate student workers that assisted with feeding, milking, and blood samples; in particular, Jessica Tolo. You were always there when I needed you and were more than happy to step up and be my top farm assistant. Thank you for taking the job seriously and investing your time and energy into our labs projects.

A special thank you goes out to Dr. Ann Kenny, for assisting me with every study either as a lab mate or as a friend. Thank you for always being willing to lend a hand with 
farm work and teaching me how to use SAS. More importantly, your support, guidance, and friendship were irreplaceable.

Lastly, I would like to thank my family and friends for their love and support throughout my graduate education. I can honestly say I would not be the dairy person I am today if it weren't for Dr. Amin Ahmadzadeh. He has continued to be a mentor, friend, and an amazing sounding board throughout the years. My parents John and Val deserve the biggest thank you of all for believing in me, encouraging me, and inspiring me to obtain my goals. Your constant and unending support has allowed me to find success and I thank you for that. 


\section{TABLE OF CONTENTS}

ACKNOWLEDGEMENTS ..........................................................

LIST OF FIGURES............................................................ viii

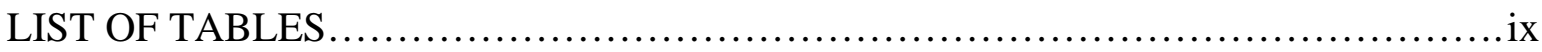

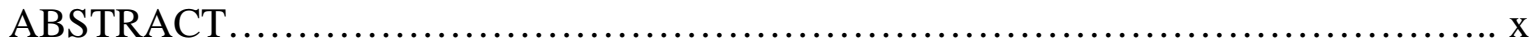

Chapters

1. REVIEW OF LITERATURE.......................................... 1

INTRODUCTION................................................... 1

Transition period and the periparturient cow.................. 1

Transition disorders and cost to producers.................. 3

Net energy balance........................................5

Lactation curve..................................... 5

Dry matter intake curve................................. 6

Physiological requirements of the prepartum cow.............. 6

Late pregnancy: Fetal growth

and mammary development............................ 7

Body condition score ................................ 7

Physiological requirements of the postpartum cow................ 9

Colostrum and milk production....................... 9

Change in body condition score........................ 10

Energy from body reserves................................ 10

Up regulation of hepatic gluconeogenesis...................... 12

Oxidative stress................................................ 12 
Biomarkers of oxidative stress......................... 13

Commercially available feed additives to aid in transition period.

Trace Minerals............................................15

Vitamins............................................. 17

Yeast culture..........................................19

Summary ................................................21

Work cited 21

2. PERFORMANCE OF DAIRY CATTLE FED THE COMMERCIAL MICRONUTRIENT SUPPLEMENT OMNIGEN-AF DURING THE PERIPARTURIENT PERIOD ................................................ 22

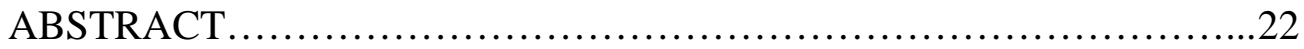

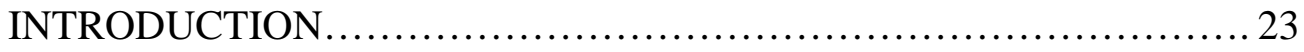

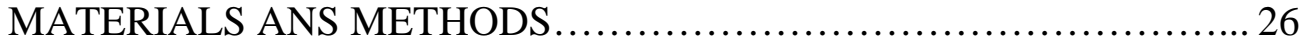

Cows and diets............................................. 26

Experimental protocol....................................... 26

Measurements and sampling ................................27

Animal observations...................................27

Dry matter intake and feed analysis..................... 28

Milk variables.............................................. 28

Plasma metabolites...........................................29

Experimental design and statistical analysis....................29

RESULTS....................................................... 31

DISCUSSION .......................................................... 33 
CONCLUSION.

3. EFFECT OF INORGANIC AND ORGANIC TRACE MINERAL SUPPLEMENTATION ON PRODUCTION AND OXIDATIVE STRESS VARIABLES IN PERIPARTURIENT HOLSTEIN DAIRY CATTLE........48

ABSTRACT .48

INTRODUCTION 49

MATERIALS ANS METHODS 52

Cows and diets. 52

Treatment preparation 53

Experimental protocol........................................ 54

Measurements and sampling .................................54

Animal observations...................................... 54

Dry matter intake................................... 55

Milk variables....................................... 55

Plasma metabolites and oxidative stress variables........... 56

Experimental design and statistical analysis....................57

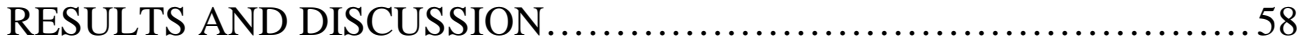

Overall animal health........................................ 58

Study diets............................................... 58

Production variables..........................................59

Metabolite and oxidative stress variables.......................64

CONCLUSION....................................................68

4. DOSE EFFECT OF YEAST CULTURE SUPPLEMENTATION ON PRODUCTION VARIABLES AND METABOLIC HEALTH OF PERIPARTURIENT HOLSTEIN CATTLE. . 


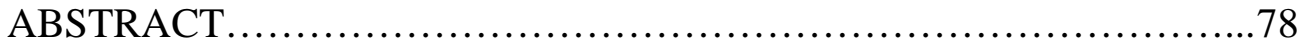

INTRODUCTION .................................................... 79

MATERIALS ANS METHODS............................................ 82

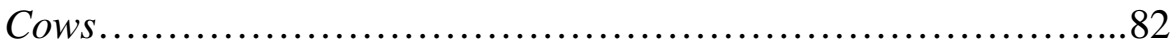

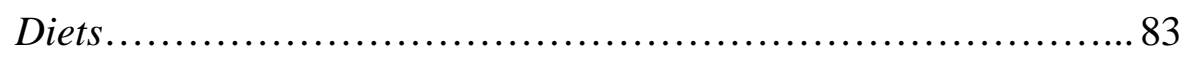

Experimental protocol............................................ 84

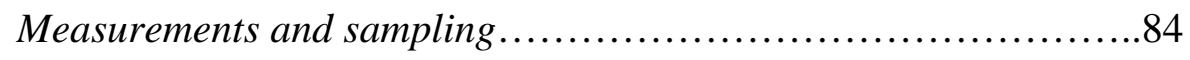

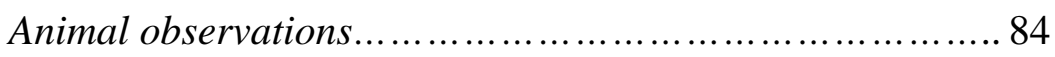

Dry matter intake............................................. 85

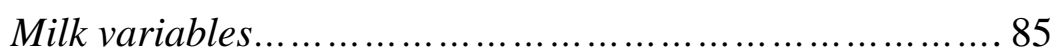

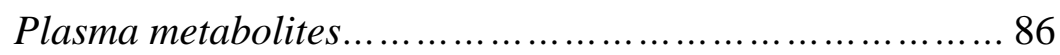

Experimental design and statistical analysis.......................... 86

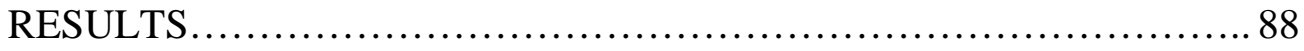

Overall animal health.......................................... 88

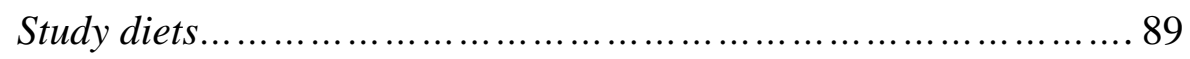

Production variables................................................... 90

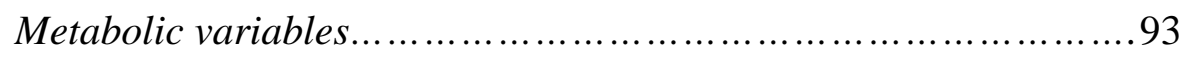

DISCUSSION ...................................................... 94

CONCLUSION....................................................... 99

LITERATURE CITED............................................................ 113

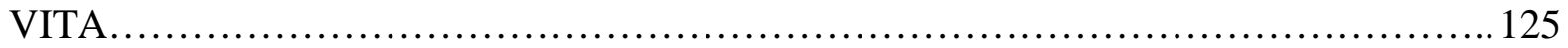




\title{
EFFECT OF COMMERCIAL FEED ADDITIVES ON PRODUCTION \\ VARIABLES AND METABOLIC MARKERS OF THE \\ PERIPARTURIENT DAIRY COW
}

\author{
Nicole Marie Barkley \\ Dr. Matthew R. Waldron, Dissertation Supervisor
}

\begin{abstract}
Three experiments were conducted to investigate the effects of commercially available feed additives on production variables and metabolic markers when supplemented during the periparturient period. The hypothesis was that the supplementation of feed additives throughout the periparturient period would improve production variables and metabolic markers. For all experiments, the variables of interest included daily dry matter intake, milk yield, and feed efficiency as well as weekly body condition score, body weight, milk composition, 3.5\% fat-corrected milk, energycorrected milk, and colostrum immunoglobulin concentrations as measures of production performance. Plasma glucose, nonesterified fatty acids (NEFA), and $\beta$-hydroxybutyrate (BHBA) were examined in all experiments as markers of metabolic health.

In the first experiment, the effects of feeding a B-vitamin and yeast supplement as a top dressing were examined. Cows received either $56 \mathrm{~g} / \mathrm{d}$ of OmniGen-AF $(\mathrm{OG} ; \mathrm{n}=9)$ or control (56 $\mathrm{g} / \mathrm{d}$ soyhulls; $\mathrm{n}=13)$ as a top dressing from -46 prepartum until $30 \mathrm{~d}$ postpartum. No overall treatment effects were observed for dry matter intake, milk yield, plasma metabolites, or colostrum immunoglobulin concentration; however treatment by time interactions were detected. Supplementation of OG increased milk protein percent in week one of lactation. Additionally, a trend indicated that OG cows had lower milk fat
\end{abstract}


yield in week one but higher in week four of lactation compared to control treated cows. Energy-corrected milk, 3.5\% fat-corrected milk, and fat-corrected milk efficiency were significantly affected over time by OG supplementation and followed the same pattern as milk fat yield. A trend in feed to milk conversion efficiency was observed with control cows more efficient on day 3 and OG supplemented cows more efficient on days 17 and 19 of lactation.

In the second experiment, the effects of trace mineral supplementation from inorganic or organic sources were examined. Cows were randomly assigned to either a control group ( $\mathrm{CTL}, \mathrm{n}=13$ ) without $\mathrm{Mn}, \mathrm{Co}, \mathrm{Cu}$, and $\mathrm{Zn}$ supplementation, an inorganic trace mineral group (ITM, $\mathrm{n}=11$ ) supplemented with $200 \mathrm{mg} \mathrm{Mn}, 25 \mathrm{mg} \mathrm{Co}, 125 \mathrm{mg} \mathrm{Cu}$ and $360 \mathrm{mg} \mathrm{Zn}$ from sulfate and carbonate sources, or an organic trace mineral group $(\mathrm{OTM}, \mathrm{n}=11)$ supplemented with the same level of these trace minerals from a combination of inorganic and organic trace minerals chelated to amino acids or glucoheptonate. Mineral supplementation or control was administered daily via an oral gelcap bolus from $-57.1 \pm 1$ prepartum through $8 \mathrm{~d}$ postpartum. In addition to the variables of interest listed above, plasma thiol and thiobarbituric acid reactive substances (TBARS) were examined at days $-58 \pm 1,-27 \pm 1,-14 \pm 1,-7 \pm 1,1$, and six relative to parturition as markers of oxidative stress. The OTM cows had the greatest intake and BCS throughout the study while ITM treated cows had the lowest. A treatment by time effect was observed when DMI was analyzed for the far-off and whole dry periods. The CTL cows had higher DMI than OTM or ITM treated cows from -58 to $-55 \mathrm{~d}$ and -51 to $-42 \mathrm{~d}$ relative to calving; respectively. The OTM treated cows had higher intakes than CTL cows during the last $17 \mathrm{~d}$ of the dry period and higher intakes than ITM treated 
cows from -52 to $-2 \mathrm{~d}$. While on treatment, OTM treated cows tended to have increased milk yield compared to CTL but not ITM cows. This trend was lost when milk yield was followed out to 26 days in milk. Milk protein yield and percent increased with trace mineral supplementation from both OTM and ITM sources. Milk solids-not-fat (SNF) yield tended to increase with OTM but not ITM and SNF percent increased with ITM but not OTM supplementation. Colostrum IgG, IgA, and IgM decreased with ITM but returned to CTL levels with OTM supplementation. Trace mineral supplementation had no effect on plasma glucose, NEFA, BHBA, thiol, TBARS, milk fat, milk urea nitrogen, or somatic cell score.

In the third experiment, the effects of feeding yeast culture were examined. Cows were randomly assigned to one of four treatments. Control (CTL, $n=39)$ without yeast culture, yeast culture supplemented at a rate of $56 \mathrm{~g} / \mathrm{d}(1 \mathrm{X}, \mathrm{n}=40)$ or $112 \mathrm{~g} / \mathrm{d}(2 \mathrm{X}, \mathrm{n}=$ 37; Diamond V XP), or a new yeast product at the rate of $14 \mathrm{~g} / \mathrm{d}(\mathrm{LAC}, \mathrm{n}=42)$. Treatment was mixed into total mixed ration diet daily from approximately $-28 \mathrm{~d}$ prepartum through $86 \mathrm{~d}$ postpartum. Plasma glucose, NEFA, and $\beta$-BHBA were measured at days $-28 \pm 1,-7 \pm 1,1 \pm 1,7 \pm 1,21 \pm 1,42 \pm 1$ and $84 \pm 1$ relative to calving. Milk fat and protein yield were increased with $1 \mathrm{X}$ but not $2 \mathrm{X} ; 2 \mathrm{X}$ supplementation decreased colostrum IgG and IgM concentrations and both $1 \mathrm{X}$ and $2 \mathrm{X}$ yeast culture supplementation decreased the net energy balance of cattle on study when compared to control cows. Dry mater intake decreased linearly while energy-corrected milk efficiency (ECM efficiency), somatic cell score, milk fat, protein, and solids-not-fat yield increased with $1 \mathrm{X}$ but not with $2 \mathrm{X}$ supplementation. The LAC treatment was also examined and found to be similar to control in nearly all variables of interest. 
In conclusion, we found limited data to support feeding OmniGen-AF or organically complexed trace minerals during the periparturient period. Variables of interest were similar to untreated control cows when either commercially feed additive was supplemented. Increased milk fat and protein yield as well as ECM efficiency results led to the conclusion that supplementation of Diamond V XP yeast culture at the suggested rate of $56 \mathrm{~g} / \mathrm{d}$ but not $112 \mathrm{~g} / \mathrm{d}$ would be beneficial to producers, however it did not improve the periparturient cow's metabolic health markers that were examined in the current study. 


\section{CHAPTER 1}

\section{REVIEW OF LITERATURE}

\section{INTRODUCTION}

The transition from pregnant and non-lactating to lactating is a precarious one for the modern dairy cow. With years of genetic selection for increased milk yield, cattle have been driven to produce higher quantities of milk in a shorter period of time than evolutionarily required. The drive for increased milk yield is coupled with a rise in calcium, amino acids, and energy requirements. When these nutrients or metabolites are limited, cattle become susceptive to a myriad of metabolic and infectious diseases. These so-called "transition disorders" are a source of reduced income to dairy producers and have increased consumer awareness of animal welfare issues in the dairy industry. In an attempt to alleviate the risk of these transition disorders, intensive management practices have been employed to improve nutrition and animal welfare during the transition period. Research conducted in our laboratory examined three commercially available feed additives that claim to aid periparturient dairy cattle through the transition period via vitamins, minerals, and direct fed microbial cultures. The possible mode of action of these feed additives will be discussed in the following literature review.

\section{Transition Period and the Periparturient Cow}

The transition period is described as being the three weeks prior to and following parturition (Grummer, 1995), and is a time of increased infectious and metabolic disease 
(Drackley, 1999). The switch from late pregnancy to early lactation necessitates extreme hormonal (Kunz et al., 1985) and metabolic adaptations within the cow (Grummer, 1995; Drackley, 1999). Failure of these adaptations results in the highest incidence of total disease occurrence within the first $10 \mathrm{~d}$ following parturition (Ingvartsen et al., 2003). Genetic selection for higher lactation potential exacerbates the amount of energy required for and partitioned to milk production (Bauman and Currie, 1980; Dillon et al., 2006). In early lactation, a period of time characterized by low dry matter intake (DMI), cattle do not consume enough feed to meet the energy demands of lactation. When energy expenditure is greater than energy intake, cattle enter into a state of negative energy balance (NEB) that results in mobilization of body reserves (Herdt, 2000). Catabolism of lipid and protein reserves results in decreased body condition score (BCS) and an influx of glucogenic and ketogenic products to the liver. When liver enzymes are unable to keep up with the rate of lipolysis, cattle develop metabolic disorders that reduce DMI further and restrict milk production. Loss of production potential, the costs associated with treatment of sick cattle, and reduced cow longevity lessen herd profitability (Beever, 2006). How well a cow is able to get through the transition period directly correlates to the cow's ability to reach peak milk production, maintain milk persistency, meet breeding guidelines, and increase herd profitability.

In addition to hormonal and nutritional adaptations, periparturient cattle experience immunosuppression (Goff and Horst, 1997; Mallard et al., 1998; Kimura et al., 2006), as well as environmental (Collier et al., 2006) and management stressors (Grant and Albright, 1995; Ingvartsen, 2006). Continued research on the periparturient cow is essential for the improvement of both nutritional and management strategies. 
Issues during the transition period carryover into the entire lactation, reproduction, and potentially into subsequent lactations; therefore, further research and improvements in management strategies are essential to decrease the rate of metabolic and infectious disease occurrence around parturition while increasing milk yield and profitability.

Transition Disorders and Cost to Producer. Transition disorders, which encompass both metabolic and infectious diseases, negatively affect overall profitability of farms. Health care costs increase with age and are highest at parturition and immediately thereafter, and decrease to much lower levels as lactation progresses (Young et al., 1985). A review of studies examined the rate of transition disorders observed between 1979 and 1995 (Kelton et al., 1998). During this time, clinical hypocalcaemia was observed between 0.03 and $22.3 \%$ with a median of $6.5 \%$ and a cost estimate of approximately $\$ 335$ per case. Rate of retained placental membrane was between 1.3 and $39.2 \%$ with a median of $8.6 \%$ and a cost of $\$ 285$ per case. Metritis ranged from 2.2 to $37.3 \%$ with a median of $10.1 \%$ and an indeterminate cost per case due to increased days open and increased culling. Incidence of ketosis ranged from 1.3 to $18.3 \%$ with a median of $4.8 \%$ and an estimated cost of $\$ 145$ per case. Left displaced abomasum occurred with rates between 0.3 to $6.3 \%$ with a median rate of $1.7 \%$ and a cost of approximately $\$ 340$ per case. Finally, the rate of clinical mastitis was reported to be between 1.7 and $54.6 \%$ with a median of $14.2 \%$. Cost of clinical mastitis was not estimated but would include loss of milk production, treatment cost, and increased culling. Kelton et al. (1998) attributed the variability in incidence rates to geography, management, and breed differences. 
Due to the increase in health issues observed during the transition period, increased milk yield is often implicated in the etiology of transition disorders. Induction of lactogenesis prior to calving is associated with an increase in calcium and energy requirements often resulting in hypocalcemia and NEB. Mulligan and Doherty (2008) described hypocalcaemia as a "gateway disease", as it is linked to dystocia, uterine prolapse, retained placenta, endometritis, infertility, mastitis, displaced abomasum, ketosis, and immunosuppression. Cattle that develop clinical hypocalcaemia are 6.5, 3.2, 8.9, and 8.1 times more likely to suffer dystocia, retained placental membrane, ketosis, and mastitis, respectively (Curtis et al., 1983). In addition to increased calcium requirements, reduction in DMI while energy requirements increase, promotes a state of NEB. The NEB is characterized as a period with increased circulating nonesterified fatty acids (NEFA) and $\beta$-hydroxybutyrate (BHBA) concentrations. Increased concentrations of these two metabolites is initiated just prior to calving and continued until DMI increased to meet energy demands or milk yield is reduced. Ketosis is a result of increased circulating BHBA and cattle suffering from sub-clinical ketosis were found to be eight times more likely to develop a displaced abomasum (LeBlanc et al., 2005).

Herd transition disorders should not be managed independently because they are all inter-related (Mulligan et al., 2006; Mulligan and Doherty, 2008). A multifactorial herd management strategy is essential to reducing the risk of transition disorders. Proper nutritional management (Drackley et al., 2006; Mulligan et al., 2006) and animal husbandry (Cameron et al., 1998; Ingvartsen, 2006) prepartum and postpartum influence the rate of transition disorders. Mulligan et al. (2006) proposed five key factors (BCS, energy balance, clinical and sub-clinical hypocalcaemia, rumen health, and trace mineral 
and antioxidant status) that affect whole herd health and should be monitored to aid in the reduction of metabolic disease incidences.

\section{Net Energy Balance}

The equation for determining net energy balance can be found in NRC (2001). In short, net energy (NE) balance is equivalent to the total net energy of lactation (NEL_Total) intake minus the combined requirements for net energy of maintenance (NEM), pregnancy (NEP), lactation (NEL), and growth (NEG).

$$
\mathrm{NE} \text { Balance }=\mathrm{NEL} \_ \text {Total }-(\mathrm{NEM}+\mathrm{NEP}+\mathrm{NEL}+\mathrm{NEG})
$$

Equations for each variable can be found in the NRC (2001), therefore further description will not be provided here.

As previously discussed, NE balance of cattle during the transition period is negative. This period of NEB is a result of the increased energy requirements of lactogenesis combined with a delay in DMI to meet energy requirements. Therefore, a discussion of the typical DMI and lactation curve is beneficial to understanding the energy imbalance of periparturient dairy cattle.

Lactation Curve. Characteristics of interest in the typical 305 d lactation curve are the time of peak milk yield, milk quantity at peak, and the persistency of milk yield. The shape of the lactation curve is a function of genetics, parity, animal health, environment, and management (Macciotta et al., 2004; Rekkik and Gara, 2004); therefore, variation is to be expected. However, the typical milk curve increases rapidly the first two months of lactation with peak milk yield between 40 and $60 \mathrm{~d}$ postpartum (Val-Arreola et al., 2004; Silvestre et al., 2009). Lactation curves for heifers peak at a lesser degree than higher parity cows and typically have higher persistency (Tekerli et al., 
2000; Silvestre et al., 2009). Milk persistency is the term to describe the rate of decline in milk yield relative to peak milk yield. Cattle with greater milk persistency have flatter lactation curves and are considered to be more profitable (Togashi and Lin, 2003) and have a higher resistance to disease (Appuhamy et al., 2007). Therefore management for greater milk persistency would be beneficial to animal health and overall profitability.

Dry Matter Intake Curve. Marquardt et al. (1977) indicated a 30 to 35\%

reduction in DMI at 1 and $0 \mathrm{~d}$ prepartum compared to DMI $14 \mathrm{~d}$ prepartum (Marquardt et al., 1977). The cause for the reduction in DMI prepartum is not completely understood. Hayirli et al. (2002) examined the relationship between variation in prepartum DMI and animal factors. It was determined that DMI was positively correlated with parity (accounting for $10 \%$ of variation) and negatively correlated with BCS (accounting for $9.7 \%$ of variation) indicating that cows consume greater amounts of dry matter than heifers and over-conditioned animals consume less dry matter than under-conditioned animals in the days leading up to parturition. In the same study the influence of day on DMI was examined and it was concluded that $56.1 \%$ of variation in DMI was due to day prepartum. With the fluctuation in hormones that occurs around the time of parturition, there is likely a degree of hormonal control to DMI (NRC, 2001). Postpartum DMI increases and reaches peak within 12 to 13 weeks. Increasing the rate of DMI postpartum is essential to reducing the degree and longevity of NEB and the rate of metabolic disorders observed with periparturient dairy cattle.

\section{Physiological Requirements of the Prepartum Cow}

Energy requirements of the non-lactating pregnant cow (dry cow) increase in the last month of gestation (Bell, 1995). This period of time is characterized by 
replenishment of body condition, intensified fetal growth, and mammary gland development (Bauman and Currie, 1980; Bell, 1995). As fetal growth and mammary gland development are minimally influenced by on farm management techniques, discussion of these topics will be limited. On the other hand, a great deal of work has been conducted to manage dry cows for replenishment and maintenance of body conditioning to promote a healthy transition into lactation. Therefore BCS will be discussed in depth below.

Late Pregnancy: Fetal Growth and Mammary Development. The NRC (2001) suggests a 2-stage dry cow diet be fed during the voluntary $60 \mathrm{~d}$ dry period prior to calving. Stage 1, to be fed from dry-off until 3 wks prior to expected calving, consists of feeding a diet with $1.25 \mathrm{Mcal} / \mathrm{kg}$ of NEL. The energy provided by the stage 1 diet is designed to provide for BCS maintenance and not accretion of conditioning. During stage 2 , fed the 3 wks prior to expected calving, the NEL of the diet is increased to between 1.54 and $1.62 \mathrm{Mcal} / \mathrm{kg}$. The increase in energy density provided in the diet allows for maintenance of BCS as well as provided energy for fetal growth and mammary development. As reviewed by Bell (1995) and Bell and Bauman (1997), the increase in energy demands of the gravid uterus make up 46,72 , and $12 \%$ of the maternal supply of glucose, amino acids, and acetate, respectively. The 2-stage feeding strategy is a management technique that is coupled with the naturally occurring homeohretic regulation of energy metabolism that will be discussed in the partitioning of nutrients section of this report.

Body Condition Score. The importance of managing for a desired dry cow BCS has been shown to influence the degree of DMI decline prepartum (Mulligan et al., 
2006), rate and intensity of metabolic disorders postpartum (Gillund et al., 2001), reproduction (Gillund et al., 2001; Pryce et al., 2001), and milk yield (Domecq et al., 1997). With proper management, dairy cattle can be expected to calve once every $12-15$ months. Due to this calving interval, cattle experience extended lactation periods to allow for maximum profitability. Longer lactation periods often mean cattle reach a point of positive energy balance (PEB) early enough in lactation that they are able to replenish body reserves prior to dry-off. Managing cattle to reach a healthy body condition by the end of lactation and to maintain conditioning throughout the dry period is essential to maintaining animal health, welfare, reproduction, and production (Roche et al., 2009). When using the one to five point BCS scale (Edmonson et al., 1989) an average BCS of 2.77 at dry-off with a one point increase in BCS between dry-off and parturition was associated with an increase of $545.5 \mathrm{~kg}$ of milk yield in the first $120 \mathrm{~d}$ postpartum (Domecq et al., 1997). However further increases in BCS resulted in a decrease of $300 \mathrm{~kg}$ for each additional BCS point increase (Domecq et al., 1997). Results from this study and others (reviewed in Overton and Waldron, 2004; Mulligan et al., 2006; Roche et al., 2009 ) suggest a BCS of 2.75 to 3.25 to be ideal at dry-off. When BCS were higher than 3.5 during the dry period, DMI was reduced prepartum (Hayirli et al., 2002). Reduction in DMI prepartum may potentiate the initiation of and degree of NEB experienced by the periparturient cow. Furthermore, cows with greater BCS tend to mobilize a greater amount of NEFA postpartum than cows with less conditioning (Busato et al., 2002) which predisposes periparturient cattle to fatty liver and ketosis. 


\section{Physiological Requirements of the Postpartum Cow}

Energy requirements of the periparturient dairy cow increase just prior to calving as colostrum production is initiated. These requirements are further increased as normal milk production is rapidly ramped up in the first two months postpartum. As discussed previously, DMI is reduced just prior to parturition resulting in the initiation of NEB. Induction of lactogenesis increases the degree of NEB further and results in an increase in mobilization of energy reserves and reduction of BCS.

Colostrum and Milk Production. Energy requirements for colostrum production are not known at this time but are considered to be minimal compared to the energy requirements of normal milk production (Bell, 1995). Providing high quality colostrum to calves is beneficial for growth and essential to the promotion of a strong immune system; therefore, it should not be overlooked. Even with minimal quantities of colostrum produced at parturition, the energy density of colostrum is greater than normal milk as colostrum contains proteins, amino acids, lipids, lactose, vitamins, and minerals as well as hormones, growth factors, enzymes, and immunoglobulins (Zaracula et al., 2010). Onfarm management techniques to reduce transition problems at calving influence the quality of colostrum. A study examining the effects of length of dry period on colostrum indicated that colostrum quality was reduced when cows were milked throughout the typical dry period (Rastani et al., 2005). However, colostrum quality from a shortened dry period supplemented with a higher density diet was similar in quality to colostrum collected after a traditional $60 \mathrm{~d}$ dry period (Rastani et al., 2005). While normal milk is not as rich in nutrients as colostrum, the quantity of normal milk produced early in lactation results in a greater energy demand (Bell, 1995). Bell (1995) estimated mammary 
uptake of nutrients just $4 \mathrm{~d}$ postpartum to be as high as $1,775,1,374$, and 1,224 $\mathrm{g} / \mathrm{d}$ for glucose, amino acids, and fatty acids; accounting for approximately 2.7, 2.0, and 4.5 times the energy requirements of the gravid uterus prepartum.

Change in Body Condition Score. Because DMI at parturition does not support the amount of energy that is partitioned to milk production, cattle enter into a state of NEB resulting in the mobilization of body reserves and a loss of 0.5 to 1 BCS within the first two months of lactation (Garnsworthy and Topps, 1982; Garnsworthy and Jones, 1987; Busato et al., 2002). Managing BCS in late lactation for an ideal BCS at dry-off was previously discussed above. Similarly, managing BCS during the dry period for an ideal BCS at calving should be considered (Mulligan et al., 2006). Body condition score at calving influences the change in BCS that is observed during the first two months of lactation, milk yield, predisposition to transition disorders, duration and intensity of NEB, and overall feed to milk efficiency(Garnsworthy and Topps, 1982; Garnsworthy and Jones, 1987; Cameron et al., 1998; Heuer et al., 1999; Gillund et al., 2001; Busato et al., 2002; Hayirli et al., 2002; Roche et al., 2009). According to Mulligan et al. (2006) the target BCS at calving should be 3.0 with a targeted breeding BCS of $>2.5$ (Buckley et al., 2003). Considering that breeding is initiated approximately $60 \mathrm{~d}$ postpartum, a change in BCS of 0.5 units is acceptable in early lactation.

\section{Energy from Body Reserves}

One adaptation to the NEB that occurs around parturition consists of a homeohretic shift in glucose utilization by non-uterine and non-mammary tissues (Herdt, 2000). Glucose is needed in large quantities for lactose production in the mammary gland; therefore non-mammary tissues become insulin resistant as a means of glucose 
conservation. Mobilization of body fat reserves provides an alternate energy source during this period of NEB. Release of NEFA from adipose tissue to meet the energetic requirements of the periparturient cow in late gestation and early lactation is seen in all cattle. The degree of body fat catabolized for release of NEFA into the bloodstream is variable; with parity, BCS, and DMI as contributing factors (Vizcarra et al., 1998; Rukkwamsuk et al., 2000; Rastani et al., 2005). Once released from adipose tissue, circulating NEFA can be shunted to the mammary gland to be utilized for up to $40 \%$ of milk fat in the first few days of lactation (Bell, 1995), taken up by the liver and undergo $\beta$-oxidation, or utilized by skeletal muscle for fuel. The glycerol backbone from adipose mobilization will be used as a precursor for gluconeogenesis.

Increased plasma NEFA concentrations are linked to an increase in fatty acid uptake by the liver, fatty acid esterification, and triglyceride storage (Grummer, 1993). Grummer (1993) reported a four- to five-fold increase in liver triglyceride concentration $1 \mathrm{~d}$ prepartum compared to $17 \mathrm{~d}$ prepartum. It is unknown at what level of circulating plasma NEFA concentration that the liver becomes overwhelmed and can no longer enzymatically keep up with the removal of triglycerides and achieve maximal gluconeogenesis. However, it has been documented that the synthesis and accumulation of triglycerides in the liver are in proportion to the concentration of NEFA in the blood (Herdt et al., 1988). Therefore, cows with increased lipolysis are at a high risk to develop fatty liver (Herdt et al., 1988; Herdt, 2000).

Protein stores are also mobilized during the period of NEB around parturition, although at a much lower rate than adipose tissue (Herdt et al., 1988). Amino acids from 
catabolized muscle are used by the liver for gluconeogenesis and the mammary gland to produce milk proteins.

\section{Up Regulation of Hepatic Gluconeogenesis}

Requirements for glucose increase two to three-fold from $21 \mathrm{~d}$ before to $21 \mathrm{~d}$ after parturition (Drackley et al., 2001) and as much as 4-fold with genetically superior lactating dairy cattle (Bell and Bauman, 1997). In order to meet the increased demands of glucose for uterine and mammary tissues, hepatic gluconeogenesis is increased and glucose utilization by non-uterine and non-mammary tissue is attenuated (Bell and Bauman, 1997). Increase in metabolic activity per gram of liver tissue, as well as increased liver mass is observed $1 \mathrm{~d}$ postpartum compared to $21 \mathrm{~d}$ prepartum (Drackley et al., 2001). Increased capacity of the liver to produce glucose for energy was also reported by Reynolds et al. (2003) who measured the net flux of glucose across the portal drained viscera. Reynolds et al. (2003) reported that the $267 \%$ increase in total splanchnic output of glucose from $9 \mathrm{~d}$ prepartum to $21 \mathrm{~d}$ postpartum resulted almost completely from increased hepatic gluconeogenesis. During this time, the major substrates used for glucose production by hepatocytes were proprionate, lactate, amino acids, and glycerol (Seal and Reynolds, 1993). Increased net liver removal of propionate (69\%), lactate $(20 \%)$, alanine $(8 \%)$, and glycerol $(4 \%)$ can account for increased liver glucose release in transition cows from $9 \mathrm{~d}$ before to $11 \mathrm{~d}$ after calving (Reynolds et al., 2003).

\section{Oxidative Stress}

As energy requirements increase at parturition so do the metabolic processes that allow for energy production and their potentially damaging by-products. Antioxidants from the diet (e.g. vitamin E and selenium) and naturally occurring enzymes (e.g. 
superoxide dismutase and glutathione peroxidase) are able to keep oxidative by-products in check during periods of PEB or neutral EB (Sharma et al., 2011). However, during NEB, oxidative by-products (e.g. free radicals and reactive oxygen species) of metabolism can quickly accumulate and result in oxidative stress. When free radicals and reactive oxygen (ROS) are left unchecked, they can cause cellular and tissue damage leading to disruption of normal metabolism and physiology (Trevisan et al., 2001) as well as immunity (Sordillo and Aitken, 2009). Reduction in DMI around parturition may perpetuate the risk of oxidative stress as ingestion of vitamins and minerals essential to antioxidant status decline when requirements are elevated.

Antioxidants. Free radicals and ROS are products of oxygen metabolism that are neutralized by antioxidants. Antioxidants can be either enzymatic or non-enzymatic in nature. A review of the key antioxidant enzymes can be found in a report by Sordillo and Aitken (2009) but will be briefly mentioned here. Some of the best known antioxidant enzymes are superoxide dismutase (SOD) which catalyzes the conversion of superoxide $\left(\mathrm{O}_{2}-\right)$ to oxygen and hydrogen peroxide $\left(\mathrm{H}_{2} \mathrm{O}_{2}\right)$, catalase which reduces $\mathrm{H}_{2} \mathrm{O}_{2}$ to water and oxygen, and glutathione peroxidase (GPX) which catalyzes the conversion lipid hydroperoxides to alcohols. Commonly known non-enzymatic antioxidants consist of vitamins $\mathrm{A}, \mathrm{C}$, and $\mathrm{E}$. These vitamins exert their antioxidant properties by scavenging free radicals (Sordillo and Aitken, 2009).

Biomarkers of Oxidative Stress. There are no clinical signs of oxidative stress, therefore, biomarkers are key to the evaluation of oxidative stress in dairy cattle (Celi, 2011). Two biomarkers were employed in our laboratory to examine the effects of organic and inorganic minerals on oxidative stress in the periparturient cow. Plasma thiol 
was examined as a measure of the non-enzymatic protein antioxidants and plasma thiobarbituric acid reactive substances (TBARS) were examined to establish the occurrence of lipid peroxidation (Bernabucci et al., 2005). Limitations of using biomarkers to evaluate oxidative stress in dairy cattle were reviewed by Celi (2011) who indicated that the high level of reactivity and lack of assay specificity were the greatest hurdles to overcome when evaluating biomarkers of oxidative stress.

\section{Commercially Available Feed Additives to Aid in Transition Period}

Intensive management of the periparturient cow is necessary to reduce the metabolic strain observed during the transition period. A great deal of work has been conducted to improve nutritional status of the pre and postpartum cow. However; there is

still room for improvement. As a result, feed companies have developed additives that are marketed towards aiding the periparturient cow with modes of action as diverse as the additives themselves. Three such feed additives were examined in our laboratory and will be discussed in depth as follows. Other commercially available feed additives include buffers, ionophores, and rumen-protected nutrients.

Buffers (e.g. sodium bicarbonate) allow for consumption of higher energy diets as they limit the normal $\mathrm{pH}$ fluctuations observed with higher starch diets (Emery and Brown, 1961), increase acetate production (Erdman et al., 1980), and increase fluid consumption and passage rate (Haaland and Tyrrell, 1982). Ionophores (e.g. monensin) alter rumen fermentation products to increase propionate while reducing methane production by gram positive microbes. Ionophores also reduce the rate of protein degradation in the rumen to allow for increased protein flow to the intestines (McGuffey et al., 2001). Finally, a multitude of rumen-protected compounds are supplemented to 
ensure that the cow receives the desired nutrient rather than being utilized by rumen microbes. Examples of these compounds include rumen-protected amino acids, fat, and vitamins.

\section{Trace Minerals}

Trace minerals are chemical elements required in milligram or microgram quantities and often serve as components of metalloenzymes, enzyme cofactors, or components of hormones (NRC, 2001). The list of trace minerals includes cobalt, copper, iodine, iron, manganese, molybdenum, selenium, and zinc. Requirements of trace mineral supplementation increase in late gestation and early lactation due to fetal growth and lactation. However inorganically bound trace minerals interact with each other in the rumen and can reduce absorption, leading to over supplementation and additional costs to producers.

Current research in the area of trace minerals has been focused on the partial substitution of inorganically-complexed trace minerals with organically-complexed trace minerals to observe the effects on claw integrity, reproduction, milk production, milk composition, DMI, and immunity(Uchida et al., 2001; Ballantine et al., 2002; Kellogg et al., 2003; Toni et al., 2007; Siciliano-Jones et al., 2008; Spears and Weiss, 2008). In a meta-analysis of several studies, multiple individual trace mineral-amino acid chelates and Co-glucoheptonate were reported to increase milk production, energy corrected milk, and $3.5 \%$ fat corrected milk (Raibee et al., 2010). The bioavailability of the trace minerals used to supplement dairy cows during the transition period is influenced by chemical form (e.g. inorganic salts or chelated to amino acids, peptides, or proteins) and the presence of dietary antagonists (Linn et al., 2011). Organic minerals have the 
potential to increase bioavailability at lower levels of supplementation than their inorganic counterparts as there are fewer negative interactions between minerals in the rumen.

The trace minerals of interest to research conducted in our laboratory were zinc, manganese, copper, and cobalt. Zinc is a component of a myriad of enzymes, proteins, and hormones with absorption sites in the small intestines (NRC, 2001). The coefficient of zinc absorption is $15 \%$ for all animals and zinc requirements range from 23 to 63 $\mathrm{mg} / \mathrm{kg}$ of diet.

Manganese is a component of the enzyme manganese super oxide dismutase, an antioxidant enzyme that aids in the removal of reactive oxygen species that can cause cellular damage (NRC, 2001). Manganese requirements have been set at $40 \mathrm{mg} / \mathrm{kg}$ dietary DM for all classes of cattle (NRC, 2001).

Copper is a component of multiple enzymes; cytochrome oxidase, lysyl oxidase, ceruloplasmin, tyrosinase, and superoxide dismutase (NRC, 2001). Copper requirements for the periparturient dairy cow are set at $2.0 \mathrm{mg} /$ day with copper absorption in ruminants between 1 and $5 \%$ of the dietary supply (NRC, 2001). Presence of sulfur and molybdenum in the diet reduce copper absorption further via formation of tetrathiomolybdates which bind to copper and form insoluble complexes (Allen and Gawthorne, 1987).

Cobalt is a component of the vitamin $\mathrm{B}_{12}$. Vitamin $\mathrm{B}_{12}$, an important cofactor in the process of gluconeogenesis and is supplied by rumen microbes at sufficient levels to prevent deficiencies as long as adequate cobalt is supplied in the diet (NRC, 2001). 
Current NRC requirements suggest supplementing cobalt at a rate of $0.11 \mathrm{mg} / \mathrm{kg}$ of dietary DM.

\section{Vitamins}

Vitamins are classified as either; fat-soluble or water-soluble. Fat-soluble vitamins can be stored in the adipose tissues of animals; therefore, deficiencies are uncommon while toxicities are a possibility if supplementation is higher than necessary. Water-soluble vitamins are not stored in the body and therefore are required in the daily diet to fulfill requirements. The fat-soluble vitamins are $\mathrm{A}, \mathrm{D}, \mathrm{E}$, and $\mathrm{K}$ and the watersoluble vitamins are the B-complex and $\mathrm{C}$. Rumen microbes produce vitamins $\mathrm{B}$ and $\mathrm{K}$ while vitamin $\mathrm{D}$ is converted to its active form by skin exposure to ultraviolet light (NRC, 2001). Vitamin A precursors ( $\beta$-carotene) and vitamin $\mathrm{E}$ can be found at sufficient

levels in high quality forages. However, additional supplementation of these vitamins and vitamin $\mathrm{D}$ are recommended as the concentration of vitamins in feeds, vitamin degradation in feedstuffs, and sunlight exposure are variable (NRC, 2001).

Vitamin requirements in the periparturient dairy cow increase as they are essential to energy and calcium metabolism, as well as the antioxidant status of cattle. There are eight B-vitamins; biotin, inositol, niacin, panthothenic acid, riboflavin $\left(\mathrm{B}_{2}\right)$, thiamin $\left(\mathrm{B}_{1}\right)$, and vitamin $\mathrm{B}_{12}$. The $\mathrm{B}$-vitamins are cofactors in energy metabolism and will be discussed independently as follows. Vitamins A, E, and C act as non-enzyme antioxidants by scavenging reactive oxygen species during the transition period when oxygen requirements and energy metabolism is increased. Vitamin D is integral to calcium metabolism as calcium requirements increase with lactogenesis. 
Until recently, it has been generally accepted that rumen microbes are able to produce enough B-vitamins to support cattle without additional supplementation; as this has been the dogma, B-vitamin requirements of cattle are unknown (NRC, 2001). With the emphasis on increased milk yield and the concomitant increase in feed concentrate levels in modern dairy diets, it is quite possible that B-vitamin requirements have increased and may need to be supplemented to optimize animal performance.

Biotin is an essential cofactor for carboxylation enzymes involved in gluconeogesis and carboxylation of fatty acids. When supplemented during the periparturient period, $20 \mathrm{mg} / \mathrm{d}$ of biotin increased milk yield (Zimmerly and Weiss, 2001, Majee et al., 2003) and DMI (Majee et al., 2003). As plasma glucose and NEFA concentrations were unaltered by biotin supplementation (Zimmerly and Weiss, 2001), it is unlikely that biotin supplementation led to an increase in enzymatic reactions supporting gluconeogenesis. The same rate of supplementation was found to improve hoof health (NRC, 2001) and may be the causality for improved DMI.

Inositol is an important nutrient in the metabolism and transport of lipids (NRC, 2001). Niacin functions as a coenzyme for $\mathrm{NAD}(\mathrm{H})$ and $\mathrm{NADP}(\mathrm{H})$ and is critical to mitochondrial respiration and the metabolism of carbohydrates, lipids, and amino acids (NRC, 2001). Studies supplementing each of the B vitamins were conducted to examine potential prevention of fatty liver disease in the periparturient cow. No reduction in liver triglycerides were observed with inositol (Gerloff et al., 1984) or niacin (Skaar et al., 1989).

Pantothenic acid is a component of coenzyme A and as such is essential for fatty acid oxidation, amino acid catabolism, and acetylcholine synthesis (NRC, 2001). Rumen 
microbes appear to synthesis pantothenic acid at rates 20 to 30 times more than dietary amounts therefore research examining supplementation have not improved performance of cattle (NRC, 2001).

Riboflavin is a component of several enzymes of metabolism and was found to be $100 \%$ degraded by rumen microbes when supplemented in the diet (NRC, 2001). Thiamin is involved in several of the energy producing Kreb cycle reactions and can become deficient when thaiminases are present in the diet. Deficiencies lead to central nervous system disorders (NRC, 2001).

Vitamin $\mathrm{B}_{12}$ is a cofactor for methyl-malonyl coenzyme A mutase which is responsible for the conversion of propionate to succinate, and tetrahydrofolate methyl transferase, which is the enzyme responsible for the formation of methionine and tetrahydrofolate from 5-methyltetrahydrofolate (NRC, 2001). As discussed in the trace mineral section, cobalt is necessary for rumen microbial production of vitamin $\mathrm{B}_{12}$ and as long as cobalt supply is sufficient cattle will not become deficient.

\section{Yeast Culture}

Direct fed microbial feed additives are live naturally occurring organisms supplemented to cattle to enhance production performance, alter rumen fermentation, or improve nutrient utilization (NRC, 2001). The most commonly studied has been the yeast strain Saccharomyces cerevisiae, which has been supplemented to cattle as live yeast and yeast culture (dead yeast). As live yeast, the proposed a mode of action involves removal of oxygen from the rumen leading to increased anaerobic bacterial viability (Wallace, 1994; Newbold et al., 1996). Increased bacterial viability in turn would allow for greater microbial population turnover, cellulose digestion, and microbial protein production 
potentiating a greater influx of post-ruminal substrates essential for hepatic glucose production (e.g. propionate and microbial protein). However, this mode of action would not be reasonable with dried yeast cultures, such as that employed in our laboratory, as they contain a fraction of the number of viable yeast cells and would be limited in oxygen scavenging abilities within the rumen.

Yeast cultures, for example XP from Diamond V Mills, are produced by fermenting selected liquid and cereal grain raw ingredients with baker's yeast (Saccharomyces cerevisiae) and drying the entire culture-media without destroying the yeast factors, B-vitamins, and other fermentation products (Diamond V Mills). Therefore, the mode of action is likely through yeast fermentation products. Wiedmeier et al, (1987) hypothesized that the yeast culture provides factors stimulatory to proteolytic bacteria while Callaway and Martin, (1997) suggested the mode of action to be through provision of growth factors (e.g. B-vitamins and amino acids) to ruminal bacteria that utilize lactate and digest cellulose.

Supplementation of live yeast or yeast cultures to periparturient dairy cattle has been employed in hopes of improving energy balance and performance during the transition period; however, results are inconsistent at best. In some studies, yeast culture supplementation improved dry matter intake (Putnam et al, 1997; Dann et al., 2000; Erasmus et al., 2005; Ramsing et al 2009), milk yield (Erasmus et al., 1992; Putnam et al., 1997; Shaver and Garrett, 1997; Ramsing et al., 2009), milk composition (Hippen et al., 2007; Lehloenya et al., 2008), and efficiency (Schingoethe et al., 2004); however, others found no response to yeast culture (Arambel and Kent, 1990; Robinson, 1997; Robinson and Garrett, 1999). Inconsistencies in response are likely due to the age of 
animal, stage of lactation, amount and strain of yeast culture administered, diet, and length of treatment.

\section{Summary}

Advancements in periparturient nutrition and management combined with genetic selection have allowed for greater cow performance; however, animal welfare still remains an issue for producers. The natural homeohretic and homeostatic responses observed in the periparturient cow are unable to prevent transition disorders in all cows. Further research needs to be conducted to allow for improvements in pre and postpartum ration formulation to alleviate transition disorders as we continue with the trend for

increased milk yield potential. While there are a great number of feed additives already available to producers, there are a couple key factors that need to be given thorough consideration before employment. For instance, do they work on commercial farms and in research, what is the most beneficial period for supplementation, and what is the cost to benefit ratio of the product. 


\title{
CHAPTER 2
}

\section{PERFORMANCE OF DAIRY CATTLE FED THE COMMERCIAL MICRONUTRIENT SUPPLEMENT OMNIGEN-AF DURING THE PERIPARTURIENT PERIOD}

\begin{abstract}
The objective of the study was to investigate the effects of feeding OmniGen-AF on production variables in periparturient cows. Twenty-two multiparous Holstein cows were randomly assigned to either a control group $(\mathrm{n}=13$; soy hulls $56 \mathrm{~g} / \mathrm{cow} /$ day $)$ or treatment group supplemented with OmniGen-AF (OG; $\mathrm{n}=9 ; 56$ g/cow/day; Prince Agri Products, Quincy, IL). Both groups received the same basal diet. Treatment or sham was administered daily as a top dressing with $225 \mathrm{~g}$ sweet feed to entice consumption from $d-46 \pm 1$ through $d+30$ relative to calving. Variables of interest included daily dry matter intake, milk yield, and feed efficiency as well as weekly body condition score, body weight, milk composition, 3.5\% fat-corrected milk, and energy-corrected milk. Plasma glucose, nonesterified fatty acids, and $\beta$-hydroxybutyrate concentrations were measured on $\mathrm{d}-46 \pm 1,-29 \pm 1,-20 \pm 1,-9 \pm 1,1 \pm 1,7 \pm 1,15 \pm 1$, and $30 \pm 1$ relative to calving. Immunoglobulin concentrations ( $\operatorname{IgG}, \operatorname{IgA}$, and $\operatorname{IgM}$ ) were examined from colostrum samples collected at the first milking postpartum. No overall treatment effects were observed for dry matter intake, milk yield, plasma metabolites, or colostrum immunoglobulin concentration; however, treatment by time interactions were detected.
\end{abstract}


Consumption of OG influenced milk composition during the first month of lactation.

Feeding OG increased milk protein percent in week one of lactation. Additionally, a trend indicated that OG cows had lower milk fat yield in week one but higher in week four of lactation compared to sham treated cows. Energy-corrected milk, 3.5\% fat-corrected milk, and fat-corrected milk efficiency were significantly affected over time by OG supplementation and followed the same pattern as milk fat yield. A trend in feed to milk conversion efficiency was observed with sham cows more efficient on day 3 and OG supplemented cows more efficient on days 17 and 19 of lactation.

Omnigen-AF supplementation resulted in modest effects on performance variables during the peripartum period. However, the current study was not designed to analyze production variables, as its primary purpose was to establish effects of OG on neutrophil function. Therefore the study was limited in statistical power to detect potential performance differences. To better understand the possible performance effects of the micronutrient supplement, a greater number of animals would need to be studied.

\section{INTRODUCTION}

OmniGen-AF is a commercially available feed additive containing a proprietary blend of B-vitamins, active dried yeast, aluminosilicates, and diatomaceous earth. The supplement has been reported to improve the health and production of lactating dairy cattle; however, the mechanism of action is unknown. Previous research on the micronutrient additive focused on immune benefits with limited interest in potential production effects. Current literature suggests the micronutrient supplement increases the 
level of L-selectin during immune suppression (Wang et al., 2007; Wang et al., 2009). Lselectin is a molecule essential for neutrophil adhesion, and increased expression may aid in the innate immune response to infection. Dairy industry field trials have reported improved herd health, production, and milk quality (Chapman, 2011), but it is unknown if the production improvements are primary effects of supplementation or secondary effects of healthier animals.

It has been generally accepted that ruminal microbes produce B-vitamins at sufficient quantities to meet the daily requirements of ruminants; however, exact Bvitamin requirements are not well characterized in dairy cattle (NRC, 2001). With the emphasis to increase milk yield (MY) and the concomitant increase in feed concentrate levels in some dairy diets, it is possible that B-vitamin requirements have increased and may need to be supplemented in the diet to optimize animal performance. Forage to concentrate ratio of diets effects microbial B-vitamin production (Santschi et al., 2005b). Additionally, increased intake, ruminal digestibility of diet, and microbial nitrogen production improve B-vitamin production (Schwab et al., 2006). Recent research has examined the effect of supplementing biotin (Zimmerly and Weiss, 2001; Majee et al., 2003), folic acid (Girard et al., 1995; Girard and Matte, 1998), B 12 (Girard and Matte, 1998), thiamin (Shaver and Bal, 2000), and rumen protected B-vitamin premix (Sacadura et al., 2008) on lactation performance. Degradation of B-vitamins by rumen microbes is extensive, with nearly $100 \%$ degradation of some B-vitamins (Santschi et al., 2005a). Therefore, supplementation levels of B-vitamins potentially need to be elevated or protected from rumen degradation to meet animal requirements. Considerably lower levels of B-vitamins were supplied via the micronutrient supplement in the current study 
(Table 2.2.) when compared to studies reporting positive production responses. As this study was sponsored by Prince Agri Products, level of OG supplementation was fed according to manufacturer's instructions.

In addition to B-vitamins, OmniGen-AF contains active dried yeast (Saccharomyces cerevisiae). The S. cerevisiae has been shown to increase DMI and MY (Williams et al., 1991; Stella et al., 2007), increase total volatile fatty acid (VFA) concentration (Chaucheyras and Fonty, 2001), reduce rumen ammonia concentration (Chaucheyras and Fonty, 2001), increase rumen pH (Williams et al., 1991; Thrune et al., 2009), enhanced forage digestion (Williams et al., 1991), and attenuate actions of (Chaucheyras et al., 1995; Chung et al., 2011) and populations of microflora (Chaucheyras and Fonty, 2001) in ruminants. In contrast, other studies have shown no improvement in DMI (Thrune et al., 2009), no effect on (Williams et al., 1991; Chung et al., 2011) or a decrease in total VFA production (Thrune et al., 2009), no effect on rumen ammonia concentration (Thrune et al., 2009), and either no effect (Lynch and Martin, 2002) or a reduction in rumen $\mathrm{pH}$ (Chung et al., 2011). Inconsistencies in the effects of dietary yeast addition have been attributed to the number of cells and their viability, strain of S. cerevisiae supplemented, diet, and physiological stage of ruminants.

Published peer-reviewed research investigating the effects of OmniGen-AF on MY, milk composition, DMI, and metabolic markers of energy balance does not exist. Research has focused on immune benefits and production literature has been limited to whole-herd field trials published by the proprietors of the feed additive. Therefore, production data were collected during a time course study conducted to examine the effects of OG on neutrophil function (Revelo, 2012; data not shown). 


\section{MATERIALS AND METHODS}

\section{Cows and Diet}

Thirty-two Holstein cows from the University of Missouri Foremost Dairy Research and Teaching Farm entering into their second or greater lactation were used in this experiment. All animal procedures were approved by the University of Missouri Animal Care and Use Committee. Cows were housed in a free stall barn in two pens and individual daily feed intake was measured using Calan doors (American Calan, Northwood, NH). Cows were fed total mixed ration (TMR) diets formulated using the Cornell Net Carbohydrate and Protein System (Fox et al., 2004) to meet or exceed NRC recommendations (2001). The prepartum diet consisted of $44.5 \%$ brome hay, $20.4 \%$ corn silage, $12.9 \%$ soybean hulls, $8.6 \%$ soybean meal, and $13.6 \%$ concentrate grain, vitamin, and mineral mix on a DM basis. At parturition, cows were fed a lactating TMR diet which consisted of $29.9 \%$ corn silage, $16.7 \%$ dry corn, $13.1 \%$ alfalfa haylage, $6.8 \%$ alfalfa hay, $6.8 \%$ soybean meal, $4.4 \%$ brewers grain, $4.2 \%$ soybean hulls, $3.6 \%$ soyplus, and $14.5 \%$ concentrate grain, vitamin, and mineral mix on a DM basis. Pre- and postpartum diet nutrient compositions are shown in Table 2.1. Treatment, either $56 \mathrm{~g}$ of

soyhulls (sham) or OG (Prince Agri Products, Quincy, IL) was supplied as a top dressing with $225 \mathrm{~g}$ of sweet feed daily during the morning feeding. Further detail of OG composition and nutrients provided per treatment dose is provided in Table 2.2.

\section{Experimental Protocol}

Cows were enrolled in the study from $d-46 \pm 1$ through $d+30$ relative to calving. Feed issue and refusal weights were recorded daily to determine DMI. Cows were 
evaluated weekly by two individuals to determine body condition score (BCS)

(Edmonson et al., 1989) and body weights were recorded weekly from eight weeks before expected calving through four weeks after parturition. Blood was sampled on $d$ $48 \pm 1,-29 \pm 1,-20 \pm 1,-9 \pm 1,1 \pm 1,7 \pm 1,15 \pm 1$, and $30 \pm 1$ relative to parturition for determination of plasma glucose, non-esterified fatty acids (NEFA), and $\beta$ hydroxybutyrate (BHBA) concentrations. A $50 \mathrm{~mL}$ sample of colostrum was collected during the first milking post-calving (less than twelve hours from parturition) to determine immunoglobulin concentrations. Cows were milked twice daily. Milk yield was recorded at each milking and milk samples were collected weekly during two consecutive milkings for compositional analyses.

\section{Measurements and Sampling}

Animal Observations. Study personnel monitored cows daily for health issues and lameness by walking through pens. Observations were recorded and used during analysis to qualify data. Any cows with suspect health events were referred to University of Missouri staff veterinarians for clinical evaluation. Twenty cows were enrolled on study the spring of 2010. Due to health issues, eleven cows were culled from the experiment and a second group of twelve cows were enrolled on study in the fall of 2010. Overall, thirty-two cows were enrolled on study and data from twelve cows were removed from data analysis due to animal health issues diagnosed by study personnel and verified by veterinary staff. Thirty-one of the thirty-two cows completed study. Cows were removed from data analysis if they suffered more than one health issue while on study, required surgery, or were given anti-inflammatory medication. A total of ten cows were removed from data analysis ( $\mathrm{n}=3$; control and $\mathrm{n}=7$; OG). Cows were culled for 
the following health reasons: lameness, dystocia, retained placental membrane or metritis, hypocalcemia, displaced abomasum or impaction of the gastrointestinal tract, and mastitis.

Dry Matter Intake and Feed Analysis. Individual cow feed issue and refusal was recorded daily to establish DMI. Dry cow diets were fed once daily and lactating diets were fed twice daily. Feed refusal weights were collected once daily for both dry and lactating diets to determine DMI. Individual feed ingredients and TMR diets were collected weekly and composited monthly throughout the study. Samples were dried in ovens at $55^{\circ} \mathrm{C}$ for four days to determine static DM content and then ground through a 2 $\mathrm{mm}$ screen in a Thomas-Wiley mill. Wet chemical analysis of monthly composite feed samples was performed by Dairy One Laboratories (Ithaca, NY).

Milk Variables. Cows were milked twice daily upon parturition and milk records were recorded until 150 days in milk (DIM) to establish any carry-over effect of treatment supplementation. Milk samples were collected during two consecutive milkings for compositional analysis. Composite samples were analyzed for milk fat, true protein, solids-not-fat (SNF), milk urea nitrogen (MUN), somatic cell score (SCS), and somatic cell count (SCC; Mid-South Dairy Records, Springfield, MO). Milk composition data were analyzed using the weighted average of two samples obtained from consecutive milkings. Milk fat content was used to calculate 3.5\% fat-corrected milk (FCM) using the formula $3.5 \% \mathrm{FCM}=(0.432 \times \mathrm{kg}$ milk $)+(16.216 \times \mathrm{kg}$ fat $)$. Energy-corrected milk $(\mathrm{ECM})$ was calculated using the formula $\mathrm{ECM}=(12.82 \times \mathrm{kg}$ fat $)+(7.13 \times \mathrm{kg}$ protein $)+$ (0.323 x kg of milk). Colostrum samples were obtained during the first milking (within 12 hours of parturition) to assess IgG, IgA, and IgM concentrations. Immunoglobulin 
concentrations were determined by ELISA using affinity purified bovine IgG (E10-118), $\operatorname{IgA}(\mathrm{E} 10-121)$, and $\operatorname{IgM}(\mathrm{E} 10-101)$ coating antibodies with the corresponding horseradish peroxidase conjugated bovine immunoglobulin detection antibody (ELISA starter kits, Bethyl Laboratories, Montgomery, TX).

Plasma Metabolites. Blood was sampled $-48 \pm 1,-29 \pm 1,-20 \pm 1,-9 \pm 1,1 \pm 1,7$ $\pm 1,14 \pm 1$, and $30 \pm 1 \mathrm{~d}$ relative to calving for the evaluation of plasma glucose, BHBA, and NEFA concentration. Briefly, blood was collected via the coccygeal vein into $10 \mathrm{ml}$ Vacutainer tubes containing sodium heparin (BD, Franklin Lakes, NJ). Blood was centrifuged at $1900 \mathrm{xg}$ for 15 minutes at $4^{\circ} \mathrm{C}$ at the University of Missouri dairy farm. Plasma was harvested and stored in $1.5 \mathrm{ml}$ micro centrifuge tubes (triplicates) at $-20^{\circ} \mathrm{C}$. All metabolites were analyzed by enzymatic colorimetric assays in 96-well microplates (Costar, Corning Inc., Acton, MA) and read using a microplate reader spectrophotometer (Synergy II BioTek, Winooski, VT). Assay procedures were modified from available kits to allow for use with 96-well plates. All procedures were validated in our laboratory. Plasma glucose was determined by glucose oxidase (Sigma-Aldrich, St. Louis, MO), plasma BHBA with the use of D-3-Hydroxybutyrate: NAD oxidoreductase (Roche Applied Science, Indianapolis, IN), and plasma NEFA with NEFA-C reagents (WAKO Chemicals, Dallas, TX). Plasma samples were accumulated and metabolite assays were conducted consecutive days upon completion of animal experimentation.

\section{Experimental Design and Statistical Analysis}

The experiment was conducted as a randomized complete block design. Cows were screened prior to enrollment into the study for previous lactation SCC of less than $300,000 / \mathrm{ml}$, and a locomotion score of less than two (Sprecher et al., 1997). Thirty-two 
multiparous Holstein cows were assigned to blocks $(\mathrm{n}=16)$ for balanced matureequivalent 305 day MY, BCS, and previous lactation average SCC. Within blocks, cows were randomly assigned to one of two treatments- control (CTL) or OmniGen-AF supplemented (OG). Due to illness during the study, ten cows were removed in the final analysis, giving final treatment numbers of CTL $(n=13)$ and $\mathrm{OG}(\mathrm{n}=9)$.

Data outliers were detected using PROC REG of SAS (2001). Outliers were identified within the data set if they presented at least two of the following characteristics: standardized residual $\left(\mathrm{r}_{\mathrm{i}}\right)>2.5$ standard deviations, high leverage $\left(\mathrm{h}_{\mathrm{ii}} \geq\right.$ $2 \mathrm{pn}^{-1}$, where $\mathrm{n}=$ number of observations and $\mathrm{p}=$ number of parameters), and cook's distance $\left(D_{\mathrm{i}}\right)>1$ (Kaps and Lamberson, 2004). Determination of outlier data removal was carried out if outliers made up at least $5 \%$ of the data set or experimental observations justified removal of data. Distribution of all variables was determined using PROC GLM procedures in SAS (2001) to determine treatment residuals and PROC UNIVARIATE to determine if the treatment residuals were normally distributed. Data that did not follow a normal distribution were transformed to elicit a normal distribution.

Removal of the ten cows from the data set for clinical reasons required the data to be analyzed as a completely randomized design with cow as the experimental unit, instead of a randomized complete block design as originally planned. Data were analyzed by analysis of variance as a mixed model using the MIXED procedure in SAS (2001). All MY, milk protein, SNF, MUN, and FCM efficiency data were analyzed with compound symmetry as the covariance structure; all other variables with repeated measures were analyzed using auto-regression as the covariance structure (Littell et al., 1998). Pretreatment values were used as covariates for BCS, weight, and plasma glucose. 
Covariates were used to adjust means to account for pretreatment variation. The PDIFF (SAS, 2001) option was used to determine differences in individual least squares means when overall treatment or treatment by time interactions were observed. Data are presented as least square means \pm standard error of the mean. Statistical significance was declared at $P \leq 0.05$ and $P \geq 0.05$ but $\leq 0.10$ was considered a trend.

\section{RESULTS}

No treatment differences were observed for live weight [757 $\pm 7 \mathrm{~kg}$ (CTL) and $761 \pm 9 \mathrm{~kg}(\mathrm{OG}), P=0.6956]$ and BCS $[3.57 \pm 0.04(\mathrm{CTL})$ and $3.58 \pm 0.05(\mathrm{OG}), P=$ 0.9058]. Furthermore, there were no treatment by time interactions observed for live weight $(P=0.90)$ or BCS $(P=0.44$; Figure 2.1$)$. Daily DMI was not different between groups (treatment, $P=0.48$; treatment by time, $P=0.76$ ) with $\mathrm{CTL}$ cows consuming 17.1 $\pm 0.7 \mathrm{~kg} / \mathrm{d}$ and $\mathrm{OG}$ cows consuming $16.3 \pm 0.9 \mathrm{~kg} / \mathrm{d}$ (Figure 2.2) However, a number of observations were made that warranted analyzing prepartum and postpartum data independently. Prepartum DMI was not different between treatments and did not have a significant treatment by time interaction $(P=0.39$ and $P=0.57$; respectively); however, the duration of DMI decline prior to calving was shorter in OG cows (less than one week) compared to CTL cows (approximately two weeks). Supplemented cows also appeared to have a more consistent DMI during the prepartum period compared to CTL cows. A treatment by time effect was observed when postpartum DMI was analyzed $(P<0.05)$ showing that CTL cows consumed more dry matter than OG cows on 117 and 25 after parturition. 
Milk component variables were analyzed during the first $30 \mathrm{~d}$ of lactation to examine treatment effect and extended out the first $150 \mathrm{~d}$ of lactation to examine potential treatment carryover (Table 2.3). MY, milk fat percent, milk protein yield, SNF (percent and yield), MUN, and SCC were not different between treatment groups during either the first $30 \mathrm{~d}$ or extended lactation $(P>0.15)$. A treatment by time effect was observed during the first $30 \mathrm{~d}$ of lactation for milk fat yield and milk protein percent $(P=$ 0.07 and $P=0.01$, respectively). Milk fat yield tended to be lower during the first week of lactation and higher during the fourth week of lactation in OG cows compared to CTL cows. Additionally, milk protein percent was higher in OG cows during the first week of lactation. No treatment or treatment by time interaction was observed when milk fat yield or milk protein percent were examined during the extended lactation period. Somatic cell score was not different during the first $30 \mathrm{~d}$ of lactation; however, a treatment by time trend was observed within the extended lactation period for CTL cows to have lower SCS $(P=0.09)$. The OG supplemented cows tended to have increased SCC during the fifth month of lactation. Treatment by time effects were observed for 3.5\% FCM and ECM during the first $30 \mathrm{~d}$ of lactation ( $P=0.04$ and $P=0.03$, respectively) with $\mathrm{OG}$ cows having lower yields in the first week of lactation but higher yields in the fourth week of lactation compared to CTL cows. There was no treatment or treatment by time effect with $3.5 \% \mathrm{FCM}$ and ECM when extended lactation was examined.

Dry matter intake was only recorded during the first $30 \mathrm{~d}$ of lactation therefore carryover effects of treatment could not be analyzed for feed conversion data. Treatment by time effects were observed for feed to milk conversion and feed to $3.5 \% \mathrm{FCM}$ conversion ( $P=0.07$ and $P=0.04$, respectively). Feed to milk conversion tended to be 
more efficient on d 3 and less efficient on d 17 and 19 after parturition for CTL cows compared to OG cows. Feed to $3.5 \%$ FCM conversion analysis indicates that CTL cows were more efficient the first week but less efficient the fourth week of lactation compared to OG cows. There was no treatment or treatment by time effect for feed to ECM conversion. Colostrum IgG, IgA, and IgM concentrations were not different between treatment groups $(P>0.35)$.

The plasma metabolites glucose $(41.4 \pm 1.6 \mathrm{mg} / \mathrm{dL}$ and $44.1 \pm 1.9 \mathrm{mg} / \mathrm{dL} ; P=$ $0.2904), \operatorname{BHBA}(5.8 \pm 0.5 \mathrm{mg} / \mathrm{dL}$ and $6.1 \pm 0.6 \mathrm{mg} / \mathrm{dL} ; P=0.7117)$, and NEFA $(378.4 \pm$ $28.2 \mu \mathrm{Eq} / \mathrm{L}$ and $347.3 \pm 33.5 \mu \mathrm{Eq} / \mathrm{L} ; P=0.2765)$ were not different between treatments and no treatment by time interactions were observed for the duration of the study (Figure 2.3). The pattern of plasma glucose, BHBA, and NEFA observed in this study follow that of other metabolite studies. The cows were likely in a negative energy balance approximately a week prior to calving, indicated by an increase in plasma NEFA and BHBA. Plasma BHBA remained elevated for the duration of the study while plasma NEFA peaked on $\mathrm{d} 7$ and began to decline by d 14 postpartum.

\section{DISCUSSION}

Studies investigating the effects of OmniGen-AF on DMI, MY, milk composition, and plasma metabolite markers have been limited. This feed additive is marketed as an immune modulator that improves the innate immune system of immunosuppressed animals and therefore most studies are designed to determine differences in treatment at the cellular level. The results presented in this paper were available as secondary data 
collected during an immune function study designed to observe effects of OmniGen-AF during the periparturient period when natural immunosuppression is observed. To better understand potential benefits of OmniGen-AF on production and metabolism, large scale studies need to be conducted.

A literature search for previous production based research investigating the effects of OmniGen-AF was performed with minimal results. A 2009 field trial, conducted by Prince Agri Products, compared the effects of feeding the additive prepartum on postpartum health, MY, and milk quality (Chapman, 2011). Using barn as the experimental unit, Chapman (2011) observed a $3.65 \mathrm{lb}$ (approximately $1.65 \mathrm{~kg}$ ) summit milk increase when OG was fed prepartum (no reported p-value). Bulk tank somatic cell count (BTSCC), used to indicate milk quality, were higher in the supplemented barn during the trial period (four milk test dates), but lower during the three milk test dates immediately following the trial completion (Chapman, 2011; no reported p-value). Increased BTSCC may be supporting evidence towards increased immune response following supplementation as neutrophils make up a large proportion of mammary SCC. Wang et al, (2007) proposed an increase in L-selectin would increase the ability of neutrophils to adhere to capillary walls and migrate to sites of infection. Although statistically similar, SCC was numerically higher in supplemented cows compared to control cows in the current study. This, in addition to a decrease in SCC in supplemented cows following treatment termination, may be further anecdotal proof of immune modulation. While increased neutrophil presence in the mammary gland could lead to reduced intensity and longevity of intramammary infection, increased SCC reduces milk quality and producers risk losing premiums on milk with high SCC. 
In addition, Chapman et al. (2011) reported a decreased rate of health incidences with supplementation; however, this claim is believed to be confounded. Health incidences were characterized by the number of animals culled from each barn. The rate of involuntary culls was similar between barns but the barn devoid of OG supplementation had an increased voluntary cull rate over the supplemented barn. Increased voluntary cull rates are more likely attributed to management technique, than effect of lack of supplement, as a majority of voluntary culls were due to mastitis. The control barn received fewer treatments for mastitis as well as experienced longer intervals between treatments when compared to the supplemented barn.

A second field study conducted to determine the effects of OG on milk yield and persistency reported that cows supplemented with the feed additive produced 0.7 $\mathrm{kg} / \mathrm{hd} / \mathrm{day}(P<0.05)$ more milk than control cows (Chapman et al., 2005). Increased persistency of MY was also observed in OG cows with a decrease of $1.08 \mathrm{~kg} / \mathrm{hd} / \mathrm{day}$ compared to control cows with a decrease of $2.42 \mathrm{~kg} / \mathrm{hd} / \mathrm{day}$ during the 60 day lactation trial $(P<0.05$; Chapman et al., 2005). The current study was unable to detect significant treatment effects on either $30 \mathrm{~d}$ MY or MY followed out to $150 \mathrm{~d}$ in lactation. Although not significant, cows receiving supplementation produced $0.82 \mathrm{~kg} / \mathrm{d}$ and $1.56 \mathrm{~kg} / \mathrm{d}$ more milk than control cows during the 30 and $150 \mathrm{~d}$ lactation periods. The difference between MY observed from 30 and $150 \mathrm{~d}$ in lactation was 0.96 and $1.89 \mathrm{~kg} / \mathrm{d}$ for control and supplemented cows, respectively. Both groups showed increased MY from 30 to $150 \mathrm{~d}$ in lactation and supplemented cows maintained a $0.92 \mathrm{~kg} / \mathrm{d}$ higher MY than control cows. These results are in agreement with those of the Chapman studies. Although not 
statistically significant; OmniGen-AF supplementation appears to improve MY and persistency. Neither of the Chapman studies examined milk composition beyond SCC.

With limited production studies examining the effects of the B-vitamin and active dried yeast supplement, a brief comparison of results observed with supplementation of various B-vitamins and active dried yeast will be discussed. In the current study, supplementation effects were limited to milk composition during the first month of lactation while no intake or metabolic differences were observed between treatment groups. Likewise, Zimmerly and Weiss (2001) found no effect of biotin supplementation on DMI and plasma glucose or NEFA concentration. Periparturient dairy cattle supplemented with 0,10 , and $20 \mathrm{mg} / \mathrm{d}$ of biotin had a linear increase in MY and milk protein yield with no effect on milk fat percent or yield and protein percent (Zimmerly and Weiss, 2001). Contrary to the present study and that of Zimmerly and Weiss (2001), Majee et al. (2003) observed an increase in DMI of $0.7 \mathrm{~kg} / \mathrm{d}$ after supplementation of 20 $\mathrm{mg} / \mathrm{d}$ biotin to dairy cattle approximately $50 \mathrm{~d}$ in lactation. Majee et al. (2003) reported an increase in MY of $1.7 \mathrm{~kg} / \mathrm{d}$ as well as a $0.6 \mathrm{~kg} / \mathrm{d}$ increase in milk protein yield compared to control cows. It was suggested by the authors that a $1.7 \mathrm{~kg} / \mathrm{d}$ increase in MY could not be sustained by a $0.7 \mathrm{~kg} / \mathrm{d}$ increase in DMI. Therefore, biotin must have a direct mechanism for increasing MY above and beyond improvement of hoof health and increased DMI. This mechanism has not yet been determined.

Folic acid proved beneficial in multiparous but not primiparous cows when supplemented from four weeks prepartum to $305 \mathrm{~d}$ in lactation (Girard and Matte, 1998). Stage of lactation impacted the effects of folic acid supplementation with no effect observed during the first six weeks of lactation (Girard et al., 1995) or a 6 and 10\% 
increase in MY from 3 to $100 \mathrm{~d}$ and 100 to $200 \mathrm{~d}$ in lactation over control cows;

respectively (Girard and Matte, 1998). The authors indicated folic acid requirements are elevated in early lactation and therefore masked potential of folic acid supplementation as a mechanism to improve MY (Girard et al., 1995). Girard and Matte (1998) hypothesized that low levels of serum vitamin $B_{12}$ in primiparous cows was the reason for lack of folic acid supplementation effect. Vitamin $\mathrm{B}_{12}$ is essential for demethylation of circulating folic acid to allow for entry into cells. Serum folic acid concentrations were increased with supplementation indicating folic acid was not able to escape circulation and enter cells (Girard and Matte, 1998).

Here to fore, we have discussed supplementation of individual B-vitamins. However, interactions between B-vitamins may change the expected effects on production performance of dairy cattle. Sacadura et al. (2008) supplemented cows in either early or mid-lactation (96 vs. $216 \mathrm{~d}$ postpartum) with a ruminally protected Bvitamin premix that provided $10 \mathrm{mg} / \mathrm{d}$ biotin, $12 \mathrm{mg} / \mathrm{d}$ folic acid, $120 \mathrm{mg} / \mathrm{d}$ pantothenic acid, and $75 \mathrm{mg} / \mathrm{d}$ pyridoxine. In mid-lactation cows, milk and milk fat yield were unaffected by treatment while cows receiving B-vitamins had higher milk protein yield. Early lactation cows receiving B-vitamins had improved MY, milk fat yield, milk energy output, and decreased SCC (Sacadura et al., 2008). Dry matter intake was unaffected by treatment in the two stages of lactation; however, mid-lactation cows had higher DMI compared to early lactation cows. Sacadura et al. (2008) postulated that improvements in early lactation MY and milk composition were more apparent due to lower DMI and that lower DMI may result in a lower ruminal escape of B-vitamins. 
In addition to B-vitamins, OmniGen-AF contains active dried yeast. Active dried yeast is produced by growing yeast cells in growth medium, isolating cells from medium, and then drying the cells in a manner that does not kill the yeast cells. The particular strain of Saccharomyces cerevisiae in the current micronutrient supplement is undefined. As individual strains of yeast have differing effects on ruminant microbes (Chung et al., 2011) it is hard to determine if results from the current study correspond to other studies using the same strain of yeast. In addition, studies examining the effects of live yeast cells on DMI and MY tend to supplement at varying levels. The current micronutrient supplement provides $12.34 \times 10^{9} \mathrm{CFU} / \mathrm{d}$ and caused no statistical increase in DMI or MY. In contrast, Williams et al. (1991) found that supplementation of $50 \times 10^{9} \mathrm{CFU} / \mathrm{d}$ to early lactation dairy cattle improved both DMI and MY. Williams' study supplemented cattle starting $3 \mathrm{~d}$ prior to expected calving compared to our study, in which supplementation was initiated $60 \mathrm{~d}$ prior to expected calving, and fed yeast at four times the level as the current study. However, increased supplementation rate is not required because Stella et al., (2007) improved DMI and MY by supplementing $4 \times 10^{9} \mathrm{CFU} / \mathrm{d}$ to early lactation dairy goats.

The current study indicates that supplementation of the micronutrient to perparturient dairy cattle results in limited production performance improvements. The weekly milk composition effects observed in the first month of lactation may be a product of micronutrient supplementation. However, the low level of B-vitamins and active dried yeast provided by OmniGen-AF (Table 2.2) compared to the other studies discussed leads the authors to believe fluctuation of milk components observed in the current study are a result of the normal component variation observed in early lactation. 
A greater number of animals would need to be studied in the future to determine statistical treatment differences in all the variables examined.

\section{CONCLUSION}

Results from the current study suggest limited effect of the micronutrient supplement OmniGen-AF on performance during the peripartum period. However, the current study was not designed to analyze production variables and therefore was unable to detect potential treatment differences. The current study indicates a potential for OmniGen-AF to improve milk yield, milk composition, and SCC. To better understand the possible performance effects of the micronutrient supplement, Omnigen AF, a large scale study with means of independently feeding cows would need to be completed. 
Table 2.1. Composition ${ }^{1}$ of TMR diets fed during the study (dry matter basis).

\begin{tabular}{lcc} 
Component $^{2}$ & Prepartum & Postpartum \\
\hline DM, \% & 63.92 & 50.40 \\
CP, \% DM & 12.37 & 17.38 \\
Soluble protein, \% CP & 20.17 & 26.33 \\
Metabolizable protein, g/d ${ }^{3}$ & 1,188 & 2,967 \\
ADF, \% DM & 33.50 & 21.08 \\
NDF, \% DM & 43.20 & 30.63 \\
Lignin, \% DM & 4.70 & 4.18 \\
NFC, \% DM & 30.65 & 44.73 \\
Starch, \% NFC & 13.47 & 27.40 \\
Crude fat, \% DM & 2.23 & 4.40 \\
NEL, Mcal/kg & 1.40 & 1.68 \\
Metabolizable energy, Mcal/d ${ }^{3}$ & 29.47 & 64.43 \\
Ash, \% DM & 8.37 & 7.98 \\
Ca, \% DM & 0.86 & 1.00 \\
P, \% DM & 0.23 & 0.28 \\
Mg, \% DM & 0.37 & 0.36 \\
K, \% DM & 1.34 & 1.39 \\
\hline
\end{tabular}

${ }^{1}$ Composition determined by independent lab analysis (Dairy One, Inc. Ithaca, NY). ${ }^{2} \mathrm{DM}=$ dry matter; $\mathrm{CP}=$ crude protein; $\mathrm{ADF}=$ acid detergent fiber; $\mathrm{NDF}=$ neutral detergent fiber; $\mathrm{NFC}=$ non-fibrous carbohydrates; $\mathrm{NEL}=$ net energy of lactation. ${ }^{3}$ Protein and energy supplied as predicted by the Cornell Net Carbohydrate and Protein System (Fox et al., 2004). 
Table 2.2. Treatment (OmniGen-AF) list of ingredients, amount of B-vitamin provided with treatment dose, amount of nutrient produced by rumen microbes, and the estimated daily requirement of dairy cattle.

\begin{tabular}{|c|c|c|c|c|}
\hline Nutrient & $\begin{array}{c}\text { OmniGen- } \\
\text { AF label }^{1} \\
\text { (per lb) }\end{array}$ & $\begin{array}{c}\text { Nutrient in } \\
\text { Treatment } \\
\text { Dose }^{2}\end{array}$ & $\begin{array}{c}\text { Daily } \\
\text { Ruminal } \\
\text { Synthesis of }^{\text {Nutrient }^{3}} \\
\end{array}$ & $\begin{array}{c}\text { Daily } \\
\text { Estimated } \\
\text { Requirement }\end{array}$ \\
\hline Vitamin $\mathrm{B}_{12}, \mu \mathrm{g}$ & 90 & 11.11 & $70 \mathrm{mg}$ & $0.6 \mathrm{mg}$ \\
\hline Menadione, $\mathrm{mg}$ & 7 & 0.86 & ----- & ----- \\
\hline Riboflavin $\left(\mathrm{B}_{2}\right), \mathrm{mg}$ & 65 & 8.02 & 261 & 156 \\
\hline d-Panthothenic acid, mg & 69 & 8.51 & 38 & 425 \\
\hline Thiamin $\left(\mathrm{B}_{1}\right), \mathrm{mg}$ & 34 & 4.20 & 143 & 41 \\
\hline Niacin, mg & 225 & 27.77 & 1804 & 289 \\
\hline Vitamin $\mathrm{B}_{6}, \mathrm{mg}$ & 18 & 2.22 & 96 & 48 \\
\hline Folic acid, mg & 3 & 0.37 & 7 & 35 \\
\hline Choline, mg & 33 & 4.07 & ---- & ---- \\
\hline Biotin, mg & 0.9 & 0.11 & 14 & 6 \\
\hline $\begin{array}{l}\text { Saccharomyces } \\
\text { cerevisiae, CFU }\end{array}$ & $100 \times 10^{9}$ & $12.34 \times 10^{9}$ & ---- & ----- \\
\hline
\end{tabular}

${ }^{1}$ Ingredient list from OmniGen-AF data sheet (Prince Agri Products, Quincy, IL).

${ }^{2} \mathrm{~A}$ treatment dose of $56 \mathrm{~g} / \mathrm{cow} /$ day was given as a top dressing with $225 \mathrm{~g}$ of sweet feed on top of prepartum or postpartum TMR.

${ }^{3} \mathrm{NRC}$ estimated daily B-vitamin requirements of $630 \mathrm{~kg}$ lactating dairy cow with a net output in milk of $35 \mathrm{~kg} / \mathrm{d}$. Extrapolated requirements from a $173 \mathrm{~kg}$ lactating sow.

Adapted from rumen microbial synthesis of B-vitamins table (NRC, 2001). 
Table 2.3. Milk variables ${ }^{1}$, composition ${ }^{2}$, and colostrum immunoglobulin ${ }^{3}$ reported as least square means with standard errors.

\begin{tabular}{|c|c|c|c|c|}
\hline Milk Variables ${ }^{1}$ & Control & OmniGen-AF & $\begin{array}{c}\text { Treatment } \\
\text { (P-value) }\end{array}$ & $\begin{array}{l}\text { Treatment by } \\
\text { Time (P-value) }\end{array}$ \\
\hline 30d Milk Yield, kg/d & $41.9 \pm 1.1$ & $42.8 \pm 1.4$ & 0.6478 & 0.22 \\
\hline $3.5 \%$ FCM, kg/d & $47.6 \pm 1.9$ & $48.7 \pm 2.3$ & 0.7067 & 0.04 \\
\hline $\mathrm{ECM}, \mathrm{kg} / \mathrm{d}$ & $46.5 \pm 1.6$ & $47.6 \pm 2.0$ & 0.6867 & 0.03 \\
\hline Feed to Milk & $2.1 \pm 0.09$ & $2.2 \pm 0.11$ & 0.7121 & 0.07 \\
\hline \multicolumn{5}{|l|}{ Efficiency $^{2}$} \\
\hline $3.5 \%$ FCM Efficiency & $1.0 \pm 0.01$ & $1.0 \pm 0.01$ & 0.3867 & 0.04 \\
\hline ECM Efficiency & $1.1 \pm 0.07$ & $1.2 \pm 0.09$ & 0.3794 & 0.88 \\
\hline \multicolumn{5}{|l|}{ Milk Composition $^{3}$} \\
\hline Fat, \% & $5.3 \pm 0.26$ & $5.2 \pm 0.31$ & 0.7763 & 0.19 \\
\hline Fat, $\mathrm{kg}$ & $1.9 \pm 0.09$ & $2.0 \pm 0.11$ & 0.6709 & 0.07 \\
\hline Protein, \% & $3.1 \pm 0.13$ & $3.4 \pm 0.15$ & 0.1548 & 0.01 \\
\hline Protein, kg & $1.2 \pm 0.04$ & $1.2 \pm 0.05$ & 0.5625 & 0.32 \\
\hline SNF, $\%$ & $8.7 \pm 0.10$ & $8.8 \pm 0.12$ & 0.554 & 0.19 \\
\hline SNF, kg & $3.4 \pm 0.11$ & $3.4 \pm 0.13$ & 0.9439 & 0.16 \\
\hline MUN & $12.0 \pm 0.47$ & $12.4 \pm 0.57$ & 0.5515 & 0.98 \\
\hline SCS & $2.7 \pm 0.37$ & $2.7 \pm 0.45$ & 0.8987 & 0.50 \\
\hline SCC & $177 \pm 95$ & $301 \pm 114$ & 0.8778 & 0.43 \\
\hline \multicolumn{5}{|l|}{ Extended $^{4}$ Milk } \\
\hline 150d Milk Yield, kg/d & $42.9 \pm 1.4$ & $44.5 \pm 1.7$ & 0.4856 & 0.99 \\
\hline $3.5 \%$ FCM, kg/d & $39.9 \pm 1.5$ & $41.3 \pm 1.9$ & 0.5766 & 0.45 \\
\hline $\mathrm{ECM}, \mathrm{kg} / \mathrm{d}$ & $39.9 \pm 1.5$ & $41.5 \pm 1.9$ & 0.4897 & 0.23 \\
\hline \multicolumn{5}{|l|}{$\begin{array}{l}\text { Extended } \\
\text { Composition }\end{array}$} \\
\hline Fat, $\%$ & $4.0 \pm 0.12$ & $4.0 \pm 0.15$ & 0.8694 & 0.98 \\
\hline Fat, kg & $1.7 \pm 0.06$ & $1.5 \pm 0.08$ & 0.5087 & 0.38 \\
\hline Protein, \% & $3.1 \pm 0.08$ & $3.1 \pm 0.10$ & 0.8369 & 0.58 \\
\hline Protein, $\mathrm{kg}$ & $1.1 \pm 0.05$ & $1.2 \pm 0.06$ & 0.52 & 0.64 \\
\hline SNF, $\%$ & $8.8 \pm 0.10$ & $8.8 \pm 0.12$ & 0.6695 & 0.80 \\
\hline SNF, $\mathrm{kg}$ & $3.3 \pm 0.13$ & $3.4 \pm 0.17$ & 0.5352 & 0.19 \\
\hline MUN & $13.3 \pm 0.40$ & $13.5 \pm 0.50$ & 0.7114 & 0.26 \\
\hline SCS & $2.5 \pm 0.44$ & $2.5 \pm 0.56$ & 0.9895 & 0.09 \\
\hline SCC & $278 \pm 81$ & $231 \pm 102$ & 0.3806 & 0.72 \\
\hline \multicolumn{5}{|l|}{ Colostrum $^{5}$} \\
\hline $\operatorname{IgG}(\mathrm{mg} / \mathrm{mL})$ & $61.06 \pm 6.85$ & $52.07 \pm 8.23$ & 0.4127 & $\begin{array}{ll}---- \\
\end{array}$ \\
\hline $\operatorname{IgA}(\mathrm{mg} / \mathrm{mL})$ & $0.84 \pm 0.10$ & $0.92 \pm 0.12$ & 0.5978 & ----- \\
\hline $\operatorname{IgM}(\mathrm{mg} / \mathrm{mL})$ & $8.15 \pm 0.79$ & $8.07 \pm 0.95$ & 0.3666 & ----- \\
\hline
\end{tabular}




\section{Table 2.3. (continued)}

${ }^{1}$ Variables examined during treatment period. Milk data was recorded daily and milk components were analyzed weekly. FCM =3.5\% fat-corrected milk; ECM = energycorrected milk.

${ }^{2}$ Efficiency variables were calculated using $\mathrm{kg}$ of milk variable divided by $\mathrm{kg}$ of DMI.

${ }^{3}$ Milk samples were collected at two consecutive milkings within a $24 \mathrm{hr}$ period.

Compositional analysis was conducted by an independent laboratory (Mid-South Dairy Records, Springfield, MO). SNF = solids-not-fat; MUN = milk urea nitrogen; SCS = somatic cell score; $\mathrm{SCC}=$ somatic cell count.

${ }^{4}$ Extended milk variables were collected from herd records (PCDart, Dairy Records Management Systems, Raleigh, NC). Herd test-day samples were used to determine monthly milk components.

${ }^{5}$ Colostrum was collected at first milking. Immunoglobulin concentrations were analyzed via ELISA kits purchased from Bethyl Laboratories. 
A.

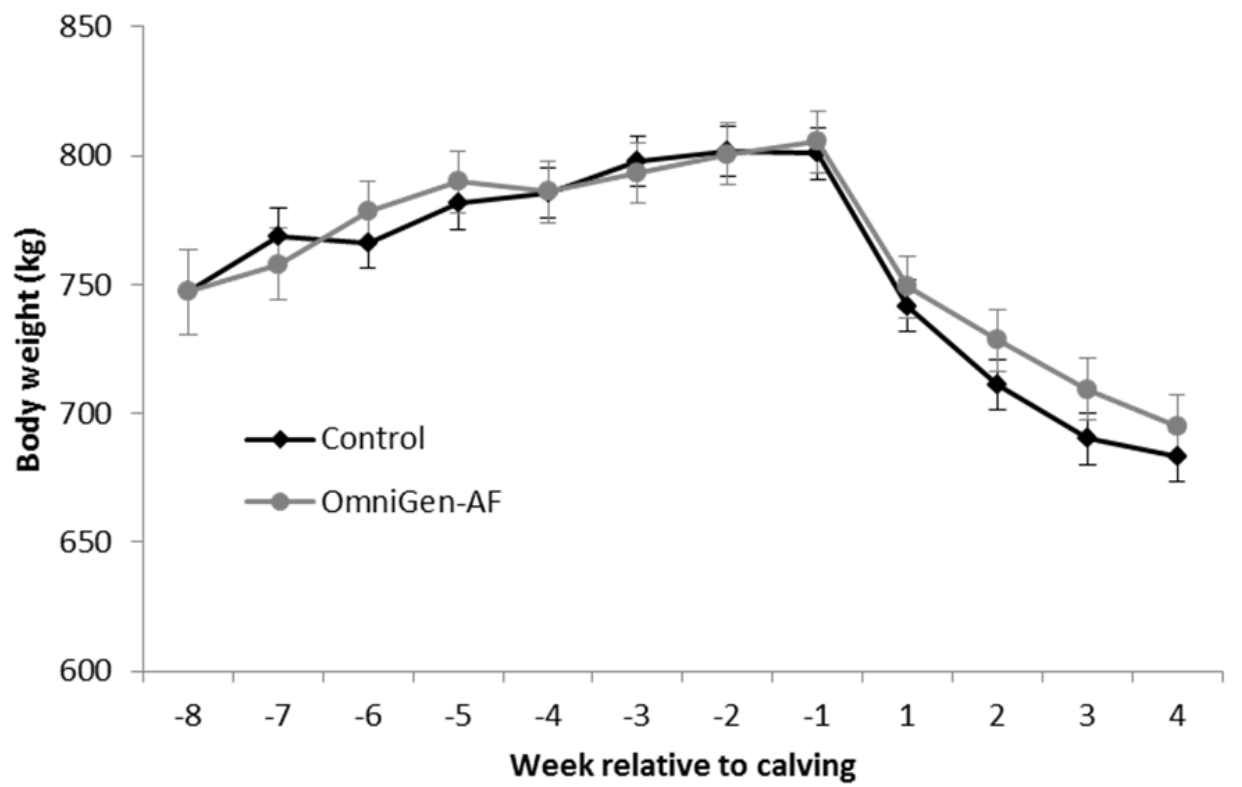

B.

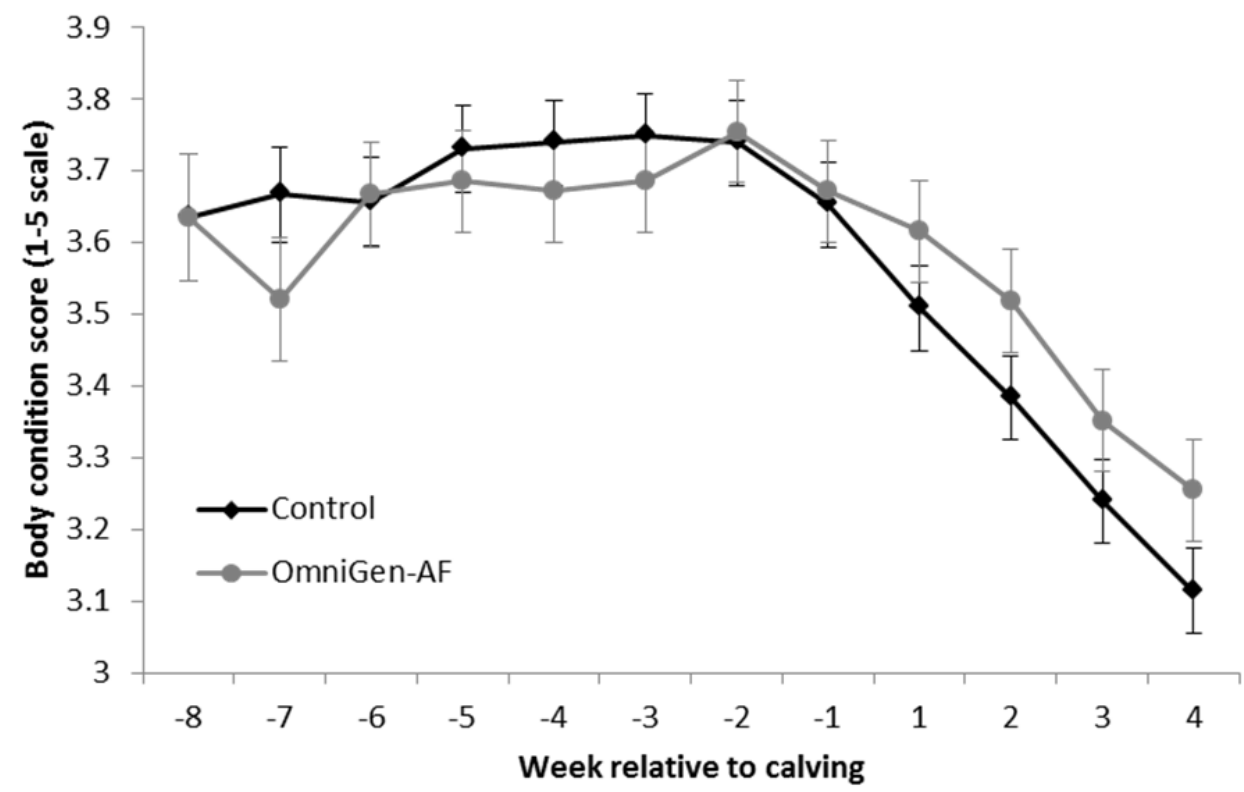

Figure 2.1. Weekly body weight and body condition score (BCS). Cows were weighed (A) weekly for the duration of the study $(P=0.70)$. BCS $(B)$ were assessed by two independent evaluators using 0.25 increments and a scale of 1 to $5(P=0.91)$. 


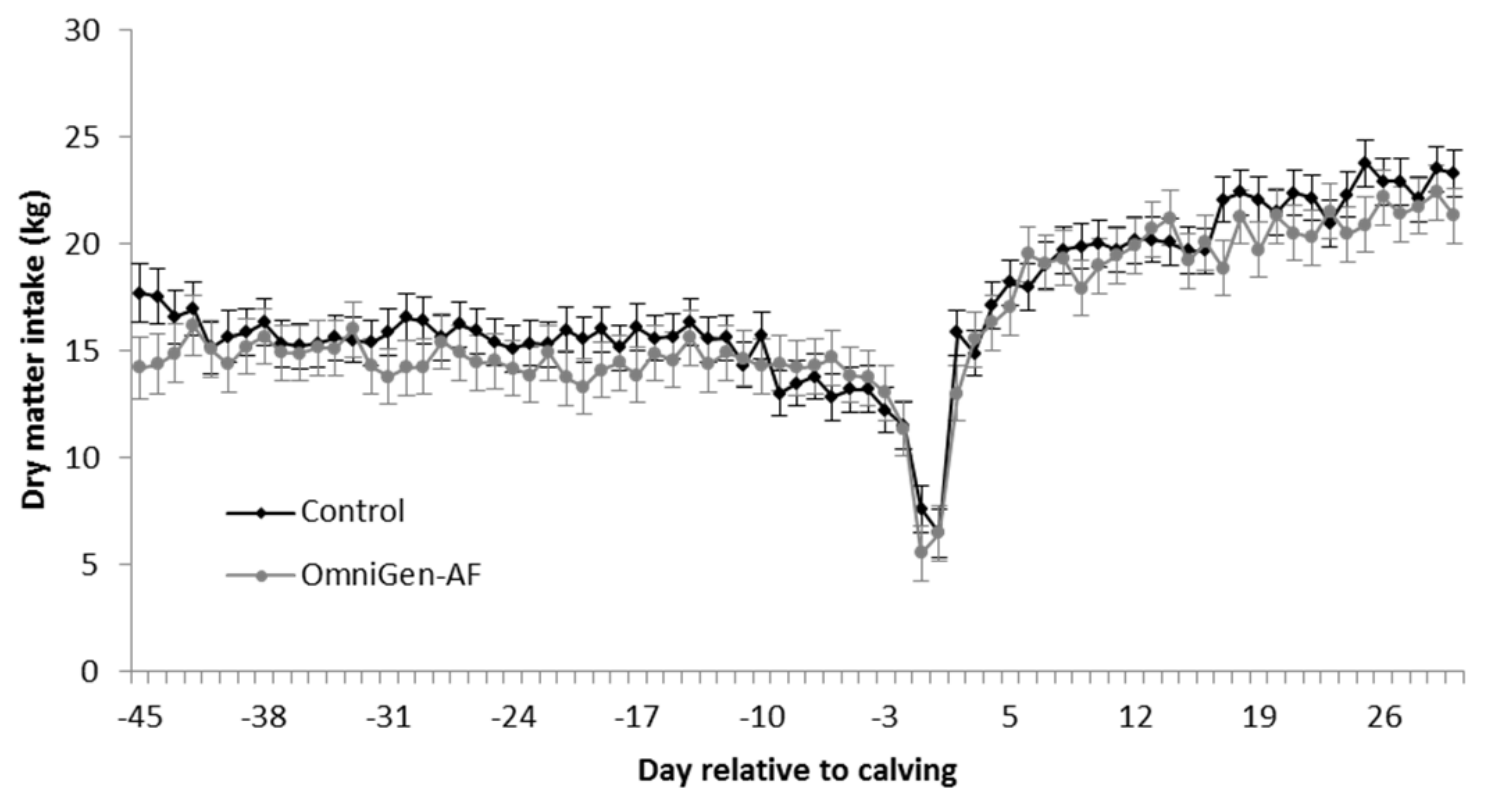

Figure 2.2. Daily dry matter intake $(P=0.48)$ of cows fed individually via Calan door systems. Cows were fed once daily during the dry period and twice daily during the lactation period. Feed refusals were weighed daily to assess feed intake and as a variable to monitor cows for potential health issues. 


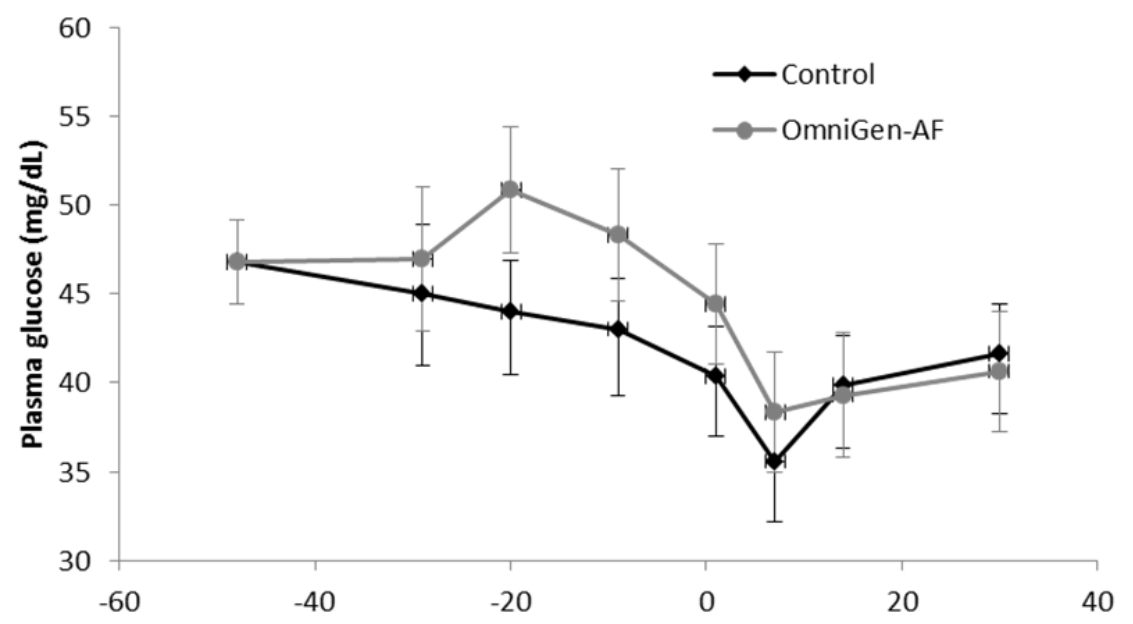

A.

Day relative to calving

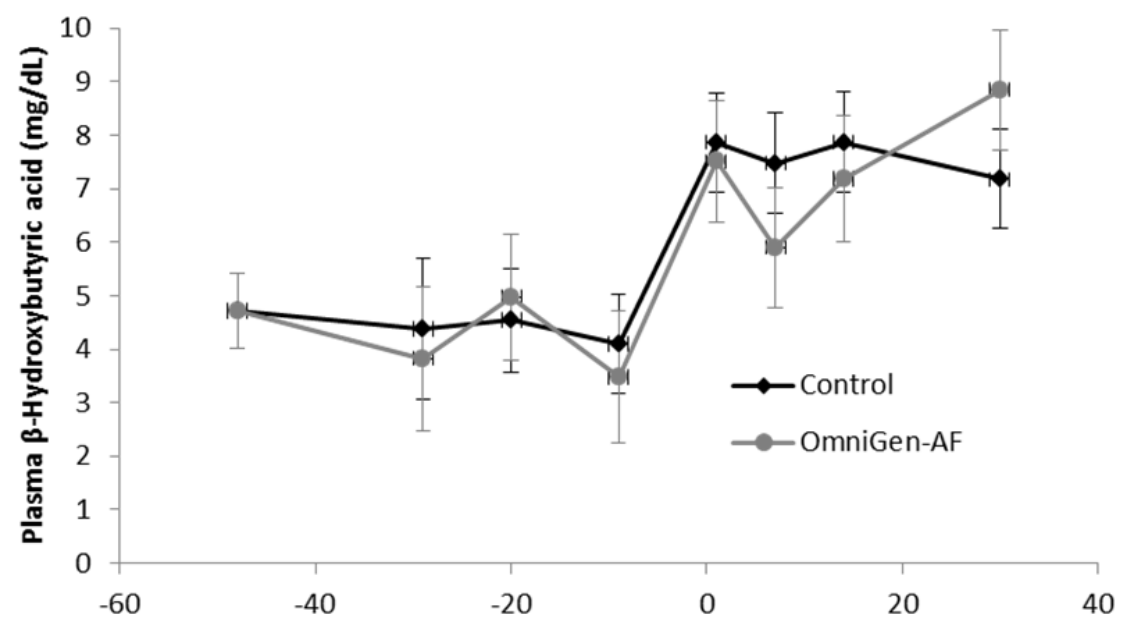

B.

Day relative to calving

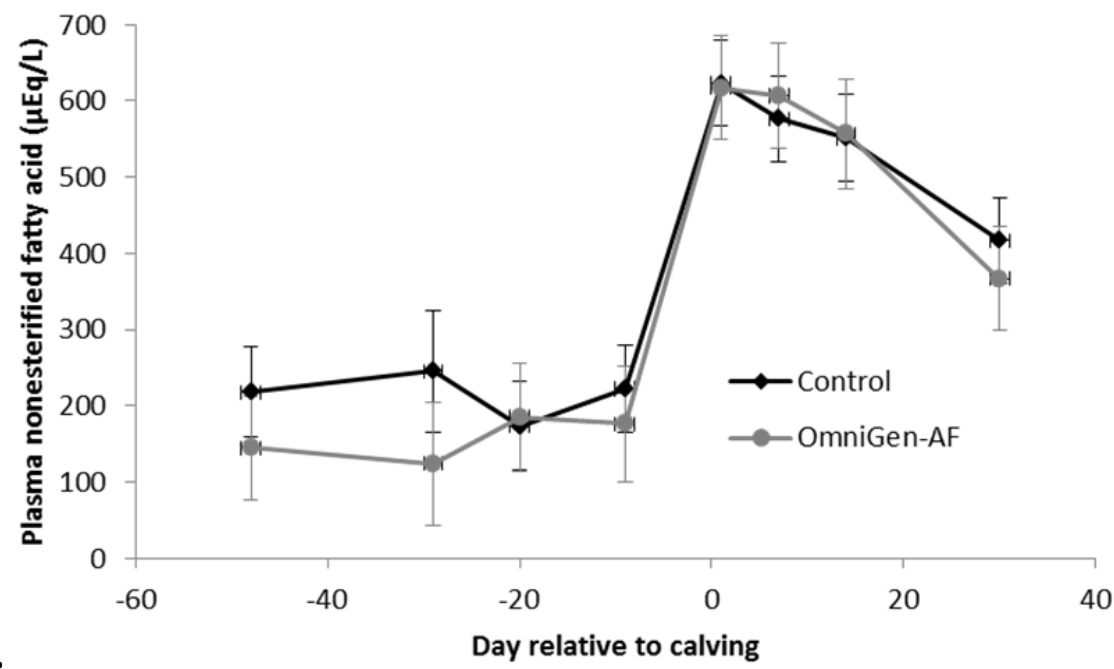


Figure 2.3. Plasma metabolite concentrations of $(\mathrm{A})$ glucose $(P=0.29)$, (B) $\beta$ hydroxybutyrate (BHBA; $P=0.71)$, and $(\mathrm{C})$ non-esterified fatty acids (NEFA; $P$ $=0.28$ ). Metabolite samples were collected on $\mathrm{d}-47 \pm 1,-30 \pm 1,-20 \pm 1,-11 \pm 1$, $1,7,14$ and 30 relative to parturition. Samples were collected at morning feeding to maintain consistency. No treatment or treatments by time interactions were observed $(P>0.15)$. 


\title{
CHAPTER 3
}

\section{EFFECT OF INORGANIC AND ORGANIC TRACE MINERAL SUPPLEMENTATION ON PRODUCTION AND OXIDATIVE STRESS VARIABLES IN PERIPARTURIENT HOLSTEIN DAIRY CATTLE}

\begin{abstract}
The objective of this study was to investigate the effects of inorganic and organic trace mineral supplementation on production variables and oxidative stress markers in the periparturient cow. Thirty-five multiparous Holstein dairy cows were randomly assigned to either a control group $(\mathrm{CTL}, \mathrm{n}=13)$ without $\mathrm{Mn}, \mathrm{Co}, \mathrm{Cu}$, and $\mathrm{Zn}$ supplementation, an inorganic trace mineral group (ITM, $\mathrm{n}=11$ ) supplemented with $200 \mathrm{mg} \mathrm{Mn}, 25 \mathrm{mg}$ Co, $125 \mathrm{mg} \mathrm{Cu}$, and $360 \mathrm{mg} \mathrm{Zn}$ from sulfate and carbonate sources, or an organic trace mineral group (OTM, $\mathrm{n}=11$ ) supplemented with the same level of these trace minerals from a combination of inorganic and organic trace minerals chelated to amino acids or glucoheptonate. All groups received the same basal diet. Mineral supplementation or sham control was administered daily via an oral gelcap bolus from $-57.1 \pm 1$ days prepartum through 8 days postpartum. Variables of interest included daily dry matter intake (DMI) and postpartum milk yield as well as weekly body condition score (BCS), body weight, and plasma concentrations of glucose, nonesterified fatty acids (NEFA), and $\beta$-hydroxybutyrate (BHBA). Plasma thiol and thiobarbituric acid reactive substances (TBARS) were examined at days $-58 \pm 1,-27 \pm 1,-14 \pm 1,-7 \pm 1,1$, and six relative to calving. Immunoglobulin concentrations (IgG, $\operatorname{IgA}$, and $\operatorname{IgM}$ ) were examined from
\end{abstract}


colostrum samples collected at the first milking postpartum and milk composition was assessed at 6 days in milk. In general, OTM cows had the greatest intake and BCS throughout the study while ITM treated cows had the lowest. A treatment by time effect was observed when DMI was analyzed for the far-off and whole dry periods. CTL cows had higher DMI than OTM and ITM treated cows from -58 to $-55 \mathrm{~d}$ and -51 to $-42 \mathrm{~d}$ relative to calving; respectively. The OTM treated cows had higher intakes than CTL cows during the last $17 \mathrm{~d}$ of the dry period and higher intakes than ITM treated cows from -52 to $-2 \mathrm{~d}$. While on treatment, OTM treated cows tended to have increased milk yield compared to CTL but not ITM cows. This trend was lost when post-treatment milk yield was followed out to 26 days in milk. Milk protein yield and percent increased with trace mineral supplementation from both OTM and ITM sources. Milk solids-not-fat (SNF) yield tended to increase with OTM but not ITM and SNF percent increased with ITM but not OTM supplementation. Colostrum IgG, IgA, and IgM decreased with ITM but returned to CTL levels with OTM supplementation. Trace mineral supplementation had no effect on concentrations of plasma glucose, NEFA, BHBA, thiol, TBARS, milk fat, milk urea nitrogen, or somatic cell score.

\section{INTRODUCTION}

The transition period in dairy cattle, described as the three weeks before and after calving, is characterized by significant metabolic and physiological changes (Drackley, 1999). The high energy demand associated with the onset of lactation is accompanied by

a period of negative energy balance (NEB). Feed intake and lipid mobilization increase to 
compensate for this NEB, resulting in increased plasma non-esterified fatty acids (NEFA) and $\beta$-hydroxybutyric acid (BHBA) concentrations. Additionally, the onset of lactation is associated with an increase in oxygen requirements and the potential for oxidative stress (Gitto et al., 2002). The NEB, increased plasma NEFA and BHBA concentrations, and oxidative stress associated with the transition period have been implicated in the transient immunosuppression observed around calving (Sordillo and Aitken, 2009). This period of diminished immunity is being closely investigated in an attempt to elucidate the causal factors and attempt to limit their effects through nutrition and herd management.

The area of trace mineral supplementation is of particular interest, as maintaining adequate trace mineral nutrition is essential to the health and profitability of dairy cattle. Trace minerals play important roles in many processes including protein synthesis (Spain et al., 2005), vitamin metabolism (Watts, 1990), enzyme formation, antioxidant systems (Chow, 1979), and immune function (Spears, 2000; Spears and Weiss, 2008).

The trace minerals in question are typically associated with immune function and ,not production in dairy cattle. However, replacing inorganic zinc with zinc methionine has been shown to increase teat keratin production and decrease the duration of intramammary infection (IMI) when challenged with E. coli (Jones, 1995). Prevention of IMI by increased physical barrier reduces production loss associated with mastitis and decreases milk somatic cell count (SCC). In addition, cobalt is utilized by rumen microbes to produce vitamin $\mathrm{B}_{12}$, a cofactor in two important enzymes. The first, methylmalonyl-CoA is responsible for converting propionate to succinate during gluconeogenesis and the second is tetrahydrofolate methyl transferase which is responsible for the transfer of methyl groups in the production of methionine (NRC, 
2001). Supplementation of organic cobalt may allow for increased gluconeogenesis and protein synthesis.

The bioavailability of the trace minerals used to supplement dairy cows during the transition period is influenced by chemical form (e.g. inorganic salts or chelated to organic molecules) and the presence of dietary antagonists (Linn et al., 2011). Current research is focused on the effects of replacing inorganic bound minerals with organicallycomplexed trace minerals on production, claw integrity, and reproductive variables (Kellogg et al., 2003; Toni et al., 2007; Sucukuabi-Jones et al., 2008). Organic minerals have the potential to increase bioavailability allowing lower levels of supplementation than their inorganic counterparts. In a meta-analysis of several studies, multiple individual trace mineral-amino acid chelates and Co-glucoheptonate were found to increase milk production, energy corrected milk, and 3.5\% fat corrected milk (Rabiee et al., 2010).

The objective of this study was to evaluate the effects of trace mineral supplementation during the periparturient period on production, metabolism, and oxidative stress responses. As part of this objective, we evaluated the effects of trace mineral supplementation and partial replacement of inorganic trace mineral salts with organically chelated trace minerals on the variables of interest. We hypothesized that cows treated with trace mineral supplementation would have improved production, metabolic and oxidative stress measurements compared to control cows. Further improvements in these variables were expected with partial replacement of inorganic trace minerals with organic trace minerals. 


\section{MATERIALS AND METHODS}

\section{Cows and Diets}

Thirty-nine Holstein cows from the University of Missouri Foremost Dairy Research and Teaching Farm entering into their second or greater lactation were used in this experiment. All animal procedures were approved by the University of Missouri Animal Care and Use Committee. Cows were evaluated weekly by two individuals to determine body condition score (BCS) (Edmonson et al., 1989) from eight weeks before expected calving through one week after calving. Cows were housed in a free stall barn in two pens and individual daily feed intake was measured via Calan doors (American Calan, Northwood, NH). A total of three diets were fed [prepartum far-off (FO), prepartum close-up (CU), and lactating] during the study. All diets were fed as total mixed rations (TMR) balanced to meet or exceed nutrient requirements for cattle as recommended by the National Research Council (2001) and Cornell Net Carbohydrate and Protein System (CNCPS) (Fox et al., 2004). The FO diet was composed of 78.5\% brome hay, $14.3 \%$ premix, and $7.2 \%$ corn silage on a DM basis. The CU diet was composed of $64.1 \%$ brome hay, $22.6 \%$ premix, and $13.3 \%$ corn silage on a DM basis. The lactating diet was composed of $28.6 \%$ corn silage, $21.6 \%$ premix, $13.3 \%$ ground corn, $12.6 \%$ alfalfa haylage, $8 \%$ alfalfa hay, $8 \%$ soy hulls, and $8 \%$ amino plus on a DM basis. Water was added to the prepartum diets to reduce sorting by cows. Samples of the TMR diets were collected daily and composited monthly throughout the study. Samples were dried in ovens at $55^{\circ} \mathrm{C}$ for four days to determine DM content and then ground through a $2 \mathrm{~mm}$ screen in a Thomas-Wiley mill. Chemical analysis of monthly composite 
feed samples was performed by Dairy One Laboratories (Ithaca, NY). The pre- and postcalving diet specifications are found in Table 3.1. Premixes were prepared by the University of Missouri Feed mill in batches of 1,000 lbs. and specifications are shown in Table 3.2.

\section{Treatment Preparation}

A basal trace mineral premix was formulated with ethylene diamine dihydroiodide, sodium selenite, and ferrous sulfate to provide dietary I, Se, and Fe at concentrations of 1.0, 0.30 , and $10 \mathrm{ppm}$, respectively. The CTL treatment consisted of the basal trace mineral premix with no $\mathrm{Zn}, \mathrm{Mn}, \mathrm{Cu}$, and $\mathrm{Co}$ supplementation. The inorganic and organic trace mineral premixes were formulated assuming that the forage and grain based diets contributed no $\mathrm{Zn}, \mathrm{Mn}, \mathrm{Cu}$, or $\mathrm{Co}$. The ITM treatment consisted of the basal trace mineral premix plus feed-grade zinc sulfate, manganese sulfate, copper sulfate, and cobaltous carbonate formulated to contain $75,65,15$, and $2.5 \mathrm{ppm}$ dietary $\mathrm{Zn}, \mathrm{Mn}, \mathrm{Cu}$, and Co; respectively. The OTM treatment consisted of the basal trace mineral premix plus $360 \mathrm{mg} \mathrm{Zn}, 200 \mathrm{mg} \mathrm{Mn,} 125 \mathrm{mg} \mathrm{Cu}$, and $12.6 \mathrm{mg}$ Co (Availa-4 ${ }^{\circledR}$; Zinpro Corporation, Eden Prairie, MN) and 13mg Co glucoheptonate $\left(\mathrm{COPRO}^{\circledR}\right.$ cobalt; Zinpro Corporation, Eden Prairie, MN) per cow per day. Inorganic trace minerals were added to the organic treatment to achieve $75,65,15$, and 2.5 ppm dietary $\mathrm{Zn}, \mathrm{Mn}, \mathrm{Cu}$, and $\mathrm{Co}$; respectively. The amount of organic mineral provided by Availa-4 and COPRO were 14, 15 , and 12 percent of the total mineral treatments for the FO, CU, and lactating periods, respectively. Treatment was issued with ground corn as a carrier daily via a gel-cap bolus. All dietary treatment premixes were formulated and mixed by our lab at the University of Missouri (Columbia, MO). All treatments were analyzed by wet chemistry 
(Dairyland Laboratories, Arcadia, WI) prior to the beginning of the experiment to ensure accuracy of the formulation (Table 3.3).

\section{Experimental Protocol}

Cows were enrolled in the study from dry-off (d $-58 \pm 1)$ until d 8 postpartum. On the day of dry-off, pre-study milk samples were collected to establish somatic cell score (SCS) and cows were treated with Spectramast DC and Orbeseal (Pfizer Animal Health,

New York, NY). There was no difference in pre-treatment SCS among groups $(P=0.92)$. Treatments were administered daily via gelcap bolus beginning $\mathrm{d}-57 \pm 1$ prepartum. Feed intake was recorded daily and daily milk records were collected following calving. A $50 \mathrm{~mL}$ sample of colostrum was collected from the first milking post-calving to establish immunoglobulin concentrations. Liver samples were collected via percutaneous trochar biopsy on $\mathrm{d} 7$ postpartum for determination of liver trace mineral content. Liver trace mineral content was determined by the Diagnostic Center for Population and Animal Health at Michigan State University. All treatment groups had sufficient liver trace mineral concentrations to meet physiological requirements. There was no difference in liver copper, iron, molybdenum, selenium, or zinc among treatment groups. Cows supplemented with trace minerals had higher liver cobalt and manganese concentrations than CTL cows $(P<0.0001$ and $P=0.005$, respectively).

\section{Measurements and Sampling}

Animal Observations. Study personnel monitored cows for health issues and lameness daily upon treatment administration. Observations were recorded and used during analysis to qualify data. All cows completed the trial; however data of four cows 
were removed from analysis due to health issues diagnosed by study personnel and verified by veterinary staff.

Dry Matter Intake. Individual cow feed issue and refusal was recorded daily to establish DMI. Dry cows were fed in a two phase program with FO and CU diets formulated to meet or exceed NRC recommendations (NRC, 2001). Far-off diets were fed from dry-off until $28 \mathrm{~d}$ prior to the expected calving date, at which point $\mathrm{CU}$ diets were fed until parturition. A single lactation diet was fed from calving until eight days in milk (DIM) when cows completed the experimental trial. Dry cow diets were fed once daily and lactating diets were fed twice daily. Feed refusal weights were collected once daily for both dry and lactating diets to determine DMI.

Milk Variables. Milk yield was recorded daily and milk samples were collected during two consecutive milkings on day of dry-off (d $-58 \pm 1)$ and d 6 postpartum to measure milk composition. Milk samples collected at dry-off were analyzed to confirm SCS at dry-off and were similar among treatment groups. Compositional samples were analyzed for milk fat, true protein, solids-not-fat (SNF), milk urea nitrogen (MUN), and SCS (Mid-South Dairy Records, Springfield, MO). Milk composition was analyzed using the weighted average of two samples obtained from consecutive milkings. Milk fat was used to calculate $3.5 \% \mathrm{FCM}$ using the formula $3.5 \% \mathrm{FCM}=(0.432 \times \mathrm{kg}$ milk $)+(16.216$ $\mathrm{x} \mathrm{kg}$ fat). Colostrum samples were obtained during the first milking postpartum to assess IgG, IgA, and IgM concentration. Immunoglobulin concentrations were determined by ELISA using affinity purified bovine IgG (E10-118), IgA (E10-121), and IgM (E10-101) coating antibodies with the corresponding horseradish peroxidase conjugated bovine 
immunoglobulin detection antibody (ELISA starter kits, Bethyl Laboratories, Montgomery, TX).

Plasma Metabolites and Oxidative Stress Variables. Blood was sampled weekly for plasma glucose, NEFA, and BHBA analysis and on $\mathrm{d}-58 \pm 1,-27 \pm 1,-14 \pm 1,-7 \pm 1$, 1, and 6 relative to calving for plasma thiol and TBARS. Briefly, blood was collected via the coccygeal vein into $10 \mathrm{ml}$ Vacutainer tubes containing sodium heparin (BD, Franklin Lakes, NJ). Blood collected for metabolite analyses was centrifuged at $1900 \mathrm{x} g$ for 15 minutes at the University of Missouri dairy farm. Plasma was harvested and stored in triplicate in $1.5 \mathrm{ml}$ micro centrifuge tubes at $-20 \mathrm{C}^{\circ}$. Blood for oxidative stress analysis was centrifuged at $1000 \times \mathrm{g}$ for 10 minutes and the plasma was removed and stored in 1.5 $\mathrm{ml}$ micro centrifuge tubes (triplicate) at $-80 \mathrm{C}^{\mathrm{o}}$.

All metabolites were analyzed by enzymatic colorimetric assays in 96-well microplates (Costar, Corning Inc., Acton, MA) and read using a microplate reader spectrophotometer (BioTek, Winooski, VT). Assay procedures were modified as necessary from available kits to allow for use with 96-well microplates. All procedures were validated in our laboratory. Plasma glucose was determined by glucose oxidase (Sigma-Aldrich, St. Louis, MO), plasma BHBA with the use of D-3-Hydroxybutyrate: NAD oxidoreductase (Roche Applied Science, Indianapolis, IN), and plasma NEFA with NEFA-C reagents (WAKO Chemicals, Dallas, TX). All plasma metabolite assays were conducted upon completion of animal work.

Preparation of samples for the oxidative stress assays was performed on the same day as blood collection to ensure samples were processed with limited degradation. Assay procedures were modified to increase the number of samples analyzed per kit. 
Procedures were validated in our laboratory. Plasma thiol was analyzed using the SensoLyte Thiol Quantitation kit (AnaSpec, Fremont, CA). Plasma TBARS was analyzed using the TBARS assay kit (Cayman Chemical Company, Ann Arbor, MI).

\section{Experimental Design and Statistical Analysis}

This study was conducted as a randomized complete block design. Thirty-nine multiparous Holstein cows were assigned to blocks $(\mathrm{n}=13)$ for balanced mature equivalent 305 day milk yield, body condition score, and previous lactation average somatic cell count. Within blocks, cows were randomly assigned to one of three treatments, control (CTL), inorganic (ITM) or organic (OTM). Cows were screened prior to enrollment into the study for previous lactation SCC of less than $300,000 / \mathrm{ml}$, and a locomotion score of less than two (Sprecher et al., 1997). Due to illness during the study, four cows were removed in the final analysis, giving final treatment numbers of CTM ( $\mathrm{n}$ $=13)$, $\operatorname{ITM}(\mathrm{n}=11)$ and $\operatorname{OTM}(\mathrm{n}=11)$.

Data outliers were detected using PROC REG of SAS (2001) and were identified by the following characteristics: standardized residual $\left(\mathrm{r}_{\mathrm{i}}\right)>2.5$ standard deviations, high leverage $\left(h_{\mathrm{ii}} \geq 2 \mathrm{pn}^{-1}\right.$, where $\mathrm{n}=$ number of observations and $\mathrm{p}=$ number of parameters $)$, and cook's distance $\left(D_{i}\right)>1$ (Kaps and Lamberson, 2004). Outliers were removed from the dataset only if outliers made up at least $5 \%$ of the data set or documented experimental observations justified removal of the data point. Distribution of all variables was determined using PROC GLM procedures in SAS (2001) to determine treatment residuals and PROC UNIVARIATE to determine if the treatment residuals were normally distributed. Data that were not normally distributed were transformed to elicit a normal distribution. Data were then analyzed by analysis of variance (ANOVA) as a 
mixed model using the MIXED procedure in SAS (2001). All variables were analyzed with repeated measures except for colostrum immunoglobulin concentration and milk composition. Covariance structure was determined according to Littell et al. (1998). Dry matter intake was analyzed using compound symmetry and all other variables with repeated measures were analyzed using an auto-regressive covariance structure.

Pretreatment values were used as covariates for BCS and body weight. Separation of least squares means was completed using the PDIFF operation (SAS, 2001) when overall treatment or treatment by time effects were observed. Data are presented as least square means \pm standard error of the mean. Significance was declared at $P \leq 0$. and values of $P>$ 0.05 but $<0.10$ were considered a trend.

\section{RESULTS AND DISCUSSION}

\section{Overall Animal Health}

Of the thirty-nine cows enrolled in the study; four cows exhibited milk fever $(\mathrm{n}=$ $2 \mathrm{CTL}, \mathrm{n}=1 \mathrm{ITM}$, and $\mathrm{n}=1$ OTM), two others retained placental membranes past $24 \mathrm{hrs}$ post calving ( $n=1$ ITM and $n=1$ OTM), and one suffered from hardware disease (OTM). Three cows were removed from study analysis due to health issues (e.g. hardware disease or compounded disorders) and a fourth was removed due to sporadic DMI and possible consumption of non-study diets.

\section{Study Diets}

Analysis of the base diets (Table 3.1) fed during the study period indicates the basal forage-based diets met the dietary trace mineral requirements of 23, 40, 11 to 15 , 
and $0.11 \mathrm{ppm}, \mathrm{Zn}, \mathrm{Mn}, \mathrm{Cu}$, and Co, respectively (NRC, 2001). The basal study diets contained on average $33.2,63.2,10.5$, and 0.18 ppm of dietary $\mathrm{Zn}, \mathrm{Mn}, \mathrm{Cu}$, and $\mathrm{Co}$, respectively. Depending on bioavailability, cows receiving control treatments devoid of supplemental $\mathrm{Zn}, \mathrm{Mn}, \mathrm{Cu}$, and Co may not have been deficient in the trace minerals studied. It was the goal of this study to supplement $\mathrm{Zn}, \mathrm{Mn}, \mathrm{Cu}$, and $\mathrm{Co}$ at a concentration of $75,65,15$, and $2.5 \mathrm{ppm}$, respectively, above the basal diet to examine the effects of inorganic and organic complexed trace minerals on production variables and oxidative stress markers in the periparturient cow. Analysis of mineral premixes was completed prior to study initiation and is shown in Table 3.3. Minerals are expressed in ppm of total expected DMI, as cows received a consistent volume of trace mineral premix via daily gelcap bolus. Bolus administration of treatments removed mineral intake variation on a mass basis due to fluctuations in DMI experienced during the transition period. Mineral analysis of premixes indicated that the desired concentrations of $75,65,15$, and $2.5 \mathrm{ppm}$ dietary $\mathrm{Zn}, \mathrm{Mn}, \mathrm{Cu}$, and $\mathrm{Co}$, respectively, above basal diet were not consistently achieved. Modest variation in mineral concentration among treatment groups was observed. Laboratory records indicate that the premixes were formulated and mixed correctly and that a certain amount of variation is to be expected when creating and sampling small batches $(<10 \mathrm{~kg} / \mathrm{batch})$. Mineral premixes were stirred periodically throughout the study to ensure consistency of mineral concentrations within the premix administered to animals.

\section{Production Variables}

Whole prepartum DMI differed among treatments with cows consuming $14.4 \pm$ $0.56,12.8 \pm 0.59$, and $15.5 \pm 0.60 \mathrm{~kg} / \mathrm{d}$ DMI for CTL, ITM, and OTM, respectively $(P=$ 
0.01; Figures 2.1a and b). No difference in prepartum DMI was observed between CTL and OTM treated cows $(P=0.20)$, however; there was a difference between ITM and OTM $(P=0.004)$ and a trend towards a difference between CTL and ITM $(P=0.06)$ supplemented cows. In addition to treatment differences, a treatment by time effect was observed throughout the prepartum period $(P=0.0002)$. On average, OTM cows consumed $2.6 \mathrm{~kg}$ more DM per daythan ITM cows from -52 to $-2 \mathrm{~d}$ relative to calving. To better understand the treatment by time effects, prepartum DMI was divided and analyzed by diet consumed (FO or $\mathrm{CU}$ ) and the last two weeks before calving. A treatment by time effect was observed during the FO period $(P=0.0006)$. The CTL cows consumed more DM than OTM and ITM treated cows from -58 to $-55 \mathrm{~d}$ and -51 to $-42 \mathrm{~d}$ relative to calving' respectively. Intake differed during the close-up period $(P=0.006)$. The OTM treated cows consumed more DM than CTL cows during the last $17 \mathrm{~d}$ of the dry period. This treatment effect was confirmed when the last two weeks of prepartum DMI were analyzed separately $(P=0.01)$. The DMI tended to be higher in OTM cows compared to CTL and ITM cows following parturition ( $P=0.09$; Figures 3.1a and $b)$.

To our knowledge this is the first study to statistically report effects of Availa- $4^{\circledR}$ trace mineral supplementation on DMI. Ballantine et al. (2002) reported a $1.3 \mathrm{~kg} / \mathrm{d}$ increase in DMI when cows were supplemented with organic trace minerals compared to inorganic; however, cows were fed in pens and individual DMI data were not statistically analyzed (Ballantine et al., 2002). Our results would suggest a $2.6 \mathrm{~kg} / \mathrm{d}$ increase in intake prepartum when cows were supplemented with organic minerals compared to inorganic minerals. An increase in DMI during the dry period is generally considered a positive effect, but diets must be balanced appropriately to ensure that cows do not gain too much 
body condition and increase the risk of dystocia and metabolic disorders in early lactation (Roche et al., 2009). It is interesting to note that cows supplemented with trace minerals above requirement appeared to have a delayed decrease in DMI prior to calving compared to control cows. Control cow DMI began to decline as early as $-12 \mathrm{~d}$ while trace mineral supplemented cows maintained intake until $-7 \mathrm{~d}$ relative to calving. Prolonged maintenance of intake prior to calving may delay the onset of NEB and thus decrease the potential for postpartum metabolic disorders (Grummer, 2006).

There were no treatment or treatment by time interactions observed for BCS $(P=$ 0.22; Figure 3.2a). Average BCS at start of study was 3.5 for all treatment groups. The OTM cows showed the greatest increase in BCS with an average BCS of 3.7 the week prior to parturition. The ITM cows remained relatively consistent throughout prepartum period with a BCS of 3.5. Beginning one week prior to parturition, BCS for all treatments groups began to decline, completing the study one week after parturition with approximately 0.25 of a BCS unit lower than peak BCS. Likewise, body weight was not affected by treatment $(P=0.16$; Figure $3.2 \mathrm{~b})$ and followed a similar pattern to that of BCS with peak weight one week prior to parturition and approximately 60 to $80 \mathrm{~kg}$ decrease in weight from peak to end of study.

Average milk yields during the first week of lactation were $22.9 \pm 1 \mathrm{~kg}, 25.2 \pm 1$ $\mathrm{kg}$, and $26.1 \pm 1 \mathrm{~kg}$ for CTL, ITM, and OTM supplemented cows, respectively and milk yield tended to be affected by treatment $(P=0.07$; Figure 3.3a). Supplementation with OTM increased milk production by $3.2 \pm 1 \mathrm{~kg}$ compared to CTL cows $(P=0.03)$. Milk yield tended to increase with ITM supplementation as ITM cows produced $2.3 \pm 1 \mathrm{~kg}$ more milk than CTL cows $(P=0.10)$. Milk yield was not different between ITM and 
OTM cows $(P=0.54)$. Improved MY in the OTM cows may be a result of increased DMI postpartum. However, ITM cows tended to have improved MY while DMI observed postpartum was less than control cows. When milk yield was followed out to 26 DIM to examine treatment carry-over effects, the treatment trend observed in the first week of lactation was lost $(P=0.65)$. Our study is the first to terminate treatment one week into lactation and therefore makes comparison to other studies examining trace mineral source effects on lactation complicated. Studies by Uchida et al. (2001) and Ferguson et al. (2004) found no increase in milk yield following organic trace minerals supplementation. Conversely, Ballantine et al. (2002) found a $1.2 \mathrm{~kg} / \mathrm{d}$ increase in milk yield and Siciliano-Jones et al. (2008) reported a tendency for increased milk yield when organic trace minerals were supplemented. Discrepancies between the studies are likely due to differences in stage of lactation examined as indicated by reports of increased milk production during peak lactation but not during early or mid-lactation (Kincaid and Socha, 2004) as well as the physiological period and duration of treatment.

Milk composition samples collected six DIM were influenced by treatment, with significant differences observed for protein yield $(P=0.04)$ and SNF percent $(P=0.04)$ and a trend in protein percent $(P=0.06)$ and SNF yield $(P=0.06$; Table 3.4$)$. When differences were observed, OTM increased the milk component variable over CTL but was similar to ITM. Milk fat (yield or percent), MUN, and 3.5\% FCM were not different among treatment groups $(P>0.15)$. Monthly milk composition data were gathered from DHI records for the first six months of lactation to determine carry-over effects of trace mineral supplementation (data not shown). A trend in milk protein percent $(P=0.07)$ was observed with higher protein levels in CTL and OTM cows than ITM supplemented cows 
$(P=0.02$ and $P=0.11)$. No other treatment differences or treatment by time interactions were observed for extended milk composition. Pre-treatment milk samples collected at dry-off showed no difference in SCS among treatment groups prior to the onset of treatment $(P=0.88)$. Additionally, there were no SCS differences detected at six DIM among treatment groups $(P=0.49)$. A meta-analysis of twenty research papers and reports examining 4-Plex ${ }^{\circledR}$ (Zinpro Corporation) and Availa- $4{ }^{\circledR}$ as organic mineral sources found a high degree of heterogeneity in production responses (Rabiee et al., 2010). Supplementation of trace minerals with other additives (e.g. Monensin) and the duration of supplementation influenced production responses (Rabiee et al., 2010). Most consistently, an increase in energy corrected milk, milk protein, and milk solids was observed with no effect on somatic cell count, milk fat, protein or solids percent(Ballantine et al., 2002; Nocek et al., 2006; Siciliano-Jones et al., 2008). More studies need to be conducted with similar parameters to verify the effects of feeding organic trace minerals on milk composition. To our knowledge, this is the first study to terminate treatment eight DIM while examining production variables; therefore it is inappropriate to compare data from this study to that of other studies.

Immunoglobulin concentration of colostrum collected during the first milking was significantly different among treatments for $\operatorname{IgG}, \operatorname{IgA}$, and $\operatorname{IgM}(P=0.01, P=0.005$, and $P=0.007$, respectively; Table 3.4). In all cases, CTL and OTM cows had higher concentrations of immunoglobulin compared to ITM cows $(P=0.10$ and $P<0.08$, respectively). The CTL and OTM cows had similar concentrations of IgG and IgM, however CTL cows tended to have higher IgA $(P=0.11)$ than OTM cows. Golombeski (2010) observed no difference in $\operatorname{IgG}$ and $\operatorname{IgM}$ concentration of colostrum when $\mathrm{Zn}$ 
methionine was used to double daily $\mathrm{Zn}$ supplementation of dairy cows throughout the dry period and Formigoni et al. (2009) reported no differences in total colostrum immunoglobulin concentration when supplementing cows with 50\% organic complexed Zn, Mn, and Cu via KeyShure ${ }^{\circledR}$. Conversely, Formigoni et al., (2011) found a 19\% increase in total immunoglobulin concentration when feeding a mineral mix with $50 \%$ KeyShure ${ }^{\circledR}$ during the dry period and then reducing the organic mineral concentration at calving to $25 \%$ of total mineral supplementation. Therefore, immunoglobulin response to trace mineral supplementation above NRC (2001) requirements appears to have varied effects on colostrum quality. The current study did not double the amount of mineral supplementation or replace ITM with OTM at a rate of 50\%. If we had, we may have observed improvements in the immunoglobulin concentrations of colostrum compared to CTL. Instead, we observed a decline in immunoglobulin concentrations when ITM was supplemented and a return to CTL levels when 12 to $15 \%$ of ITM was replaced with OTM.

\section{Metabolite and Oxidative Stress Variables}

Plasma metabolites were analyzed to help assess metabolic status of cattle during the study. No treatment effects were observed for plasma BHBA $(P=0.40$; Figure 3.4a), plasma glucose $(P=0.99$; Figure $3.4 \mathrm{~b})$ or plasma NEFA concentrations $(P=0.72$; Figure 3.4c). All three treatment groups followed the typical BHBA profile of transition cows with an increase in plasma concentrations one to two weeks prior to calving. Upon calving, plasma BHBA concentrations declined slightly yet remained elevated above levels observed during the dry period. Even at the highest level, approximately $11 \mathrm{mg} / \mathrm{dL}$, plasma BHBA levels were below the threshold indicating sub-clinical ketosis as 
described by McArt et al., (2012). In general, plasma BHBA and NEFA levels increased while plasma glucose levels decreased during the week leading up to calving (from week -1 to calving). Plasma glucose levels continued to decrease during the week following calving while plasma NEFA levels continued to increase in the CTL and OTM but not ITM treated cows. There were no treatments by week interactions for plasma BHBA or glucose metabolites $(P>0.1)$; however, a treatment by time tendency was observed for plasma NEFA concentration $(P=0.11)$. For this interaction, the time points most affected were weeks $-5,-3,0$, and 1 relative to calving. The ITM cows had the highest plasma NEFA levels from -7 through -5 wks relative to calving. By -3 wks from calving, NEFA levels in CTL cows were highest amongst the treatment groups. Elevated levels of plasma NEFA were observed in all three treatment groups at calving with highest to lowest concentrations in CTL, OTM, and ITM, respectively. One week following calving, CTL cows exhibited a decline in NEFA concentrations while OTM remained consistent, and ITM levels appeared to continue to increase.

While trace mineral supplementation did not universally increase DMI, it appears that it may have delayed DMI reduction prior to calving, potentially suspending the onset or severity of NEB associated with calving. Rectal temperature and urine ketone levels were monitored for $14 \mathrm{~d}$ post-calving; according to these variables, all cows remained healthy during this period (data not shown). Furthermore, no study cows developed displaced abomasum or suffered from clinical ketosis during the first two weeks of lactation. Numerically lower plasma BHBA and plasma NEFA concentrations the week of and following calving potentially offer further evidence to support the argument of delayed or reduced NEB. 
Oxidative stress was examined using total plasma thiol as a marker of nonenzymatic protein antioxidants and plasma TBARS as a marker of lipid peroxidation. The current study found no treatment or treatment by time differences in plasma oxidative stress markers thiol $(P=0.96$; Figure $3.4 \mathrm{~d})$ and TBARS $(P=0.28$; Figure $3.4 \mathrm{e})$. Plasma thiol and TBARS levels observed in this study are higher than those observed in previous studies. Bernabucci et al. (2002) observed the effects of heat stress on oxidative stress at calving and observed plasma thiol levels between 500 and $600 \mu \mathrm{mol} / \mathrm{L}$ and plasma TBARS between 1.5 and $2 \mathrm{nmol} / \mathrm{mL}$. A second study examining the effects of BCS on oxidative stress at calving resulted in plasma thiol levels between 400 and $500 \mu \mathrm{mol} / \mathrm{L}$ and plasma TBARS between 1.5 and $2.1 \mathrm{nmol} / \mathrm{mL}$ (Bernabucci et al., 2005). Bernabucci et al. (2005) reported that higher pre-partum BCS resulted in increased plasma thiol levels prior to calving as well as increased plasma TBARS post-calving. The average starting BCS of cows enrolled in the current study was higher for all three treatments than the highest BCS examined in the Bernabucci (2005) study. In addition to increased BCS, the current study occurred between the months of August and December with the majority of cows initiating study in August and September experiencing heat stress during their $60 \mathrm{~d}$ dry period. Higher BCS and possible heat stress exposure may be the cause of the increased oxidative markers in the current study. As we did not record barn temperature and humidity, this theory is purely speculative.

The current study replaced ITM with OTM at 12 to $15 \%$ of the total mineral supplementation rate. It is possible that the reduced rate of OTM supplementation that was utilized in the current study, compared to other studies, was insufficient to affect the production and metabolic variables examined. Cows were supplemented above NRC 
requirements. All treatment groups had sufficient liver trace mineral concentrations to meet physiological requirements, with no difference in liver copper, iron, molybdenum, selenium, or zinc among treatment groups. Bioavailability of trace minerals may have played a role in the inconsistent responses that were observed. The ITM supplementation appeared to reduce a number of variables of interest in the current study when compared to CTL cows. Replacing 12 to $15 \%$ of ITM with OTM allowed for a return to or improvements on CTL levels.

The inorganic mineral premixes were formulated using feed-grade zinc sulfate, manganese sulfate, copper sulfate, and cobaltous carbonate. Absorption coefficients for zinc sulfate, manganese sulfate, and copper sulfate are $0.2,0.012$, and 0.05 , respectively (NRC, 2001). However, these absorption coefficients can be greatly reduced with the presence of dietary antagonists. For example, dietary copper absorption in ruminants is between 1 to $5 \%$ and can be reduced further by dietary sulfur and molybdenum (reviewed by NRC, 2001 and (Spears, 2003)). Therefore, replacing a portion of copper sulfate with copper proteinate via Availa-4 may have improved copper availability to animals in the current study. Inconsistent increases in relative bioavailability when OTM are supplemented in place of ITM have been attributed to physiological stage of animal, dietary antagonists, supplemental source, and rate of supplementation (Ammerman and Miller, 1972; NRC, 2001; Spears, 2003). 


\section{CONCLUSION}

Trace mineral supplementation with either inorganic or organically bound minerals had mixed effects on the production, metabolite, and oxidative stress variables examined. Cows supplemented with inorganic trace minerals consumed less DM and had less body conditioning than control cows, while supplementation with organic trace minerals increased feed consumption and body conditioning. Milk yield tended to increase with trace mineral supplementation during the first week of lactation. Milk protein yield and SNF percent were higher in supplemented cows and a trend towards improved milk protein percent and SNF yield was observed during the first week of lactation. No other milk components or 3.5\% FCM were affected by supplementation during the study and all treatment effects were lost when production and composition were examined for carry-over effect. Colostrum immunoglobulin concentration declined with ITM but increased back to CTL levels when supplemented with OTM. Trace mineral supplementation had no significant effect on plasma metabolites or any of the oxidative stress markers examined. Replacing inorganic minerals with organically complexed trace minerals had limited beneficial effects in this study. The production, metabolic, and oxidative stress variables examined require larger sample sizes to determine true treatment differences. Similar studies containing greater than 100 animals had varied results; the current study contained only 35 animals and therefore had limited power to discern treatment effects. 
Table 3.1. Diet composition ${ }^{1}$ and nutrients supplied ${ }^{2}$ by prepartum and fresh diets (dry matter basis).

\begin{tabular}{llll}
\hline Component $^{3}$ & Far-off & Close-up & Lactating \\
\hline DM, \% & 52.10 & 50.30 & 53.80 \\
CP, \% of DM & 12.8 & 13.65 & 15.65 \\
Soluble protein, \% of CP & 22.17 & 23.83 & 37.5 \\
Metabolizable protein, g/d & 1124 & 1122 & 2009 \\
ADF, \% of DM & 36.98 & 35.05 & 22.08 \\
NDF, \% of DM & 55.27 & 51.2 & 31.58 \\
Lignin, \% of DM & 6.58 & 6.03 & 3.70 \\
NFC, \% of DM & 26.03 & 28.95 & 44.53 \\
Starch, \% of NFC & 5.82 & 10.07 & 29.18 \\
Crude fat, \% of DM & 2.12 & 2.02 & 4.33 \\
NEL, Mcal/kg & 1.28 & 1.32 & 1.68 \\
Metabolizable energy, Mcal/d & 27.24 & 26.92 & 44.31 \\
Ash, \% of DM & 8.93 & 9.01 & $7 . .34$ \\
Ca, \% of DM & 0.64 & 0.83 & 0.91 \\
P, \% of DM & 0.21 & 0.23 & 0.27 \\
Mg, \% of DM & 0.36 & 0.40 & 0.35 \\
K, \% of DM & 1.50 & 1.38 & 1.29 \\
Iron, ppm & 249.5 & 220.33 & 233.75 \\
Zinc, ppm & 31.00 & 32.67 & 36.00 \\
Copper, ppm & 11.00 & 10.83 & 9.75 \\
Manganese, ppm & 81.83 & 72.00 & 35.75 \\
Molybdenum, ppm & 1.38 & 1.33 & 1.55 \\
Cobalt, ppm & 0.15 & 0.18 & 0.20 \\
\hline Composition & & &
\end{tabular}

${ }^{1}$ Composition determined by independent lab analysis (Dairy One, Inc. Ithaca, NY)

${ }^{2}$ Metabolizable protein and energy supplied as predicted by the Cornell Net Carbohydrate and Protein System (Fox et al., 2004).

${ }^{3} \mathrm{DM}=$ dry matter; $\mathrm{CP}=$ crude protein; $\mathrm{ADF}=$ acid detergent fiber; $\mathrm{NDF}=$ neutral detergent fiber; NFC = non-fibrous carbohydrates; NEL = net energy of lactation.

${ }^{4}$ Manganese levels are elevated in the dry cow diets due to brome hay. Analysis of brome hay indicates 92 ppm manganese. Brome hay made up 78.5 and 64 percent of the FO and CU diets contributing 64.24 and 46.08 ppm manganese to the overall diets; respectively. 
Table 3.2. Premix composition as prepared in batches of $1,0001 \mathrm{bs}^{1}$.

\begin{tabular}{llll}
\hline Ingredient & Far-off & Close-up & Lactating \\
\cline { 2 - 4 } Soybean Meal & 730.6 & 546.3 & 510.6 \\
Corn Meal (fine) & 120.5 & 323.9 & 218.4 \\
Blood Meal & 14.1 & 19.0 & 41.2 \\
Calcium Chloride & --- & 35.6 & --- \\
Sodium Bicarbonate & --- & --- & 33.9 \\
Magnesium Sulfate & 57.6 & 34.4 & --- \\
Magnesium Oxide & 14.9 & 9.0 & 10.2 \\
Limestone & 14.9 & --- & 44.0 \\
Potassium Carbonate & --- & --- & 13.5 \\
Salt (white) & 16.2 & 10.7 & 14.7 \\
MU Vit. E 20,000 & 21.318 & 14.322 & 11.291 \\
MU Vit. ADE & 6.609 & 4.440 & 3.387 \\
Premix & & & \\
Smartamine-M & 2.489 & 1.745 & 2.293 \\
Rumensin 90 & 0.692 & 0.435 & 0.461 \\
Energy Booster & --- & --- & 79.4 \\
Dynamate & --- & --- & 16.7 \\
\hline Premix composition expressed in lbs. of ingredient as prepared at the University of \\
Missouri Feed Mill. & & &
\end{tabular}


Table 3.3. Trace mineral concentrations expressed as ppm of total expected DMI. Mineral premixes were formulated to provide $75,65,15$, and $2.5 \mathrm{ppm}$ dietary $\mathrm{Zn}$, $\mathrm{Mn}, \mathrm{Cu}$, and $\mathrm{Co}$; respectively.

\begin{tabular}{|c|c|c|c|c|c|c|}
\hline Mineral & $\frac{\text { Basal }^{1}}{\text { Far-off }^{4}}$ & $\begin{array}{l}\text { Inorganic }^{2} \\
\text { Far-off }\end{array}$ & $\frac{\text { Organic }^{3}}{\text { Far-off }}$ & 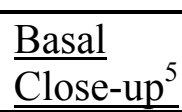 & $\frac{\text { Inorganic }}{\text { Close-up }}$ & $\frac{\text { Organic }}{\text { Close-up }}$ \\
\hline Zinc & --- & $\overline{55}$ & 65 & --- & 58 & 70 \\
\hline Manganese & --- & 54 & 58 & --- & 58 & 68 \\
\hline Copper & --- & 13 & 14 & --- & 13 & 16 \\
\hline Cobalt & --- & 2.1 & 2.5 & --- & 2.0 & 1.9 \\
\hline
\end{tabular}

${ }^{1}$ Basal mineral premix contained $\mathrm{Fe}$, Se, and I but no added $\mathrm{Zn}, \mathrm{Mn}, \mathrm{Cu}$, and $\mathrm{Co}$. Basal premix was added to both the organic and inorganic mineral premixes.

${ }^{2}$ Inorganic mineral premixes were formulated using feed-grade zinc sulfate, manganese sulfate, copper sulfate, and cobaltous carbonate.

${ }^{3}$ Organic mineral premixes were formulated using $360 \mathrm{mg} \mathrm{Zn,} 200 \mathrm{mg} \mathrm{Mn}, 125 \mathrm{mg} \mathrm{Cu}$, and $12.6 \mathrm{mg}$ Co from Availa- ${ }^{\circledR}$ (14g; Zinpro Corporation, Eden Prairie, MN) and $13 \mathrm{mg}$ Co from COPRO $^{\circledR}$ cobalt glucoheptonate per cow per day. Inorganic trace minerals were added to the organic treatment to achieve 75, 65, 15, and $2.5 \mathrm{ppm}$ dietary $\mathrm{Zn}, \mathrm{Mn}, \mathrm{Cu}$, and Co; respectively.

${ }^{4}$ FO diets were fed from dry-off until $-28 \mathrm{~d}$ from expected calving date.

${ }^{5} \mathrm{CU}$ diets were fed from $-28 \mathrm{~d}$ prior to the expected calving until the day of calving. 
Table 3.4. Milk composition ${ }^{1}$ and colostrum immunoglobulin ${ }^{2}$ concentrations reported as least square means and standard errors.

\begin{tabular}{|c|c|c|c|c|c|c|c|}
\hline Milk Component & Contro & & Inorga & & Organ & & \\
\hline & Mean & $\underline{\mathrm{SE}}$ & Mean & $\underline{\mathrm{SE}}$ & Mean & $\underline{\mathrm{SE}}$ & p-value ${ }^{3}$ \\
\hline Fat, $\mathrm{kg} / \mathrm{d}$ & 2.5 & $\overline{0.4}$ & 2.1 & $\overline{0.4}$ & $\overline{1.9}$ & $\overline{0.4}$ & 0.47 \\
\hline Fat, $\%$ & 8.1 & 1.0 & 6.3 & 1.0 & 6.6 & 1.0 & 0.27 \\
\hline Protein, kg/d & 1.0 & 0.1 & 1.2 & 0.1 & 1.3 & 0.1 & 0.04 \\
\hline Protein, \% & 3.3 & 0.2 & 3.7 & 0.2 & 3.8 & 0.2 & 0.06 \\
\hline $\mathrm{SNF}, \mathrm{kg} / \mathrm{d}$ & 2.7 & 0.1 & 3.0 & 0.2 & 3.2 & 0.1 & 0.06 \\
\hline SNF, $\%$ & 8.4 & 0.2 & 9.3 & 0.3 & 9.0 & 0.3 & 0.04 \\
\hline MUN, \% & 10.0 & 1.0 & 11.7 & 1.2 & 9.7 & 1.1 & 0.52 \\
\hline $3.5 \%$ FCM, kg/d & 51.0 & 4.7 & 38.0 & 5.2 & 47.8 & 5.2 & 0.18 \\
\hline Dry-off SCS & 3.6 & 0.4 & 3.8 & 0.4 & 3.8 & 0.4 & 0.88 \\
\hline Study SCS & 4.0 & 0.6 & 3.9 & 0.6 & 4.8 & 0.6 & 0.49 \\
\hline \multicolumn{8}{|l|}{$\underline{\text { Colostrum }}$} \\
\hline $\mathrm{IgG}, \mathrm{mg} / \mathrm{mL}$ & 61 & 10 & 37 & 10 & 64 & 10 & 0.01 \\
\hline $\mathrm{IgA}, \mathrm{mg} / \mathrm{mL}$ & 1.5 & 0.5 & 0.7 & 0.2 & 1.1 & 0.2 & 0.005 \\
\hline $\mathrm{IgM}, \mathrm{mg} / \mathrm{mL}$ & 6.1 & 0.7 & 3.3 & 0.7 & 5.2 & 0.7 & 0.007 \\
\hline
\end{tabular}

\footnotetext{
${ }^{1}$ Milk samples were collected at two consecutive milkings within a $24 \mathrm{hr}$ period. Compositional analysis was conducted by an independent laboratory (Mid-South Dairy Records, Springfield, MO). SNF = solids-not-fat; $\mathrm{MUN}=$ milk urea nitrogen; FCM = fatcorrected milk; SCS = somatic cell score; SCC = somatic cell count.

${ }^{2}$ Colostrum was collected at first milking. Immunoglobulin concentrations were analyzed via ELISA kits purchased from Bethyl Laboratories.

${ }^{3}$ Data for milk fat percent, protein percent, $\operatorname{IgG}$, and $\operatorname{IgM}$ were transformed for ANOVA; untransformed LSMEANS are shown.
} 


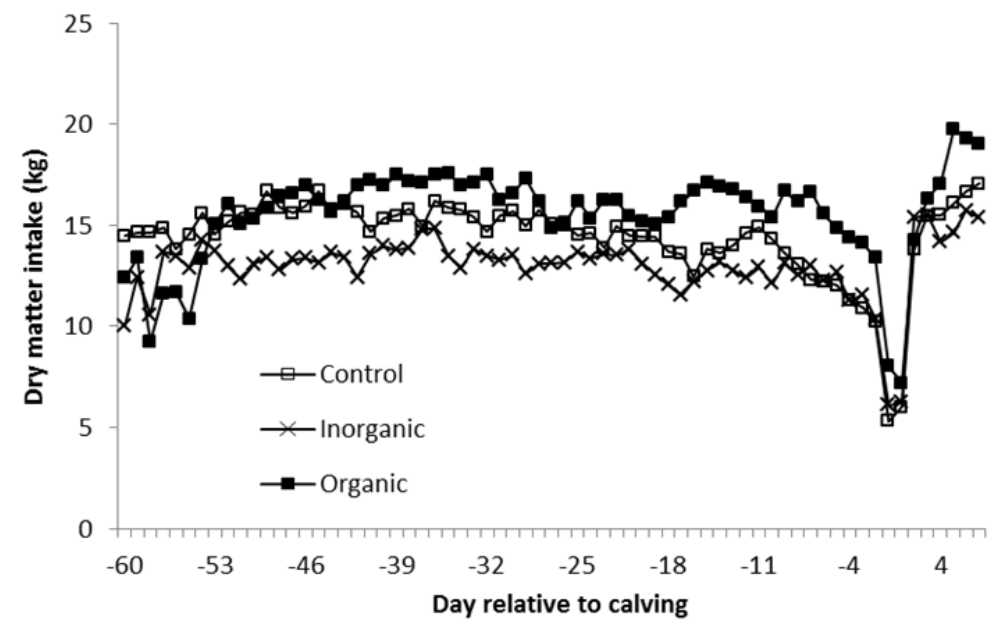

A.

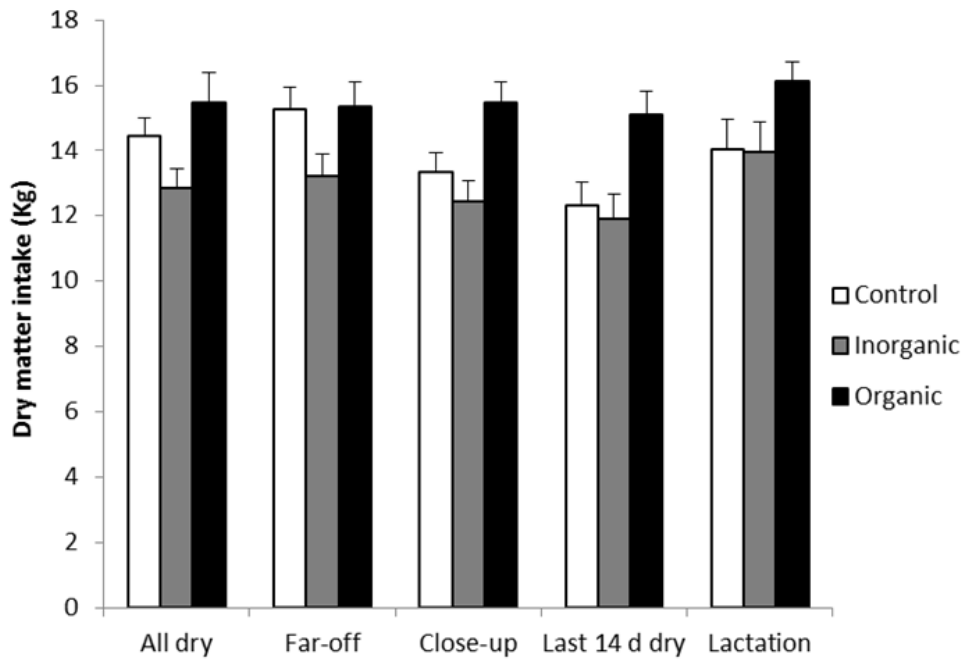

B. 
Figure 3.1. Daily dry matter intake (DMI) of cows fed individually via Calan door systems and DMI by diet and period. Daily DMI (A) of cows fed once daily during the dry period and twice daily during the lactation period. Feed refusals were weighed daily to assess daily feed intake and as a variable to monitor cows for potential health issues. Average DMI by diet and period (B). Cows were fed three separate diets (FO, CU, and lactation) throughout the study. Intakes were analyzed by diet, physiological stage (dry or lactating), and the last two weeks of the dry period. Treatment affected DMI for all periods examined $(P \leq 0.1)$. For all periods examined, organic trace mineral treated cows tended to consume more feed than cows receiving inorganic trace minerals $(P<0.06)$. Organic treated cows had similar DMI to control cows throughout the study $(P=0.14)$ with exception of the $\mathrm{CU}$, last two weeks of dry period, and lactation period $(P=0.02$, $P=0.01$, and $P=0.06$, respectively) at which point DMI was lower in control cows. Control cows had higher DMI compared to inorganically treated cows during the FO period $(P=0.05)$ but not the $\mathrm{CU}$, last two weeks of the dry period, or lactation period $(P=0.29, P=0.69$, and $P=0.93$, respectively). Treatment by time interactions were observed when DMI was examined for the entire study $(P$ $=0.0008)$. Treatment by time interactions were determined using the difference of least square means and considered significant with $P<0.1$. Control cows consumed more DMI than inorganic treated cows from -51 to $-42 \mathrm{~d}$ and organic treated cows from -58 to $-55 \mathrm{~d}$ relative to calving. Cows receiving organic trace minerals consumed more DMI from -17 to $-13 \mathrm{~d}$ and -9 to- 1 than control cows and inorganic treated cows from -52 to $-2 \mathrm{~d}$ relative to calving. 


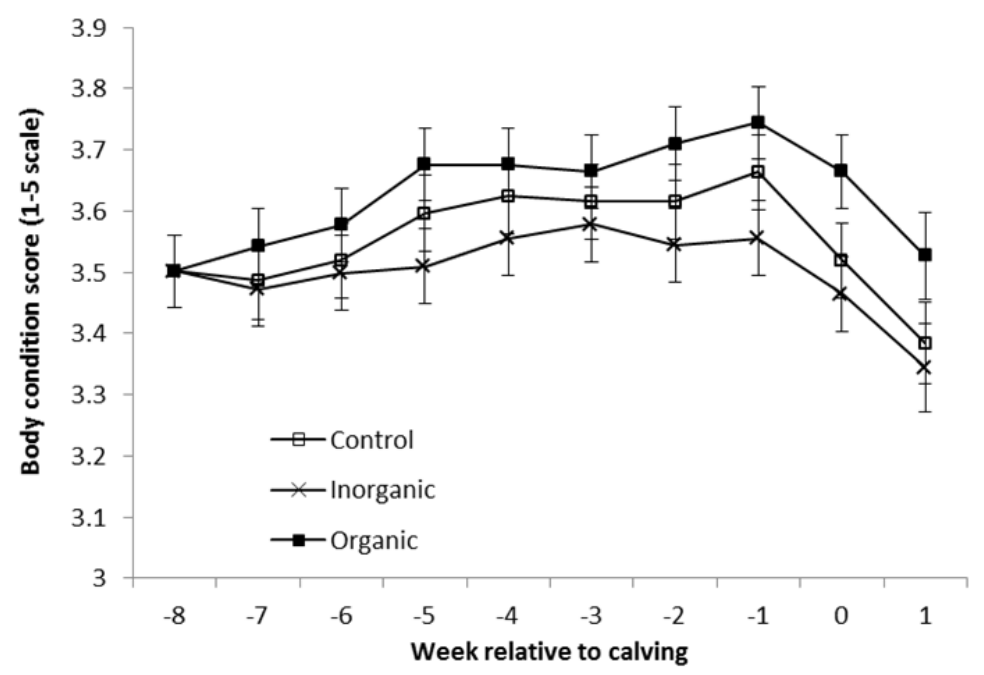

A.

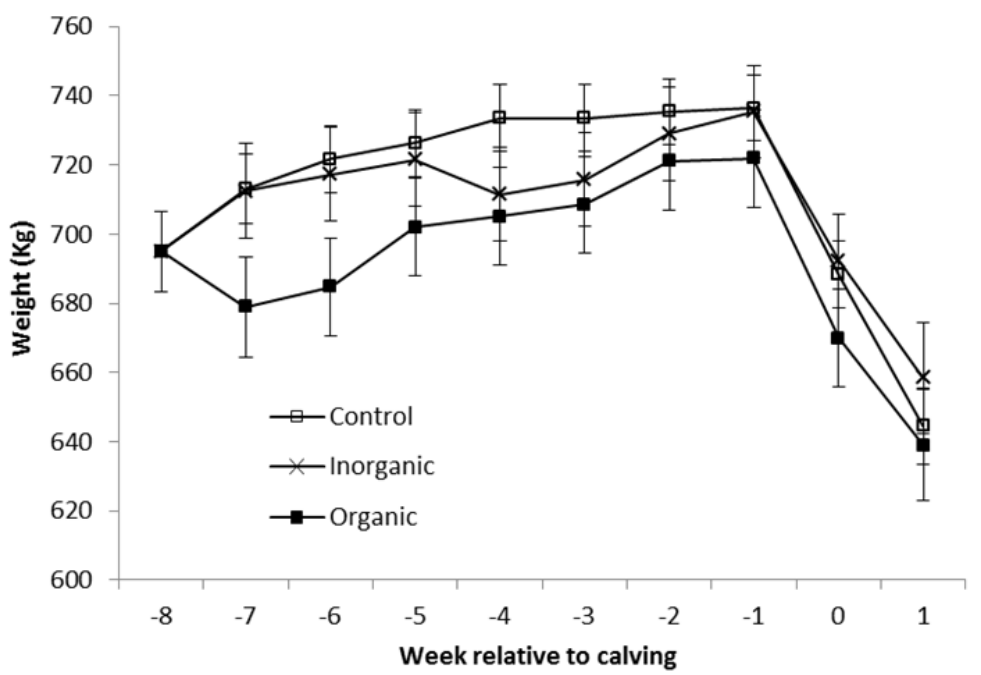

B.

Figure 3.2 Weekly body condition score (BCS) and body weight. A. Body condition score and weights (B) were determined weekly. BCS were assessed by two independent evaluators using 0.25 increments and a scale of 1 to 5 . BCS and weight were adjusted using pretreatment values as covariate. Adjusted LSMEANS are shown. 


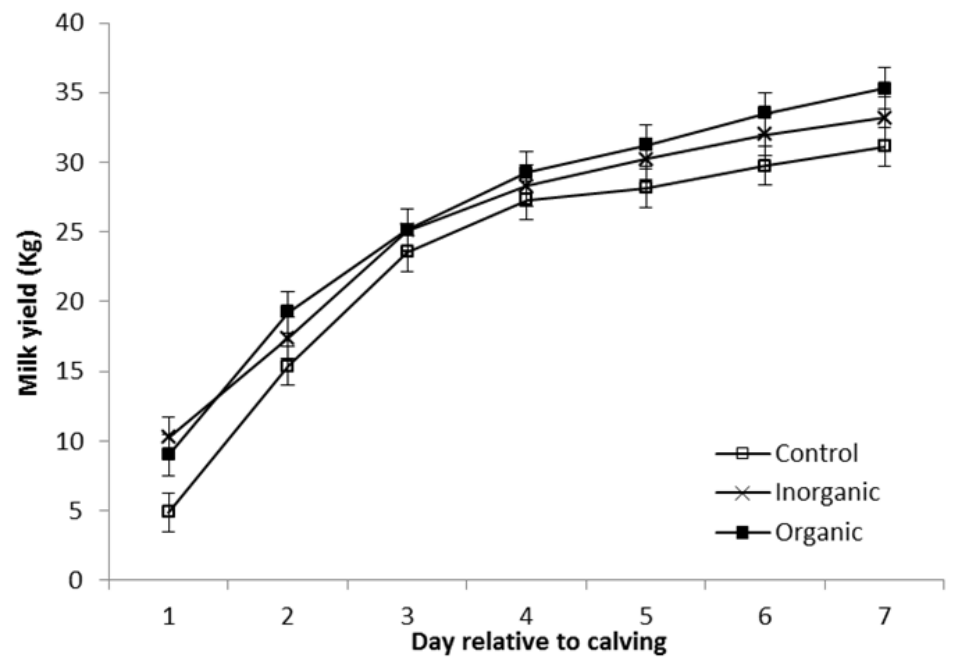

A.

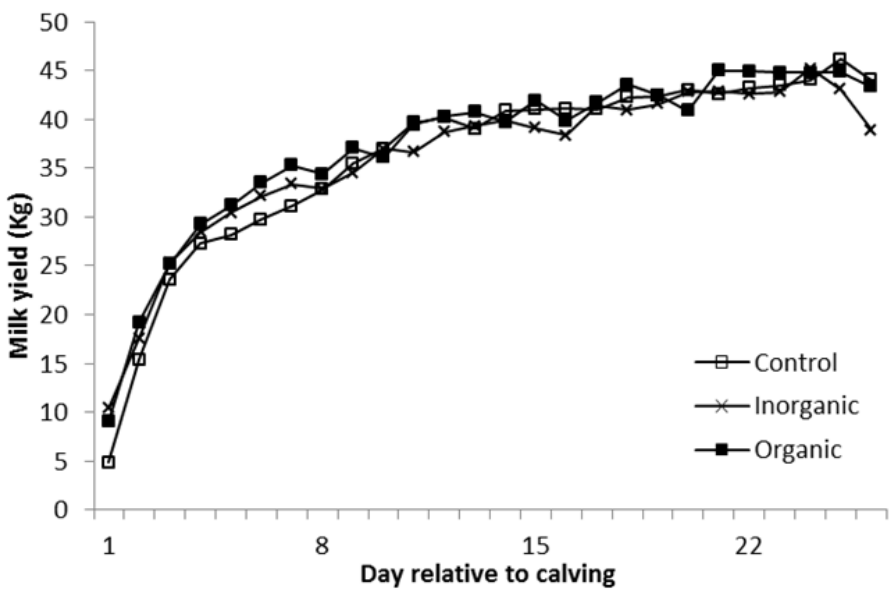

Figure 3.3 Daily milk yield and extended milk yield. A. Milk yield was recorded at each milking and combined for daily production yields. Cows were milked twice daily on a 12 hour cycle. Mean production for the first week of lactation was $22.88 \pm$ $1.0,25.21 \pm 1.1$, and $26.10 \pm 1.1 \mathrm{~kg}$ of milk for CTL, ITM, and OTM $(P=0.07)$. Supplementation with organic trace minerals increased milk production $3.2 \mathrm{~kg}$ compared to control treatment $(P=0.03)$. B. Daily milk yield was followed out to 26 DIM. Extended milk records were examined for potential treatment carry-over effects. The treatment trend observed in the first week of lactation was lost when milk yield was followed for first four weeks of lactation. Post-treatment milk weights were obtained from DHI herd records. 

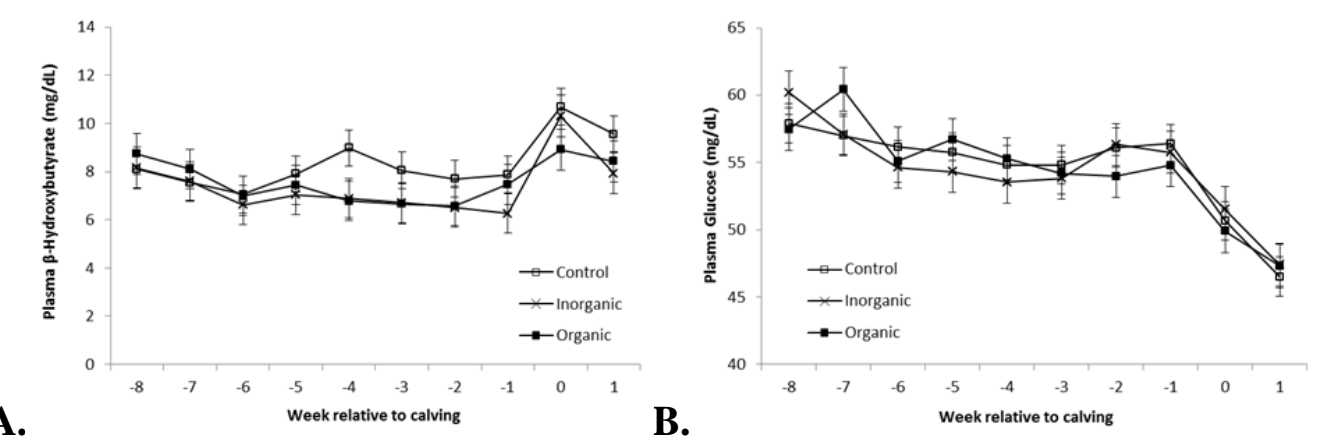

A.

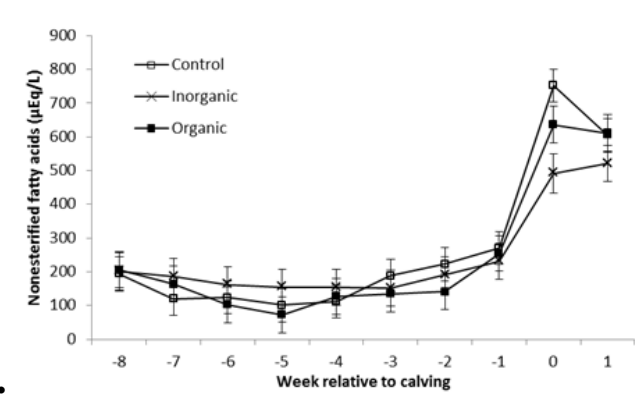

D.

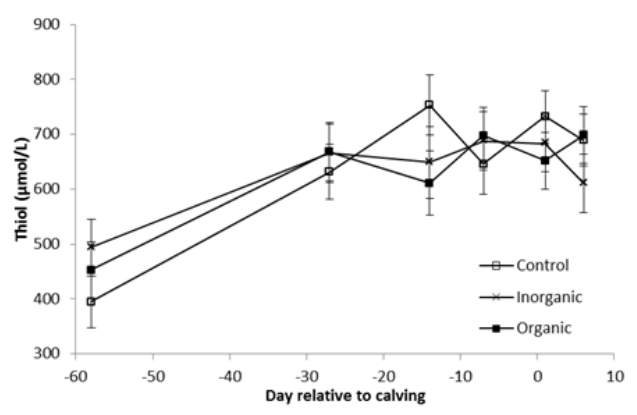

E.

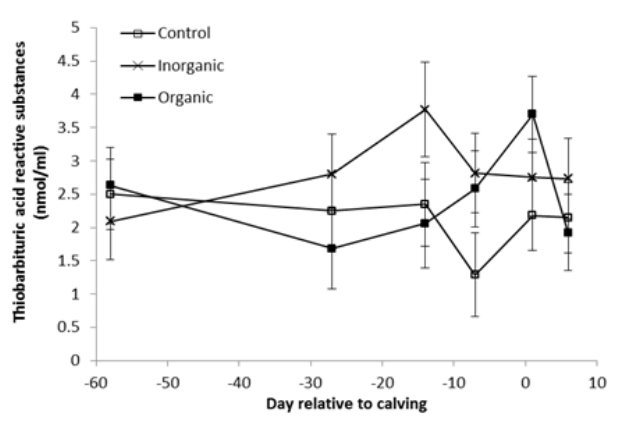

Figure 3.4. Plasma metabolite concentrations of $\beta$-Hdroxybutyrate (BHBA), glucose, non-esterified fatty acids (NEFA) and plasma oxidative stress marker concentrations of thiol and Thiobarbituric acid reactive substances (TBARS). Plasma concentrations of BHBA (A), glucose (B), NEFA (C), thiol (D) and TBARS (E). Blood samples were collected at morning feeding to maintain consistency. Metabolite samples were collected weekly and oxidative stress samples were collected on $\mathrm{d}-58 \pm 1,-27 \pm 1,-14 \pm 1,-7 \pm 1,1$, and +6 relative to calving. Treatment by time interactions trends were observed for NEFA and TBARS $(P=0.11$ and $P=0.14$, respectively). NEFA and TBARS data were $\log$ transformed for ANOVA; untransformed LSMEANS are shown. 


\title{
Chapter 4
}

\section{DOSE EFFECT OF YEAST CULTURE SUPPLEMENTATION ON PRODUCTION VARIABLES AND METABOLIC HEALTH OF PERIPARTURIENT HOLSTEIN DAIRY CATTLE}

\begin{abstract}
The objective of this study was to investigate the effects of a commercial yeast culture supplement on production and metabolic health variables in periparturient dairy cows. One-hundred and fifty-eight Holstein dairy cows were randomly assigned to one of four treatments. Control (CTL, $n=39)$ without yeast culture, yeast culture supplemented at a rate of $56 \mathrm{~g} / \mathrm{d}(1 \mathrm{X}, \mathrm{n}=40)$ or $112 \mathrm{~g} / \mathrm{d}(2 \mathrm{X}, \mathrm{n}=37$; Diamond V XP), or a new yeast product at the rate of $14 \mathrm{~g} / \mathrm{d}(\mathrm{LAC}, \mathrm{n}=42)$. All groups received the same basal diet. Treatment was mixed into the total mixed ration diet daily from approximately -28 days prepartum through 86 days postpartum. Variables of interest included daily dry matter intake (DMI) and milk yield as well as weekly body condition score, body weight, and milk composition. Plasma glucose, non-esterified fatty acids, and $\beta$-hydroxybutyrate concentrations were measured at days $-28 \pm 1,-7 \pm 1,1 \pm 1,7 \pm 1,21 \pm 1,42 \pm 1$, and 84 \pm 1 relative to calving. Immunoglobulin concentrations (IgG, $\operatorname{IgA}$, and $\operatorname{IgM})$ were measured in colostrum samples collected at the first milking post-calving. Milk fat and protein yield were increased with $1 \mathrm{X}$ but not $2 \mathrm{X}$. The $2 \mathrm{X}$ supplementation decreased colostrum $\mathrm{IgG}$ and $\operatorname{IgM}$ concentrations and both $1 \mathrm{X}$ and $2 \mathrm{X}$ yeast culture supplementation decreased the net energy balance of cattle on study when compared to
\end{abstract}


control cows. Dry matter intake decreased linearly across XP treatments, whereas energycorrected milk efficiency (ECM efficiency), somatic cell score, milk fat, protein, and solids-not-fat yield increased with $1 \mathrm{X}$ but not $2 \mathrm{X}$ supplementation. LAC treatment was also examined and results were similar to the control treatment in nearly all variables of interest. Increased milk fat and protein yield as well as ECM efficiency results led to the conclusion that supplementation of Diamond V XP yeast culture at the suggested rate of $56 \mathrm{~g} / \mathrm{d}$ but not $112 \mathrm{~g} / \mathrm{d}$ would be beneficial to producers, however it did not improve the periparturient metabolic health markers that were examined in the current study.

\section{INTRODUCTION}

The transition from late pregnancy to early lactation poses great metabolic demand on dairy cows. Intake begins to decrease as early as two weeks prior to calving; initiating the negative energy balance (NEB) observed throughout early lactation. Prolonged negative energy balance results in mobilization of body reserves leading to an increase in nonesterified fatty acids and $\beta$-hydroxybutyrate production and an increased risk of health and reproductive problems, potentiating a financial loss to producers (de Vries and Veerkamp, 2000).

Direct fed microbial feed additives are live or viable naturally occurring organisms supplemented to cattle to enhance production performance, alter rumen fermentation, or improve nutrient utilization (NRC, 2001). The most commonly studied is the yeast strain Saccharomyces cerevisiae, which has been supplemented to cattle as live yeast and yeast culture (dead yeast). The mode of action of yeast cultures has yet to be 
determined and is more than likely different among strains and yeast culture preparations. A review of yeast culture studies by Wallace (1994) proposed a mode of action involving removal of oxygen from the rumen by live Saccharomyces cerevisiae leading to increased anaerobic bacterial viability (Wallace, 1994). Increased bacterial viability in turn would allow for greater microbial population turnover, cellulose digestion, and microbial protein production potentiating a greater influx of post-ruminal substrates essential for hepatic glucose production (e.g. propionate and microbial protein). However, that mode of action would not be reasonable with dried yeast cultures, such as that employed in the current study, because they contain a fraction of the number of viable yeast cells and would be limited in oxygen scavenging abilities. Dried yeast cultures are produced by fermenting feedstuffs with live yeast. Following the fermentation process, heat is applied to the product resulting in minimal live yeast cells; therefore the mode of action is likely through yeast fermentation products and not live yeast cells. It has been hypothesized that yeast cultures provide factors stimulatory to proteolytic bacteria (Wiedmeier et al., 1987) and or growth factors (e.g. B-vitamins and amino acids) that stimulate growth of ruminal bacteria that utilize lactate and digest cellulose (Callaway and Martin, 1997).

Periparturient supplementation of yeast cultures has been employed to aid in this period of metabolic demand but results are inconsistent. In some studies, yeast culture supplementation improved dry matter intake (DMI) (Putnam et al., 1997; Dann et al., 1997; Erasmus et al., 2005; Ramsing et al., 2009), milk yield (MY) (Erasmus et al., 1992; Putnam et al., 1997; Shaver and Garrett, 1997; Ramsing et al., 2009), milk composition (Hippen et al., 2007; Lehloenya et al., 2008), and efficiency (Schingoethe et al., 2004) 
whereas others reported no response to yeast culture (Arambel and Kent, 1990; Robinson, 1997; Robinson and Garrett, 1999). Inconsistencies in response are likely due to the age of animal, stage of lactation, amount and strain of yeast culture administered, diet, and length of treatment.

Lehloenya et al. (2007) reported that yeast culture supplementation increased 4\% fat-corrected milk (FCM) of multiparous but not primiparous cows during mid but not early lactation. Ramsing et al. (2009) supplemented up to four times the amount of the $\mathrm{XP}$ yeast culture that was employed in the current study and found similar responses between primiparous and multiparous cows. Chung et al. (2011) examined the effects of two active dried yeast strains on ruminal acidosis and methane production and reported that yeast varied in their ability to modify rumen fermentation patterns. Sullivan and Martin (1999) reported that yeast culture improved In Vitro rumen fermentation when diets were higher in fibrous material compared to diets high in concentrate, thus concluding that diet should be considered when trying to optimize rumen fermentation. Robinson (1997) supplemented yeast culture from two weeks prior to expected calving until two weeks after calving and reported no effect of treatment; however other studies which began treatment approximately 28 days prior to calving and continued well into lactation observed improvements in production variables (Robinson and Garrett, 1999; Dann et al., 2000; Erasmus et al., 2005).

Without a clear mode of action, it is difficult to determine the best route of administration, duration and amount of supplementation, as well as the stage of lactation that would most benefit from yeast culture supplementation. Therefore, the objective of the current study was multifaceted. 1) Examine the effects of supplementing Diamond V 
$\mathrm{XP}$ in a dose dependent manner and 2) Compare the effects of a new generation yeast culture "LAC" to that of XP yeast on production variables and metabolic health of periparturient dairy cattle.

\section{MATERIALS AND METHODS}

\section{Cows}

Two-hundred and four Holstein cows from the University of Missouri Foremost Dairy Research and Teaching Farm entering into their first or greater lactation were enrolled in this experiment between December 2009 and September 2012 (primiparous; $\mathrm{n}$ $=28$ and multiparous; $\mathrm{n}=176$ ). All animal procedures were approved by the University of Missouri Animal Care and Use Committee. Cows were evaluated weekly by two individuals to determine BCS (Edmondson et al., 1989) from four weeks before expected calving through 12 weeks after calving. Cows were housed in a free stall barn in two pens (32 cows per pen) and individual daily feed intake was measured via Calan doors (American Calan, Northwood, NH). A subset of one hundred cows (second lactation or greater) were enrolled for intensive blood sampling and colostrum analysis. Blood samples collected via tail vein began $1 \mathrm{~d}$ prior to initiation of treatment (pre-treatment for covariate adjustment) and continued 3 times per week through the first three weeks of lactation. Blood was sampled twice weekly starting week four of lactation throughout the completion of study on d 86 postpartum. A colostrum sample was collected during the first milking following parturition. 


\section{Diets}

A total of three diets were fed during the study; one prepartum diet (DRY) and two lactating diets. A transition diet containing a moderate level of energy and concentrates was fed the first two weeks of lactation (FRESH) followed by a higher energy higher concentrate diet for the remainder of the study (PEAK). All diets were fed as total mixed rations (TMR) balanced to meet or exceed nutrient requirements for cattle as recommended by the National Research Council (2001) and Cornell Net Carbohydrate and Protein System (CNCPS; Fox et al., 2004). The DRY diet was composed of 43.4\% brome hay, $24.1 \%$ corn silage, $24.0 \%$ premix, and $8.6 \%$ soybean hulls on a DM basis. The FRESH diet was composed of $29.7 \%$ corn silage, $19.8 \%$ premix, $15.0 \%$ ground corn, $14.1 \%$ alfalfa haylage, $8.4 \%$ alfalfa hay, $6.9 \%$ soyplus, and $6.1 \%$ soybean hulls on a DM basis. The PEAK diet was composed of $31.6 \%$ corn silage, $20.0 \%$ ground corn, $18.5 \%$ premix, $12.1 \%$ alfalfa haylage, $6.1 \%$ alfalfa hay, $4.7 \%$ soybean hulls, $4.3 \%$ amino plus, and $3.6 \%$ brewer's grain on a DM basis. Samples of the TMR diets were collected weekly and composited monthly throughout the study. At the end of the study monthly samples were composited into quarterly samples for chemical analysis. Samples were dried in ovens at $55^{\circ} \mathrm{C}$ for four days to determine DM content and then ground through a $2 \mathrm{~mm}$ screen in a Thomas-Wiley mill. Chemical analysis of quarterly composite feed samples was performed by Dairy One Laboratories (Ithaca, NY). The diet specifications are found in Table 4.1. Premixes were prepared by the University of Missouri Feed mill in batches of 1000 lbs. and specifications are shown in Table 4.2. Premixes were formulated and fed to achieve three levels of Diamond V XP supplementation and a new 
product (LAC). Treatment levels consisted of a control (0 g/d), 1X (56 g/d) and 2X (112 g/d) Diamond V XP and LAC (14 g/d).

\section{Experimental Protocol}

Cows were enrolled on the study four weeks prior to expected calving (d -28 \pm 0.5 ) and remained on study until $86 \mathrm{~d}$ after calving. Treatments were mixed into the TMR diet. Feed intake was recorded daily and daily milk records were collected following calving. A $50 \mathrm{~mL}$ sample of colostrum was collected from the first milking post-calving to establish immunoglobulin concentrations. Cows enrolled in the intensive blood sampling portion of the study were removed from the freestall barn three times each week during morning feeding for blood sampling.

\section{Measurements and Sampling}

Animal Observations. Study and farm personnel monitored cows for health issues and lameness daily upon milking, feeding, and blood sampling. Observations were recorded and used during analysis to qualify data. Sixteen of the two-hundred and four cows enrolled on study did not complete the study do to major health issues or death. Upon completion of the three year study, data from the remaining one-hundred and eighty-eight cows were evaluated. Cows with multiple health issues leading to poor data were culled from the data set leaving one-hundred and fifty-eight cows in the final data set ( $\mathrm{n}=39,40,37$, and 42 for CONT, 1X, 2X, and LAC treatments, respectively), Health issues leading to culled data included but were not limited to mastitis, Johnes, displaced abomasum, and lameness due to a fall. All health issues were diagnosed by study personnel and verified by veterinary staff. 
Dry Matter Intake. All study diets were formulated to meet or exceed NRC recommendations (NRC, 2001). Individual cow feed issue and refusal was recorded daily to establish DMI. A two phase postpartum diet was employed to aid in rumen microbial adaptation to the high concentrate diet. A moderate energy FRESH diet was fed the first two weeks of lactation followed by a higher energy diet that was then provided $15 \mathrm{~d}$ after calving until completion of study (d 86). Dry cow diets were fed once daily and lactation diets were fed twice daily. Feed refusal weights were collected once daily for both dry and lactation diets to determine daily DMI.

Milk Variables. Milk yield was recorded daily and milk samples were collected during two consecutive milkings weekly to determine composition. Compositional samples were analyzed by an independent laboratory for milk fat, true protein, SNF, MUN, and SCS (Mid-South Dairy Records, Springfield, MO). Milk composition was statistically analyzed using the weighted average of two samples obtained from consecutive milkings. Milk fat percent was used to calculate 3.5\% FCM using the formula $3.5 \% \mathrm{FCM}=(0.432 \times \mathrm{kg}$ milk $)+(16.216 \times \mathrm{kg}$ fat $)$. Milk fat and milk protein percent were used to calculate Energy-Corrected Milk (ECM) using the formula ECM = $(12.82 \times \mathrm{kg}$ fat $)+(7.13 \times \mathrm{kg}$ protein $)+(0.323 \times \mathrm{kg}$ of milk $)$. Samples were obtained during the first milking to assess IgG, IgA, and IgM concentration. Immunoglobulin concentrations were determined by ELISA using affinity purified bovine IgG (E10-118), IgA (E10-121), and IgM (E10-101) coating antibodies with the corresponding horseradish peroxidase conjugated bovine immunoglobulin detection antibody (ELISA starter kits, Bethyl Laboratories, Montgomery, TX). 
Plasma Metabolites. Samples were obtained to determine plasma glucose, NEFA, and BHBA on $\mathrm{d}-28,-7,1,7,21,42$, and $84 \pm 0.3$ (standard error same for all time points). Briefly, blood was collected via the coccygeal vein into $10 \mathrm{ml}$ Vacutainer tubes containing sodium heparin (BD, Franklin Lakes, NJ). Blood for metabolite analysis was centrifuged at $1900 \mathrm{x} g$ for 15 minutes at $4^{\circ} \mathrm{C}$ at the University of Missouri dairy farm. Plasma was harvested and stored in $1.5 \mathrm{ml}$ micro centrifuge tubes (triplicates) at $-20 \mathrm{C}^{\circ}$.

All metabolites were analyzed by enzymatic colorimetric assays in 96-well microplates (Costar, Corning Inc., Acton, MA) and read using a microplate reader spectrophotometer (BioTek, Winooski, VT). Assay procedures were modified from available kits to allow for use with 96-well microplates. All procedures were validated in our laboratory. Plasma glucose was determined by glucose oxidase (Sigma-Aldrich, St. Louis, MO), plasma BHBA with the use of D-3-Hydroxybutyrate: NAD oxidoreductase (Roche Applied Science, Indianapolis, IN), and plasma NEFA with NEFA-C reagents (WAKO Chemicals, Dallas, TX). Plasma metabolite assays were conducted in one batch upon completion of animal work.

\section{Experimental Design and Statistical Analysis}

This study was conducted as a randomized complete block design. Two-hundred and four Holstein cows were assigned to blocks $(\mathrm{n}=51)$ for balanced mature equivalent 305 day milk yield, body condition score, and previous lactation average somatic cell count. Within blocks, cows were randomly assigned to one of four treatments- control (CTL), $56 \mathrm{~g} / \mathrm{d}$ XP yeast culture (1X), $112 \mathrm{~g} / \mathrm{d}$ XP yeast culture (2X), or $14 \mathrm{~g} / \mathrm{d}$ of a new product (LAC). Cows were screened prior to enrollment into the study for previous 
lactation SCC of less than $300,000 / \mathrm{ml}$, and a locomotion score of less than two (Sprecher et al., 1997).

Data outliers were detected using PROC REG of SAS (2001). Outliers were identified from the data set if they presented at least two of the following characteristics: standardized residual $\left(\mathrm{r}_{\mathrm{i}}\right)>2.5$ standard deviations, high leverage $\left(\mathrm{h}_{\mathrm{ii}} \geq 2 \mathrm{pn}^{-1}\right.$, where $\mathrm{n}=$ number of observations and $p=$ number of parameters), and Cook's distance $\left(D_{i}\right)>1$ (Kaps and Lamberson, 2004). Identified of outliers were removed if outliers made up at least $5 \%$ of the data set or if documented experimental observations justified removal of data. Equal variance and normality of the data for each variable was determined using the PROC GLM procedure in SAS (2001) to assess residuals and PROC UNIVARIATE to normality. Data that did not follow a normal distribution were transformed to elicit a normal distribution. Data were then analyzed by analysis of variance (ANOVA) as a mixed model using the MIXED procedure (SAS 9.3, Cary, NC). All variables were analyzed with repeated measures except for colostrum immunoglobulins. Body condition score means were adjusted by analysis of covariance using data collected prior to treatment initiation. All other analysis of variance was conducted without covariate adjustment. Cow was the experimental unit and classification variables were cow, block, treatment, and time of sampling (day or week). The model statement included treatment, time, and the interaction of treatment and time. The random statement included block and the interaction of block and treatment. The repeated measures statement included the effect of block by treatment interaction within time. Covariance structure was determined to be either compound symmetry or autoregressive type one by using the analysis with the lowest AICC value (Littell et al., 1998). Linear and quadratic effects of yeast culture 
dosage for each variable were tested using orthogonal contrasts. Least squared means are reported \pm standard error of the mean. Significance was declared at $P<0.05$, trends from $P>0.05$ to $<0.10$, and tendencies from $P<0.10$ to $<0.15$. Means separation analysis among treatments was achieved using the pdiff function in the lsmeans statement (SAS 9.3, Cary, NC).

\section{RESULTS}

\section{Overall Animal Health}

Of the two-hundred and four cows enrolled in the study, forty-six were culled from study or data analysis due to health reasons and farm records. Cows were culled from study if they had prolonged or multiple confounding health issues that prohibited completion of study. Cows were removed from data analysis if they had undergone a displaced abomasum (DA) surgery or had multiple confounding health issues that resulted in poor quality data. While on study, thirty-two cows underwent surgery for DA with twenty-eight confirmed and four unconfirmed DA, twenty-seven cows contracted mastitis, twenty-two cows suffered from metritis with eight of those resulting from retained placental membrane beyond 24 hrs following parturition, sixteen cows were treated for ketosis as detected by urine ketone level, eleven cows had respiratory issues, nine cows suffered from prolonged lameness, five broke with clinical Johnes, two exhibited milk fever, and eighteen cows were afflicted with "other" health issues. A total

of one-hundred and fifty-eight cows were used upon completion of study and removal of abnormal data using farm notes. The final number of cows to be analyzed for each 
treatment was 39, 40, 37, and 42 for CTL, 1X, 2X, and LAC, respectively. The rates of health issues observed in the current study were consistent across all treatments.

\section{Study Diets}

Weekly samples were dried and ground before combining into monthly and then quarterly samples for independent lab analysis (Table 4.1). The NRC (2001) guidelines for prepartum diets lists cows 240 days in gestation with mean body weight of $730 \mathrm{~kg}$ should get $871 \mathrm{~g} / \mathrm{d}$ metabolizable protein, and have a minimum of $33 \%$ neutral detergent fiber (NDF), 21\% acid detergent fiber (ADF), and a maximum of $42 \%$ non-fiber carbohydrate (NFC). The DRY diet contained 47, 34, and 31\% of NDF, ADF, and NFC, respectively. NRC (2001) guidelines for cattle $11 \mathrm{~d}$ postpartum milking $35 \mathrm{~kg} / \mathrm{d}$ milk and consuming $15.6 \mathrm{~kg} / \mathrm{d}$ DMI suggest $2,157 \mathrm{~g} / \mathrm{d}$ metabolizable protein with a minimum of 25 to $33 \%$ NDF and 17 to $21 \%$ ADF, and a maximum of 36 to $44 \%$ NFC. The FRESH diet contained $1970 \mathrm{~g} / \mathrm{d}$ metabolizable protein and 33, 24, and 41\% NDF, ADF, and NFC, respectively. The metabolizable protein level of the FRESH diet was somewhat limiting; however study cows were consuming over $17 \mathrm{~kg} / \mathrm{d}$ of DMI by $11 \mathrm{~d}$ postpartum and were therefore likely not limited by the metabolizable protein level of the FRESH diet. The NRC (2001) suggests cows 90 d postpartum milking $45 \mathrm{~kg} / \mathrm{d}$ and consuming $26.9 \mathrm{~kg} / \mathrm{d}$ DMI get 2,954 g/d metabolizable protein, and a minimum of 25 to $33 \%$ NDF, 17 to $21 \%$ ADF, and a maximum of 36 to $44 \%$ NFC. The PEAK diet contained $2832 \mathrm{~g} / \mathrm{d}$ metabolizable protein, and 30, 21, and $44 \% \mathrm{NDF}$, ADF, and NFC, respectively. The PEAK diet was somewhat limiting in metabolizable protein. Mean DMI and mean MY during the study was lower than NRC estimates for fresh and post-peak dairy cattle with mean DMI between 20 and $21 \mathrm{~kg} / \mathrm{d}$ and mean MY between 40 and $41 \mathrm{~kg} / \mathrm{d}$. 


\section{Production Variables}

No treatment differences were observed for live weight $(658 \pm 11 \mathrm{~kg}, 676 \pm 10$ $\mathrm{kg}, 668 \pm 11 \mathrm{~kg}$, and $684 \pm 10 \mathrm{~kg} ; P=0.16)$ and $\operatorname{BCS}(3.34 \pm 0.04,3.34 \pm 0.04,3.35 \pm$ 0.04, and 3.35 $\pm 0.04 P=0.99$ ), respectively, for control, 1X, 2X, and LAC (Figure 4.1). No treatment by time interactions were observed for live weight $(P=0.31)$ and $\operatorname{BCS}(P=$ 44) nor linear or quadratic responses with increasing dosage of $\mathrm{XP}(P>0.15)$. Live weight at initiation of study was similar among CTL, $1 \mathrm{X}$, and $2 \mathrm{X}$ cows at approximately $700 \mathrm{~kg}$. The LAC treated cows weighed more at approximately $740 \mathrm{~kg}$. At the time of calving, 1X, 2X, and LAC cows were similar in weight (750 kg) while CTL cows weighed less at $730 \mathrm{~kg}$. All treatments followed a similar pattern of weight change consisting of increased weight gain from treatment initiation until parturition, at which time approximately $100 \mathrm{~kg}$ of weight was lost within the first three to four weeks of lactation. From week five until completion of study weights remained relatively consistent. Body condition score was similar among all treatments (3.7) at treatment initiation, parturition (3.6), and completion of study (3.0).

A linear decline in DMI was observed with increasing dose of XP $(P=0.09)$. However there was no treatment or treatment by time interaction among treatments with $20.4 \pm 0.4,20.2 \pm 0.4,19.6 \pm 0.4$, and $19.7 \pm 0.4 \mathrm{~kg} / \mathrm{d}$ DMI for CTL, $1 \mathrm{X}, 2 \mathrm{X}$, and LAC treatments, respectively (Figure 4.2). When DMI was analyzed as either prepartum or postpartum DMI no treatment or treatment by time interactions were observed $(P>0.15)$. No effect of increasing dose of XP was observed for prepartum DMI; however, a linear decline was observed in postpartum DMI with $23.0 \pm 0.5,22.7 \pm 0.5$, and $22.0 \pm 0.5 \mathrm{~kg} / \mathrm{d}$, 
respectively $(P=0.07)$. Pretreatment DMI was not established, therefore variation in DMI among treatments was not covariate adjusted.

Milk yield, 3.5\% FCM, and energy corrected milk were not affected by treatment or its interaction with time $(P>0.15$; Figures 4.3 and 4.4). Similarly, milk fat percent, protein percent, SNF percent and yield, MUN, SCS, and SCC were not affected by treatment its interaction with time $(P>0.15$; Table 4.3). Milk fat yield was significantly affected by treatment with daily yields of $1.9 \pm 0.2,2.5 \pm 0.2,2.0 \pm 0.2$, and $2.0 \pm 0.2 \mathrm{~kg}$ of milk fat for CTL, 1X, 2X, and LAC, respectively $(P=0.05)$. Mean separation procedures further indicated that $1 \mathrm{X}$ increased milk fat yield by $0.5 \mathrm{~kg}$ over the other three treatments $(P<0.05)$. In agreement, an increasing quadratic response was observed with increasing dose of XP $(P=0.006)$. Milk protein yield tended to be affected by treatment with $1.2 \pm 0.05,1.3 \pm 0.05,1.2 \pm 0.05$, and $1.1 \pm 0.05 \mathrm{~kg} / \mathrm{d}$, respectively $(P=$ 0.13). Means separation procedures indicated that $1 \mathrm{X}$ increased milk protein yield over 2X and LAC treatments but not CTL $(P=0.09, P=0.02$, and $P=0.21$, respectively). The trend for increased milk protein yield was also observed with a positive quadratic response to increasing dose of XP $(P=0.09)$. Although no overall treatment effects were detected by analysis of variance, orthogonal contrasts suggested that SNF yield and SCS tended to have increased quadratic responses to increasing dose of XP $(P=0.12$ and $P=$ 0.13 , respectively).

Treatment tended to affect colostrum immunoglobulin concentration of IgG and $\operatorname{IgM}$ but not $\operatorname{IgA}(P=0.11, P=0.11$, and $P=0.17$, respectively; Table 4.3$)$. Mean separation procedures indicated that IgG concentrations were not different between CTL, $1 \mathrm{X}$, and LAC $(P>0.15)$, but decreased with $2 \mathrm{X}$ treatment by $23 \%$ compared to control 
$(P<0.07)$. Likewise, CTL, $1 \mathrm{X}$, and LAC contained similar concentrations of IgM in colostrum $(P>0.15)$, but $2 \mathrm{X}$ treated cows had $21 \%$ lower IgM concentration than CTL. Colostrum IgA concentration was similar across treatments; however $2 \mathrm{X}$ cows had the lowest numerical concentration $(0.94 \pm 0.5 \mathrm{mg} / \mathrm{mL})$ and CTL had the highest $(2.0 \pm 0.5$ $\mathrm{mg} / \mathrm{mL})$. There were no linear or quadratic responses to increasing dose of XP $(P>0.15)$.

Feed to milk conversion efficiency tended to increase linearly with increasing dose of XP $(P=0.15)$. Feed to milk conversion efficiency was calculated as $\mathrm{kg}$ MY divided by $\mathrm{kg}$ DMI on a daily basis with $1.80 \pm 0.05,1.88 \pm 0.05$, and $1.89 \pm 0.05$ for CTL, $1 \mathrm{X}$, and $2 \mathrm{X}$, respectively. Additionally, a treatment by time interaction $(P=0.005)$ was observed with CTL less efficient than the other treatments at varying times during the study (Figure 4.5). Control was less efficient than $1 \mathrm{X}$ from 2 through $15 \mathrm{~d}$ and 40 through $55 \mathrm{~d}$ in lactation. CTL was less efficient than $2 \mathrm{X}$ sporadically throughout the study, with the greatest number of consecutive days less efficient between 40 and $45 \mathrm{~d}$ in lactation. Control was less efficient than LAC a total of $11 \mathrm{~d}$ on study; however, no pattern of day on study was observed. In addition to being more efficient than CTL, $1 \mathrm{X}$ was more efficient than LAC the first week of lactation. All other feed to milk conversion efficiency comparisons were similar among treatments. No treatment or treatment by time interactions for feed to $3.5 \% \mathrm{FCM}$ or feed to ECM conversion efficiency were detected $(P<0.15 ;$ Figure 4.5). A trend for feed to ECM conversion efficiency was observed, with an increasing quadratic response to increased dose of XP $(P=0.09 ; 2.12 \pm$ $0.1,2.34 \pm 0.1$, and $2.22 \pm 0.1$ for control, $1 \mathrm{X}$, and $2 \mathrm{X}$, respectively). 


\section{Metabolic Variables}

Glucose $(44.1 \pm 1.1,44.0 \pm 1.1,43.6 \pm 1.1$, and $43.7 \pm 1.1 \mathrm{mg} / \mathrm{dL} ; P=0.98)$ and NEFA $(412.8 \pm 28.5,410.7 \pm 28.8,366.3 \pm 27.4$, and $394.7 \pm 28.8 \mu \mathrm{Eq} / \mathrm{L} ; P=0.57)$ were similar for CTL, 1X, 2X, and LAC, respectively. No treatment by time interactions were observed for glucose or NEFA ( $P>0.15$; Figure 4.6). Plasma BHBA was similar among treatments $(9.1 \pm 0.6,9.3 \pm 0.6,8.4 \pm 0.6$, and $9.8 \pm 0.6 \mathrm{mg} / \mathrm{dL} ; P=0.38)$; however a treatment by time trend was observed $(P=0.10)$. The LAC cows had higher concentrations of plasma BHBA $21 \mathrm{~d}$ after parturition than CTL, $1 \mathrm{X}$, and $2 \mathrm{X}$ cows. The LAC BHBA concentrations remained higher for LAC cows than CTL and 2X cows at 42 $\mathrm{d}$ after parturition but not $1 \mathrm{X}$ cows. The pattern of plasma glucose, BHBA, and NEFA observed in this study follow that of other metabolite studies. The cows were in a negative energy balance approximately a week prior to calving, indicated by an increase in plasma NEFA and BHBA.

Net energy balance was calculated following parturition and CTL tended to have higher net energy than $1 \mathrm{X}, 2 \mathrm{X}$, and LAC cows $(P=0.10)$. Mean energy balance during the 12 wk lactation period were $-4.96 \pm 0.94,-7.27 \pm 0.93,-6.71 \pm 0.96$, and $-7.19 \pm 0.92$ $\mathrm{Mcal} / \mathrm{kg}$ body weight. The CTL cows reached a state of positive energy balance between 7 and 8 wks following parturition while $1 \mathrm{X}, 2 \mathrm{X}$, and LAC remained in calculated negative energy balance for the duration of the study. No treatment by time interaction was detected $(P=0.78)$ and there was no linear or quadratic response to increasing dose of XP $(P>0.15)$. 


\section{DISCUSION}

Studies investigating the effects of Diamond V XP yeast on DMI, MY, milk composition and plasma metabolite markers are plentiful as the dried yeast culture has been commercially available since 1957. A meta-analysis of XP yeast culture studies examined the results from thirty-six separate studies with sixty-nine comparisons (Poppy et al., 2012). Milk yield, ECM, 3.5\% FCM, milk fat yield, and milk protein yield data showed substantial heterogeneity in peer-reviewed studies. The author's contributed the source of variability in effect to a high number of studies lacking sufficient sample size and consequentially lacking statistical power to determine true differences in the production variables of interest. Two-hundred and four cows were enrolled in the current study, over a three year period, to ensure a high sample size after removal of poor data. Following removal of cows with DA surgery and multiple confounding metabolic health issues, one-hundred and fifty-eight cows remained on study. In the author's opinion, a sufficient sample size was included in the data analysis and that results described from the current study are true representations of the effects of XP yeast culture.

The new generation "LAC" product examined in this study is proprietary therefore the authors are unaware of its exact compound characteristics. Comparisons of the effect of LAC to CTL and XP treatments in the current study will be discussed in the following discussion; however, results from the LAC treatment cannot be compared to those of other studies as this is the first study to our knowledge to examine its effects on production and metabolic variables. 
Body condition score and body weight were similar among all four treatments in the current study. Supplementation of yeast culture did not reduce the rate of body weight loss around the time of parturition as was described by Dann et al. (2000) or decrease the rate of body condition loss prepartum as described by Robinson (1997). Body weight can be impacted by feed and water consumption, fetal growth, and milk production therefore, although a subjective measure, BCS is a more accurate means of evaluating energy balance by appearance. The BCS of all four treatments began to decline one week prior to calving with approximately half a BCS score loss within the first three weeks of lactation. These results are to be expected as milk production increases exponentially at the time of calving while DMI increase is delayed requiring mobilization of body reserves to meet the energy requirements of lactation. Ramsing et al. (2009) observed no effect of XP or four times the commercially suggested supplementation rate of XP on BCS and body weight when supplemented $-21 \mathrm{~d}$ to $21 \mathrm{~d}$ relative to parturition. Other studies examining the effects of XP yeast culture on early lactation (Arambel and Kent, 1990; Robinson and Garrett, 1999) confirm a lack of effect on BCS and body weight. The results of the current study are consistent with these earlier reports.

Dry matter intake was similar among all treatments when examined over the entire study. However, examination of prepartum and postpartum DMI resulted in similar prepartum DMI among all treatments and a linear decrease in postpartum DMI with increasing dose of XP. A lack of treatment by time interaction indicates that DMI depression just prior to calving and the rate of increase postpartum was unaffected by dose or strain of yeast culture. These results are in agreement with those of Robinson (1997) and Robinson and Garrett (1999), but not those of Dann et al. (2000) who reported 
increased DMI compared to CTL the last seven days prior to calving when XP was supplemented. When comparing prepartum DMI of Jersey and Holstein cattle, French (2006) described a breed by day interaction with the magnitude of DMI depression being greater in Holsteins (French, 2006). The discrepancies between Dann et al. (2000) and the current study are perhaps at least partially due to breed as Dann supplemented Jersey cattle with XP while Holstein cattle were supplemented in the current study. Increased DMI with XP supplementation cannot be entirely disproved as Erasmus et al. (2005) was able to counteract the reduction of DMI seen with monensin when XP was cosupplemented. It was suggested that XP may be complementary to ionophores by counteracting the reduced DMI and thereby reducing the milk fat depression that is typically observed with ionophores. Erasmus et al. (2005) further postulated that XP increased fiber digestion and may have a complementary relationship with monensin on lactic acid utilizing bacteria.

Milk yield was not affected by treatment in the current study and a lack of treatment by time interaction indicated that cows did not respond differently to treatment between early and post peak lactation. Milk fat percent, protein percent, SNF percent and yield, MUN, SCS, and SCC were also not affected by treatment or treatment by time interaction. Milk fat yield was significantly improved while milk protein yield tended to improve with $1 \mathrm{X}$ but not $2 \mathrm{X}$ treatment compared to CTL. The authors are aware that milk fat percentages were higher than expected in the current study and are likely an artifact of milk sampling technique; however, milk sampling was carried out consistently throughout the entire study and therefore all four treatments should be affected similarly. Therefore, it is believed that the increase in milk fat yield is a result of a numerical 
increase in milk production of $0.8 \mathrm{~kg} / \mathrm{d}$ with $1 \mathrm{X}$ treatment over CTL. Additionally, while not statistically significant, both $3.5 \%$ FCM and ECM improved by $10 \%$ with $1 \mathrm{X}$ supplementation compared to CTL. Our results are in agreement with Lehloenya et al. (2008) who reported a numerical increase of $1.5 \mathrm{~kg} / \mathrm{d}$ in MY and an $11 \%$ increase in $4 \%$ FCM of mid-lactation multiparous cows. Lehloenya et al. (2008) did not observe these effects in early lactation or in primiparous cows. Both early lactation and primparous animals were examined in the current study and may be the reasoning for our lower level of MY improvement as evidenced by Shaver et al. (1997) who observed a $0.9 \mathrm{~kg} / \mathrm{d}$ increase in MY when midlactation cattle were supplemented with XP; this study (Shaver et al., 1997) contained both primiparous and multiparous animals. Conversely, Erasmus (2005) observed an increase in milk crude protein but no effect of XP on MY or the other milk components of interest. Robinson (2005) also reported no effect on MY or milk components, but this may be more of an effect of short treatment period than a true lack of treatment effect.

There are few reports regarding the effects of yeast culture supplementation on colostrum immunoglobulin concentrations. In the current study, colostrum IgG, IgM, and IgA concentrations were determined from milk samples collected at first milking. Although there was no observed difference in immunoglobulin concentration among CTL, $1 \mathrm{X}$, and LAC treated cows; $2 \mathrm{X}$ treated cows had a tendency for reduced IgG and IgM concentrations. Our results are in agreement with a pasture based study examining the effects of XP on early lactation dairy cattle, in which no effect of XP on amount, specific gravity, or IgG concentration of colostrum was observed (Irvine et al., 2011). A Polish study investigating the effects of a Saccharomyces cerevisiae strain of yeast 
culture at consistent rates of XP supplementation reported an increase in gamma globulin concentration of colostrum (Kinal et al., 2007); however, the report never indicated the product used for supplementation and did not measure $\operatorname{IgG}, \operatorname{IgM}$, and $\operatorname{IgA}$ independently.

Although not statistically significant, postpartum DMI was numerically reduced with increasing level of XP $(0.3$ and $1.0 \mathrm{~kg} / \mathrm{d}$ for $1 \mathrm{X}$ and $2 \mathrm{X}$, respectively when compared to CTL). In addition, MY was improved by $0.8 \mathrm{~kg} / \mathrm{d}$ with $1 \mathrm{X}$ treatment. Therefore, feed to milk conversion efficiency, calculated as $\mathrm{kg}$ MY divided by $\mathrm{kg}$ DMI, tended to increase a linearly with increasing dose of XP. A treatment by time interaction was observed with $1 \mathrm{X}$ treated cows being more efficient than CTL from 2 through $15 \mathrm{~d}$ and 40 through $55 \mathrm{~d}$ in lactation. The $2 \mathrm{X}$ treated cows were more efficient than CTL sporadically throughout the study, with the greatest number of consecutive days more efficient between 40 and $45 \mathrm{~d}$ in lactation. Although LAC was more efficient than CTL a total of $11 \mathrm{~d}$ on study, no pattern of day on study was observed indicating a time when LAC supplementation would be beneficial. A trend for feed to ECM conversion efficiency was observed, with an increasing quadratic response to increased dose of XP indicating that $1 \mathrm{X}$ was more efficient than $2 \mathrm{X}$ (10 and $4.5 \%$, respectively) at converting DMI to ECM compared when compared to CTL. Similarly, a 7\% increase in ECM efficiency was reported by Schingoethe et al. (2004) when midlactation cows were subjected to heat stress during a 12 week study.

Although some in vitro studies indicate an increase in dry matter digestion and propionate production with XP supplementation (Sullivan and Martin, 1999; MillerWebster et al., 2002), others show no improvement in volatile fatty acid (VFA) production (Lynch and Martin, 2002). Furthermore, the effects observed in vitro may not 
be observed in in vivo trials (Wiedmeier et al., 1987). If XP treatment improves digestibility and propionate production, it stands to reason that supplementation would either improve production or energy balance. Because the current study observed a reduced energy balance in cattle treated with $1 \mathrm{X}, 2 \mathrm{X}$, and LAC compared to CTL, we must conclude that XP did not improve energy balance. However, with a slight decline in DMI postpartum coupled with a slight increase in MY, it is quite possible that XP supplementation improved dry matter digestibility and any alteration in VFA production was partitioned towards increased MY. Furthermore, plasma glucose, NEFA, and BHBA were similar among treatments indicating that potential alteration to VFA production did not positively impact net energy balance. A treatment by time interaction was observed with LAC treatment on plasma BHBA; however increased BHBA concentrations $21 \mathrm{~d}$ following parturition are not desirable as it is a sign of continued negative energy balance. The levels observed in the current study indicate cows treated with LAC were within the threshold of subclinical ketosis from 7 through $42 \mathrm{~d}$ following parturition (Oetzel and McGuirk, 2008).

\section{CONCLUSION}

A linear trend for decreased postpartum DMI was observed with increasing dose of XP. Supplementation of XP yeast culture improved milk fat yield and tended to improve milk protein yield. These coupled with a numerical increase in MY for the $1 \mathrm{X}$ treatment, resulted in improved 3.5\% FCM and ECM by $10 \%$. Therefore, it is suggested that supplementation of XP at the current commercially recommended rate is beneficial 
to producers. No results from the current study support a doubling of the current recommended XP supplementation rate. Examination of the next generation "LAC" product showed little benefit over CTL treatment. 
Table 4.1. Diet composition ${ }^{1}$ and nutrients supplied ${ }^{2}$ by prepartum and postpartum diets (dry matter basis).

\begin{tabular}{llll}
\hline Component & Dry & Fresh & Peak \\
\hline DM, \% ${ }^{3}$ & 66.1 & 52.9 & 49.5 \\
CP, \% of DM & 14.24 & 16.72 & 17.18 \\
Soluble protein, \% of CP & 27.40 & 33.40 & 29.00 \\
Metabolizable protein, g/d & & 1970 & 2832 \\
ADF, \% of DM & 33.46 & 24.36 & 21.30 \\
NDF, \% of DM & 47.00 & 33.20 & 30.08 \\
Lignin, \% of DM & 5.62 & 3.98 & 4.26 \\
NFC, \% of DM & 30.62 & 41.44 & 43.90 \\
Starch, \% of NFC & 12.04 & 24.30 & 25.82 \\
Crude fat, \% of DM & 2.98 & 3.92 & 4.08 \\
NEL, Mcal/kg & 1.42 & 1.64 & 1.65 \\
Metabolizable energy, Mcal/d & 29.90 & 43.84 & 63.82 \\
Ash, \% of DM & 8.51 & 7.60 & 7.86 \\
Ca, \% of DM & 0.90 & 0.95 & 1.02 \\
P, \% of DM & 0.34 & 0.39 & 0.36 \\
Mg, \% of DM & 0.37 & 0.35 & 0.36 \\
K, \% of DM & 1.62 & 1.62 & 1.43 \\
\hline
\end{tabular}

${ }^{\mathrm{I}}$ Composition determined by independent lab analysis (Dairy One, Inc. Ithaca, NY). DM $=$ dry matter; $\mathrm{CP}=$ crude protein; $\mathrm{ADF}=$ acid detergent fiber; $\mathrm{NDF}=$ neutral detergent fiber; $\mathrm{NFC}=$ non-fibrous carbohydrate; and NEL = net energy lactation.

${ }^{2}$ Metabolizable protein and energy supplied as predicted by the Cornell Net Carbohydrate and Protein System (Fox et al., 2004).

${ }^{3}$ Dry matter percent determined from weekly composite diet samples and dried a $55^{\circ} \mathrm{C}$ oven for four days. 
Table 4.2. Premix composition as prepared in batches of $1000 \mathrm{lbs}^{1}$.

\begin{tabular}{|c|c|c|c|c|c|c|c|c|c|c|c|c|}
\hline \multirow[t]{2}{*}{ Ingredient } & \multicolumn{4}{|c|}{ Dry } & \multicolumn{4}{|c|}{ Fresh } & \multicolumn{4}{|c|}{ Peak } \\
\hline & Control & $\underline{1 X}$ & $\underline{2 X}$ & $\underline{\mathrm{LAC}}$ & Control & $\underline{1 X}$ & $\underline{2 X}$ & $\underline{\mathrm{LAC}}$ & $\underline{\text { Control }}$ & $\underline{1 X}$ & $\underline{2 X}$ & $\underline{\mathrm{LAC}}$ \\
\hline Soybean Meal & 554.0 & $\overline{553.0}$ & $\overline{552.0}$ & $\overline{553.4}$ & 297.3 & $\overline{296.3}$ & $\overline{295.4}$ & $\overline{296.8}$ & 381.4 & $\overline{380.7}$ & $\overline{380} .0$ & $\overline{381.0}$ \\
\hline Corn Meal (fine) & 336.5 & 321.7 & 306.9 & 333.1 & 387.5 & 373.2 & 359.0 & 384.2 & 230.7 & 220.1 & 209.4 & 228.3 \\
\hline Blood Meal & 14.4 & 14.4 & 14.4 & 14.4 & 46.8 & 46.8 & 46.8 & 46.8 & 97.8 & 97.8 & 97.8 & 97.8 \\
\hline Calcium & 32.6 & 21.7 & 21.7 & 21.7 & --- & --- & --- & --- & --- & --- & --- & --- \\
\hline Chloride & & & & & & & & & & & & \\
\hline $\begin{array}{l}\text { Magnesium } \\
\text { Sulfate }\end{array}$ & 22.1 & 31.9 & 31.9 & 31.9 & --- & --- & --- & --- & --- & --- & --- & --- \\
\hline $\begin{array}{l}\text { Magnesium } \\
\text { Oxide }\end{array}$ & 7.8 & 8.6 & 8.6 & 8.6 & 11.4 & 11.4 & 11.4 & 11.4 & 12.7 & 12.7 & 12.7 & 12.7 \\
\hline Salt (white) & 7.8 & 8.1 & 8.1 & 8.1 & 16.3 & 16.3 & 16.3 & 16.3 & 13.4 & 13.4 & 13.4 & 13.4 \\
\hline $\begin{array}{l}\text { Potassium } \\
\text { Carbonate }\end{array}$ & --- & --- & --- & --- & 18.1 & 18.1 & 18.1 & 18.1 & 19.2 & 19.2 & 19.2 & 19.2 \\
\hline Limestone & --- & --- & --- & --- & 49.4 & 49.4 & 49.4 & 49.4 & 56.5 & 56.5 & 56.5 & 56.5 \\
\hline $\begin{array}{l}\text { Sodium } \\
\text { Bicarbonate }\end{array}$ & --- & --- & --- & --- & 42.5 & 42.5 & 42.5 & 42.5 & 47.1 & 47.1 & 47.1 & 47.1 \\
\hline $\begin{array}{l}\text { MU Vit. E } \\
20,000\end{array}$ & 13.0 & 12.9 & 12.9 & 12.9 & 10.2 & 10.2 & 10.2 & 10.2 & 9.7 & 9.7 & 9.7 & 9.7 \\
\hline $\begin{array}{l}\text { MU Vit. ADE } \\
\text { Premix }\end{array}$ & 4.2 & 4.1 & 4.1 & 4.1 & 3.8 & 3.8 & 3.8 & 3.8 & 3.3 & 3.3 & 3.2 & 3.3 \\
\hline $\begin{array}{l}\text { MU Dairy Trace } \\
\text { Mineral }\end{array}$ & 7.8 & 7.8 & 7.8 & 7.8 & 9.3 & 9.3 & 9.3 & 9.3 & 9.7 & 9.7 & 9.7 & 9.7 \\
\hline Dynamate & --- & --- & --- & --- & 18.8 & 18.9 & 18.8 & 18.9 & 20.5 & 20.5 & 20.5 & 20.5 \\
\hline Energy Booster & --- & --- & --- & -- & 85.8 & 85.8 & 85.8 & 85.8 & 94.6 & 94.6 & 94.6 & 94.6 \\
\hline Smartamine & ---s & --- & --- & --- & 2.8 & 2.8 & 2.8 & 2.8 & 3.5 & 3.5 & 3.5 & 3.5 \\
\hline Diamond V XP & --- & 15.8 & 31.6 & --- & --- & 15.2 & 30.4 & --- & --- & 11.4 & 22.8 & --- \\
\hline $\begin{array}{l}\text { LAC } \\
\text { Experimental }\end{array}$ & --- & --- & --- & 4.0 & --- & --- & --- & 2.8 & --- & --- & --- & 2.8 \\
\hline
\end{tabular}

${ }^{1}$ Premix composition expressed in lbs. of ingredient as prepared at the University of Missouri Feed Mill. 
Table 4.3. Milk composition ${ }^{1}$ and colostrum immunoglobulin ${ }^{2}$ reported as least square means with standard errors.

\begin{tabular}{|c|c|c|c|c|c|c|c|c|c|}
\hline \multirow[t]{2}{*}{$\begin{array}{l}\text { Milk } \\
\text { Component }\end{array}$} & \multicolumn{2}{|c|}{ Control } & \multicolumn{2}{|l|}{$1 \mathrm{X}$} & \multicolumn{2}{|l|}{$2 X$} & \multicolumn{3}{|l|}{ LAC } \\
\hline & Mean & $\underline{\mathrm{SE}}$ & Mean & $\underline{\mathrm{SE}}$ & Mean & $\underline{\mathrm{SE}}$ & Mean & $\underline{\mathrm{SE}}$ & $\begin{array}{l}\mathrm{p} \text { - } \\
\text { value }\end{array}$ \\
\hline Fat, $\mathrm{kg} / \mathrm{d}$ & 1.9 & 0.18 & 2.5 & 0.18 & 2.0 & 0.19 & 2.0 & 0.17 & $\overline{0.05}$ \\
\hline Fat, $\%$ & 5.0 & 0.21 & 5.4 & 0.21 & 5.2 & 0.22 & 5.4 & 0.20 & 0.26 \\
\hline Protein, kg/d & 1.2 & 0.05 & 1.3 & 0.05 & 1.2 & 0.05 & 1.1 & 0.05 & 0.13 \\
\hline Protein, \% & 3.0 & 0.04 & 3.0 & 0.04 & 3.0 & 0.05 & 2.9 & 0.04 & 0.34 \\
\hline $\mathrm{SNF}, \mathrm{kg} / \mathrm{d}$ & 3.5 & 0.15 & 3.7 & 0.14 & 3.4 & 0.15 & 3.3 & 0.14 & 0.23 \\
\hline SNF, $\%$ & 8.6 & 0.07 & 8.5 & 0.07 & 8.5 & 0.08 & 8.4 & 0.07 & 0.37 \\
\hline MUN, \% & 4.8 & 0.37 & 5.3 & 0.37 & 4.9 & 0.38 & 5.0 & 0.36 & 0.70 \\
\hline $3.5 \% \mathrm{FCM}, \mathrm{kg} / \mathrm{d}$ & 49.8 & 2.9 & 55.1 & 2.8 & 49.0 & 2.9 & 50.0 & 2.8 & 0.26 \\
\hline $\mathrm{ECM}, \mathrm{kg} / \mathrm{d}$ & 48.2 & 2.7 & 53.2 & 2.7 & 47.4 & 2.8 & 47.8 & 2.6 & 0.22 \\
\hline $\mathrm{SCC}, 10^{3} / \mathrm{mL}$ & 182.9 & 53.6 & 187.7 & 52.3 & 166.7 & 54.9 & 133.4 & 51.6 & 0.79 \\
\hline SCS & 2.3 & 0.37 & 2.9 & 0.36 & 2.4 & 0.38 & 2.3 & 0.36 & 0.42 \\
\hline
\end{tabular}

$\underline{\text { Colostrum }}$

$\begin{array}{llllllllll}\mathrm{IgG}, \mathrm{mg} / \mathrm{mL} & 71.5 & 12.6 & 72.8 & 12.0 & 55.1 & 12.2 & 70.3 & 12.6 & 0.11\end{array}$ $\begin{array}{llllllllll}\mathrm{IgA}, \mathrm{mg} / \mathrm{mL} & 2.0 & 0.5 & 1.7 & 0.4 & 0.9 & 0.5 & 1.2 & 0.5 & 0.17\end{array}$ $\begin{array}{llllllllll}\mathrm{IgM}, \mathrm{mg} / \mathrm{mL} & 7.6 & 1.0 & 7.4 & 1.0 & 6.0 & 1.0 & 8.0 & 1.0 & 0.11\end{array}$

\footnotetext{
${ }^{1}$ Milk samples were collected at two consecutive milkings within a $24 \mathrm{hr}$ period. Compositional analysis was conducted by an independent laboratory (Mid-South Dairy Records, Springfield, MO). SNF = solids-not-fat; FCM $=3.5 \%$ fat-corrected milk; ECM $=$ energy-corrected milk; $\mathrm{SCC}=$ somatic cell count; and SCS $=$ somatic cell score.

${ }^{2}$ Colostrum was collected at first milking. Immunoglobulin concentrations were analyzed via ELISA kits purchased from Bethyl Laboratories.
} 


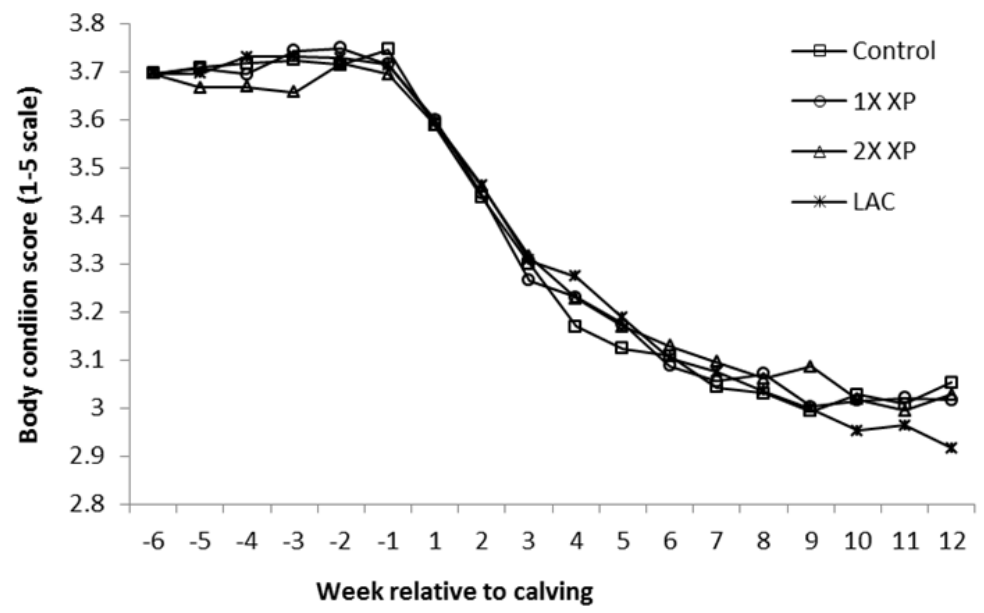

A.

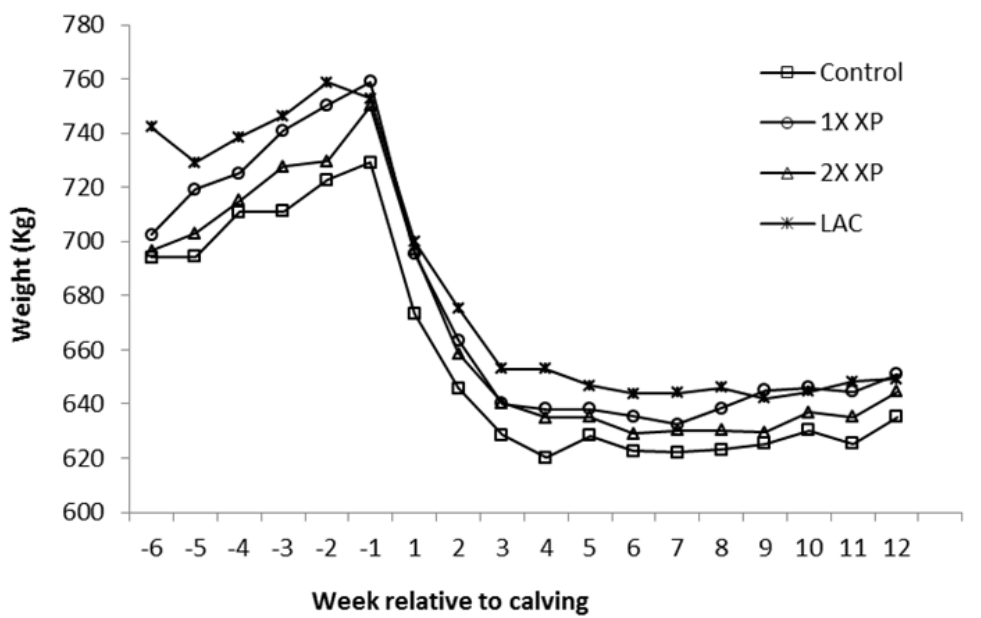

Figure 4.1. (A) Weekly body condition score (BCS) and (B) body weight. BCS were assessed by two independent evaluators using 0.25 increments and a scale of 1 to 5. Cows were weighed weekly to determine body weight. BCS was adjusted using pretreatment values as covariate. Adjusted LSMEANS are shown. There was no effect of treatment or treatment by time on BCS or body weight $(P>0.15)$. For clarity, standard error bars are not depicted in graphs but ranged from 0.03 to 0.04 for BCS and 10.3 to $10.8 \mathrm{~kg} / \mathrm{d}$ for weight. 


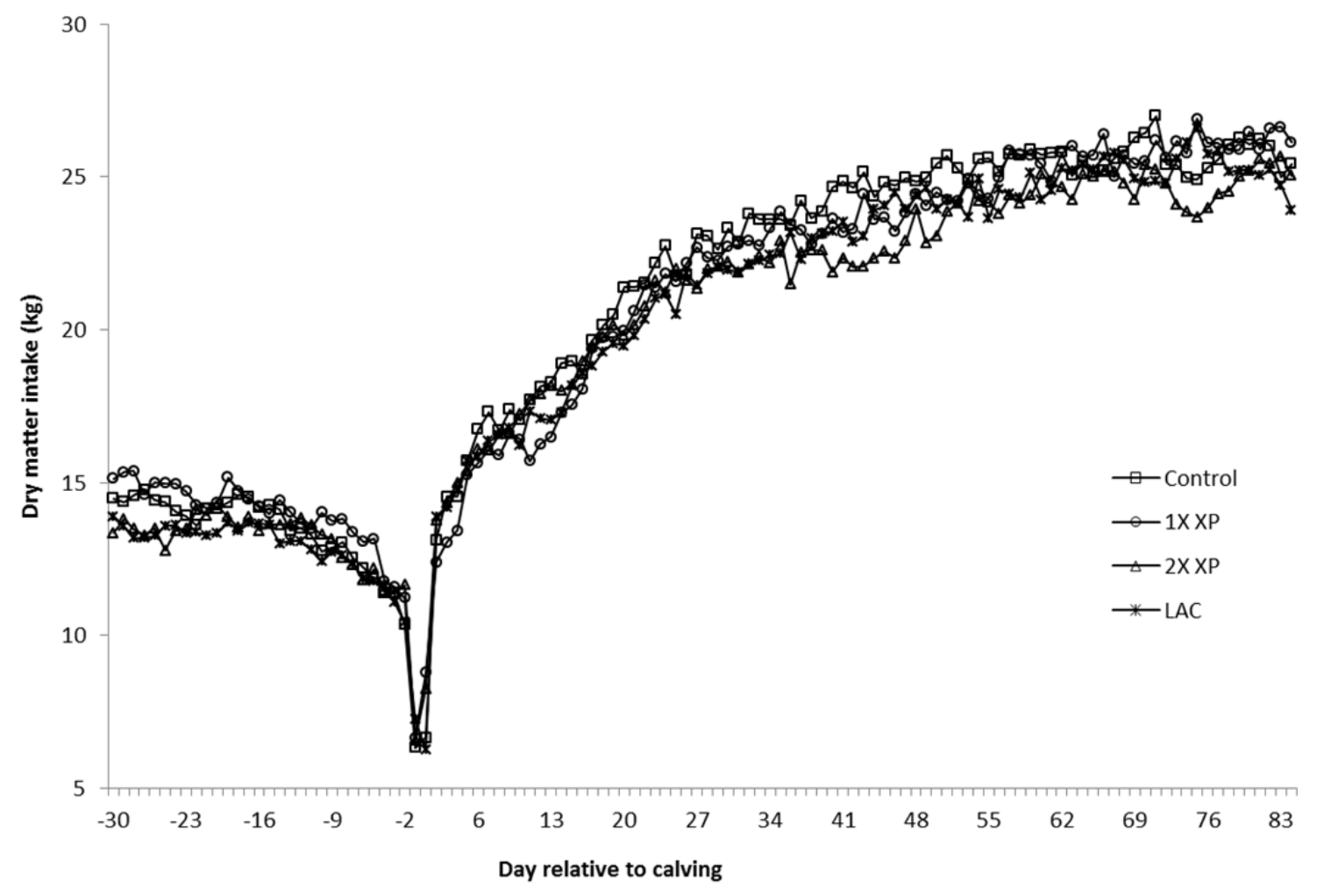

Figure 4.2. Daily dry matter intake of cows fed individually via Calan door systems. Cows were fed once daily during the dry period and twice daily during the lactation period. Feed refusals were weighed daily to assess feed intake and as a variable to monitor cows for potential health issues. There were no treatment or treatment by time effects on DMI $(P>0.15)$ however, a trend for a linear decrease in postpartum DMI was observed with increasing dose of XP $(P=0.07)$. Cows on $1 \mathrm{X}$ consumed $0.3 \mathrm{~kg} / \mathrm{d}$ and $2 \mathrm{X}$ consumed $1 \mathrm{~kg} / \mathrm{d}$ less dry matter than CTL cows. Standard error bars are not depicted in graph but ranged from 0.40 to $0.42 \mathrm{~kg} / \mathrm{d}$. 


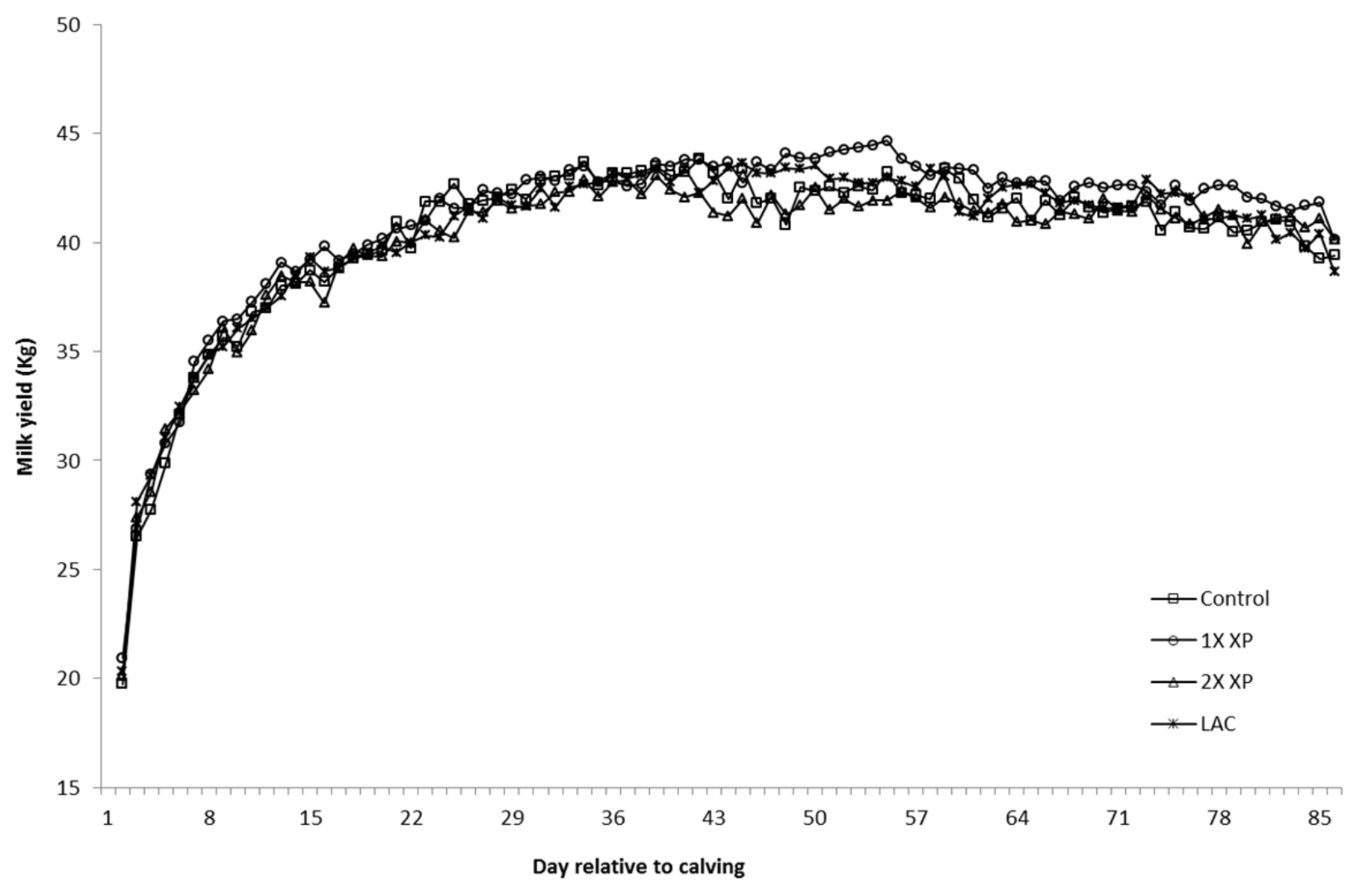

Figure 4.3. Daily milk yield. Milk yield was recorded at each milking and combined for daily production yields. Cows were milked twice daily on a 12 hour cycle. While no treatment or treatment by time effects were observed for milk yield $(P>0.15)$, a numerical increase was observed with $1 \mathrm{X}$ treatment $(0.8 \mathrm{~kg} / \mathrm{d})$ compared to CTL. Standard error bars are not depicted in graph, but were consistent for each treatment at $1.1 \mathrm{~kg} / \mathrm{d}$. 


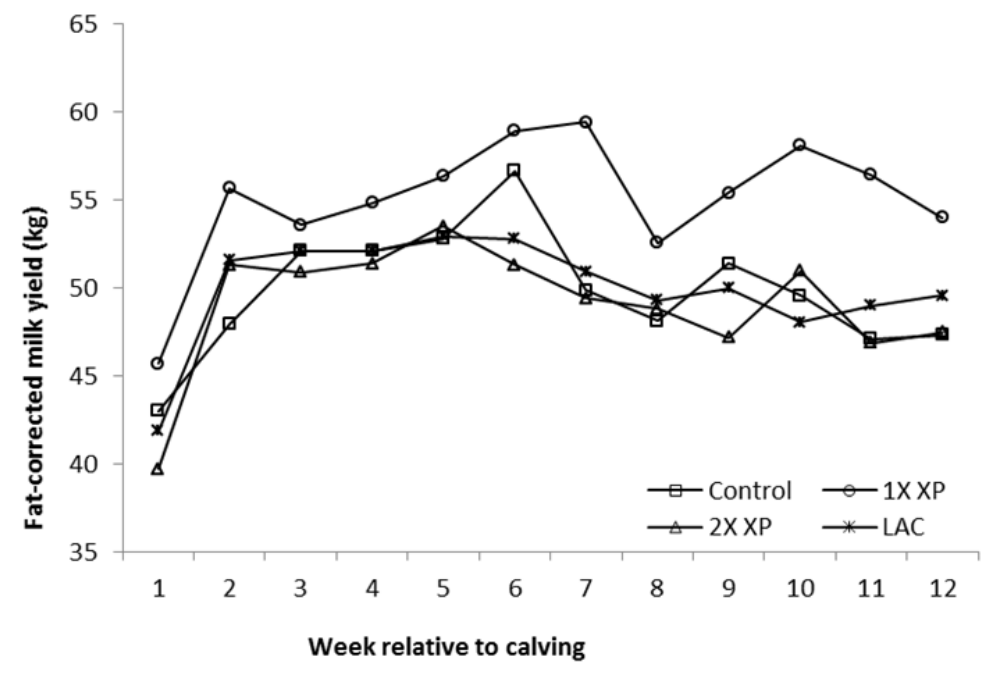

A.

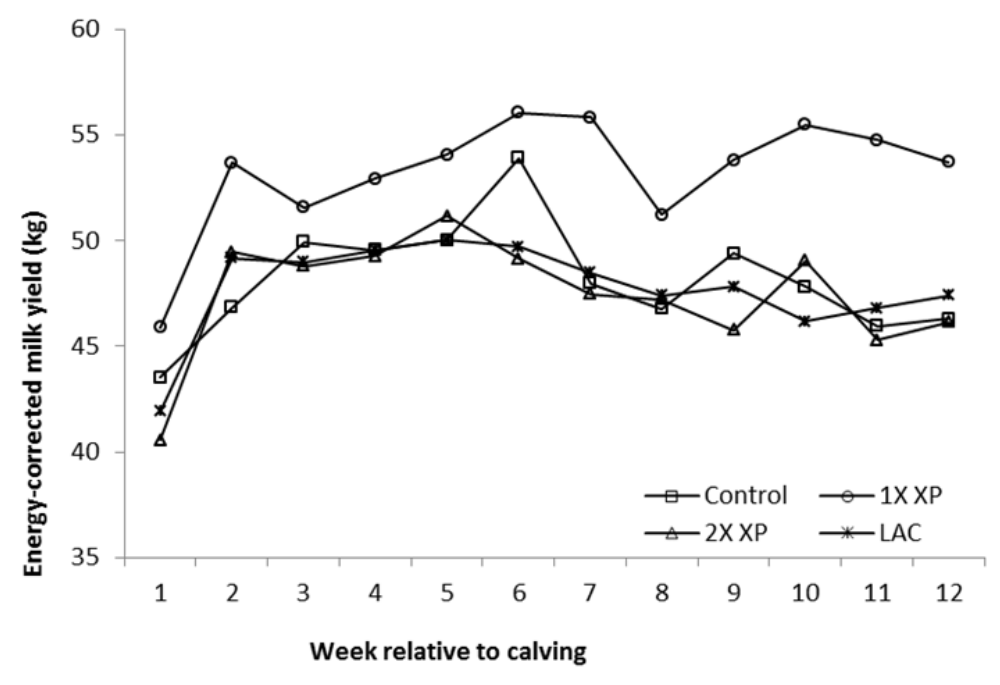

Figure 4.4. 3.5\% fat-corrected milk (FCM) and energy-corrected milk (ECM). The FCM and ECM were calculated using weekly milk composition samples collected at two consecutive milkings. There were no treatment or treatment by time effects on $3.5 \%$ FCM or ECM $(P>0.15)$; however a $10 \%$ improvement was observed for both FCM and ECM with 1X treatment compared to CTL. For clarity, standard error bars were not depicted in graph, but ranged from 2.8 to $2.9 \mathrm{~kg} / \mathrm{d}$ for FCM and 2.6 to $2.8 \mathrm{~kg} / \mathrm{d}$ for ECM. 


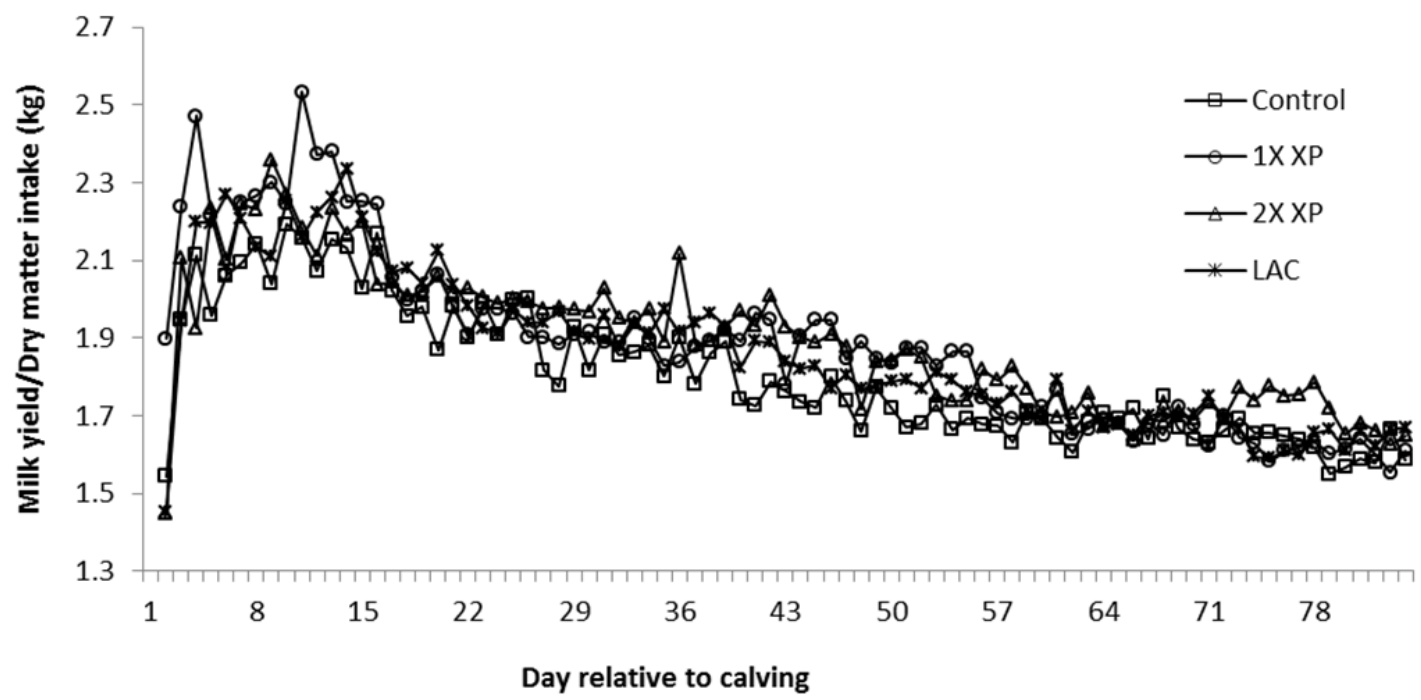

A.

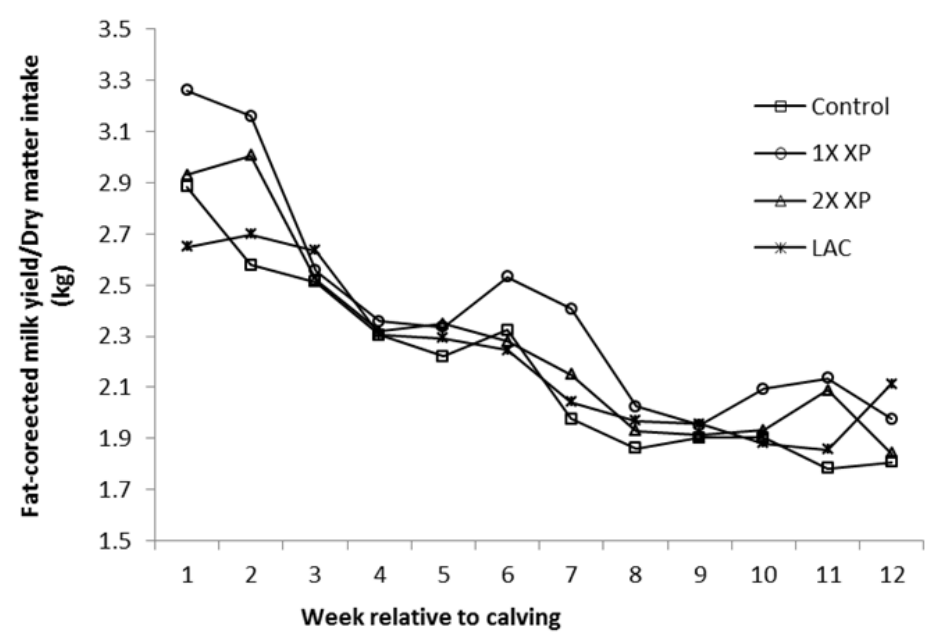

B.

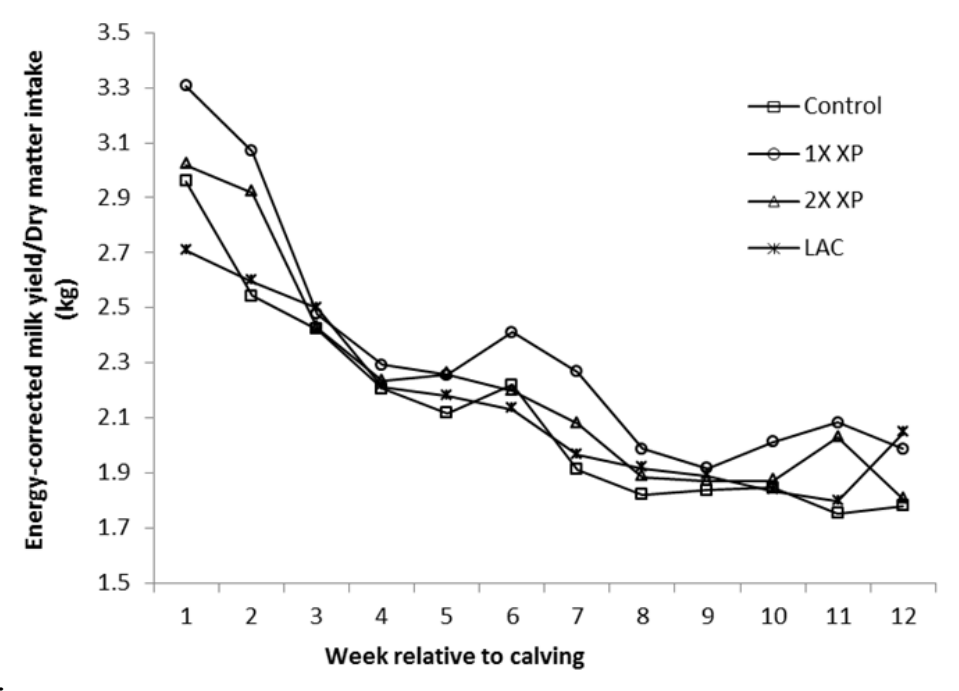


Figure 4.5. (A) Feed to milk, (B) feed to 3.5\% fat-corrected milk (FCM), and (C)feed to energy-corrected milk (ECM) efficiencies. Feed to milk efficiency was calculated by dividing the milk variable of interest by DMI. No treatment effects were observed for feed to milk but a treatment by time effect $(P=0.005)$ was evident indicating that CTL wass less efficient than the other treatments at varying times during the study. The CTL was less efficient than $1 \mathrm{X}$ from 2 through $15 \mathrm{~d}$ and 40 through $55 \mathrm{~d}$ in lactation. The CTL was less efficient than $2 \mathrm{X}$ sporadically throughout the study, with the greatest number of consecutive days less efficient between 40 and $45 \mathrm{~d}$ in lactation. The CTL was less efficient than LAC a total of $11 \mathrm{~d}$ on study; however, no pattern of day on study was observed. In addition to being more efficient than CTL, 1X was more efficient than LAC the first week of lactation. All other feed to milk conversion efficiency comparisons were similar between treatments. No treatment or treatment by time interactions for feed to $3.5 \%$ FCM or feed to ECM conversion efficiency were detected $(P<0.15)$. An increasing linear tendency for feed to milk conversion efficiency $(P=0.15)$ and a trend for increasing quadratic response of feed to ECM conversion efficiency $(P=$ $0.09)$ were observed, with an increased dose of XP. Standard error bars were not depicted in graph, but averaged 0.05 for feed to milk and 0.10 for both FCM efficiency and ECM efficiency. 


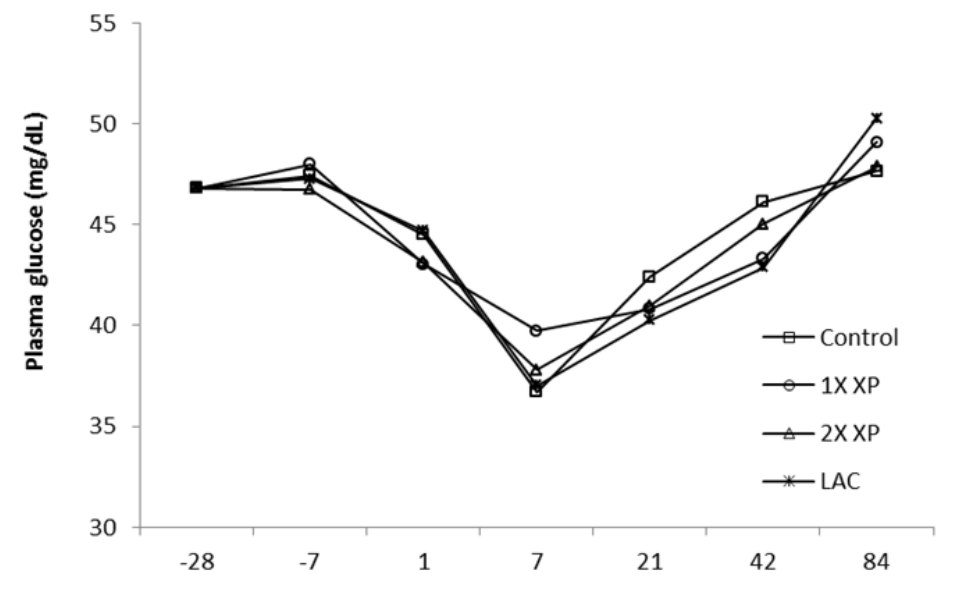

A.

Day relative to calving

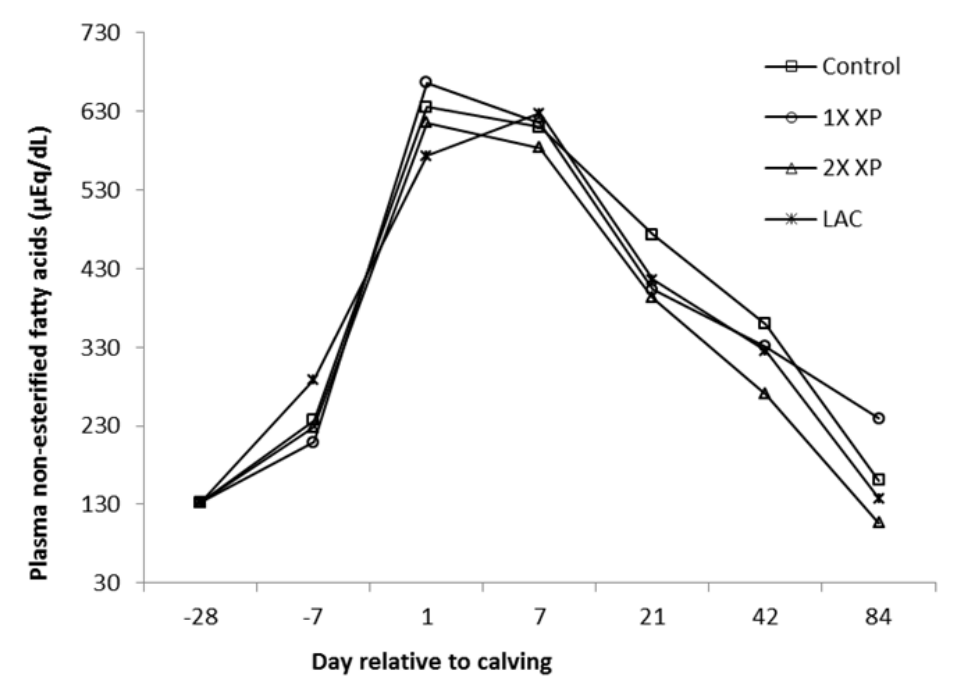

B.

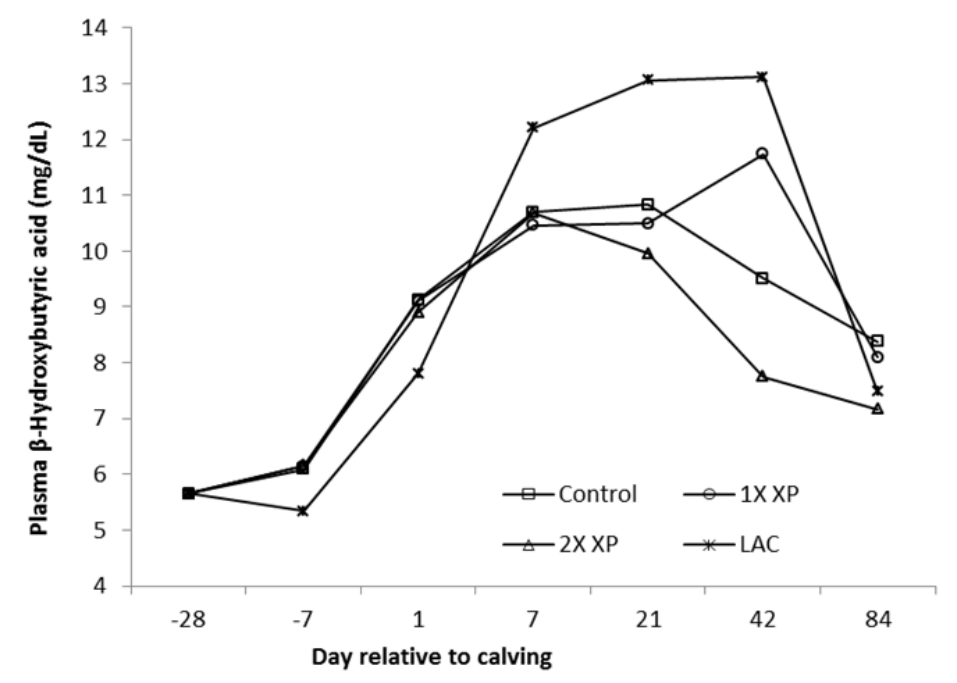

C. 
Figure 4.6. Plasma metabolite concentrations of (A) glucose, (B) non-esterified fatty acids (NEFA), and (C) $\beta$-hydroxybutyrate (BHBA). Blood samples were collected during the morning feeding on $\mathrm{d}-28 \pm 1,-7 \pm 1,1 \pm 1,7 \pm 1,21 \pm 1,42 \pm 1$, and $86 \pm 1 \mathrm{~d}$ relative to calving. There were no treatment or treatment by time interactions for plasma glucose and NEFA $(P<0.15)$. A trend towards increase plasma BHBA was observed for LAC treatment $(P=0.10)$ compared to the other treatments $21 \mathrm{~d}$ following calving. Standard error bars were not depicted in graph but averaged 1.1 for glucose, ranged 27.4 to 28.8 for NEFA, and averaged 0.6 for BHBA.Figure 4.7. 


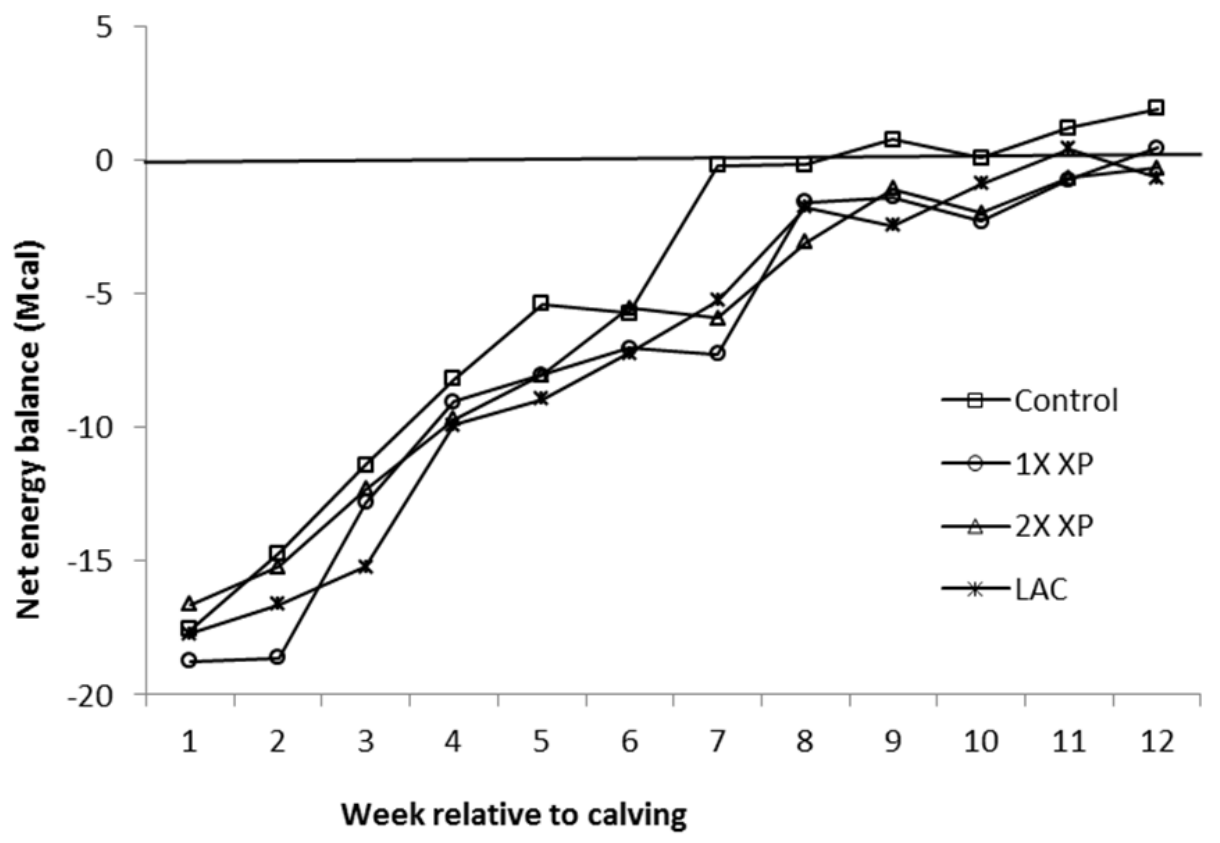

Figure 4.7. Calculated net energy balance (NEB). Calculated net energy balance of cows during lactation indicate a trend for CTL cows to be in a slight more positive energy balance than the other three treatments $(P=0.10)$. The CTL cows reached a state of neutral energy balance as early as seven weeks postpartum while the remaining treatments were in a state of negative energy balance throughout the twelve week lactation period. Standard error bars were not depicted in graph but ranged from 0.92 to 0.96 for net energy balance. 


\section{LITERATURE CITED}

Allen, J. D. and J. M. Gawthorne. 1987 Involovement of the solid phase of rumen digesta in the interaction between copper, molybdenum and sulphur in sheep. British Journal of Nutrition 58(2):265-276.

Ammerman, C. B. and D. M. Miller. 1972. Biological availability of minor ions: A review. Journal of Animal Science 35:681-694.

Appuhany, J. A. D. R. N., B. G. Cassell, C. D. Dechow, and J. B. Cole. 2007. Phenotypic relationships of common healh disorders in dair cows to lactation persistency estimated from daily milk weights. Journal of Dairy Science 90(9):442-4434.

Arambel, M. J. ad B. A. Kent. 1990. Effects of yeast culture on nutrient digestibility and milk yield response in early-to midlactation dairy cows. Journal of Dairy Science 73(6):1560-1563.

Ballantine, H. T., M. T. Socha, D. J. Tomlinson, A. B. Johnson, A. S. Fielding, J. K. Shearer, and S. R. Van Amstel. 2002. Effects of feeding complexed zinc, manganese, copper, and cobalt to late gestation and lactating dairy cows on claw integrity, reproduction, and lactation performance. Professional Animal Science 18:211-218.

Bauman, D. E. and B. W. Currie. 1980. Partitioning of nutrients during pregnancy and lactation: A review of mechanisms involoving homeostasis and homeorhesis. Journal of Dairy Science 63(9):1514-1529.

Beever, D. E. 2006. The impact of controlled nutrition during the dry period on dairy cow health, fertility and performance. Animal Reproductive Science 96(3-4):212-226.

Bell, A. W. 1995. Regulation of organic nutrient metabolism during transistion from late pregnancy to early lactation. Journal of Animal Science 73:2804-2819.

Bell, A. W. and D. E. Bauman. 1997. Adaptations of glucose metabolism during pregnancy and lactation. Journal of Mammary Gland Biology and Neonate 2(3):265-278.

Bernabucci, U., B. Ronchi, N. Lacetera, and A. Nardone. 2005. Influence of body condition score on relationships between metabolic status and oxidative stress in periparturient dairy cows. Journal of Dairy Science 88(6)2017-2026.

Buckley, F., K. O’Sullivan, J. F. Mee, R. D. Evans, and P. Dillion. 2003. Relationships among milk yield, body condition, cow weight, and reproduction in spring-calved Holstein-Friesians. Journal of Dairy Science 86(7):2308-2319.

Busato, A., D. Faissler, U. Kupfer, and J. W. Blum. 2002. Body condition scores in dairy cows: Associations with metabolic and endocrine changes in healthy dairy cows. Journal of Veterinary Medicine Series A 49(9):455-460. 
Callaway, E. S. and S. A. Martin. 1997. Effects of a Saccharomyces cerevisiae culture on ruminal bacteria the utilize lactate and digest cellulos. Journal of Dairy Science 80(9):2035-2044.

Cameron, R. E. B., P. B. Dyk, T. H. Hedt, J. B. Kaneene, R. Miller, H. F. Bucholtz, J. S. Liesman, M. J. Vandehaar, and R. S. Emery. 1998. Dry cow diet, management, and energy balance as risk factors for displaced abomasum in high producing dairy herd. Journal of Dairy Science 81(1):132-139.

Celi, P. 2011. Biomarkers of oxidative stress in ruminant medicine. Immunopharmocology and Immunotoxicology 33(2):233-240.

Chapman, J. 2001. An evaluation of health, milk and milk quality in multiparous Holstein cows fed OmniGen-AF during the dry period. Prince Agri Products.

Chapman, J., S. Puntenney, J. Verano, J. Heeg, Y. Wang, and N. Forsberg. 2005. Effects of OmniGen-AF on mikl production and on lactation persistence in a commercial dairy setting (abstract). ADSA-ASAS Joint Meetings Journal of Dairy Science 88:176 (E-Suppl. 171).

Chaucheyras, F. and G. Fonty. 2001. Establishment of cellulolytic bacteria and development of fermentative activities in the rumen of gnotobiotically-reared lambs recieveing the microbial additive Saccharomyces cerevisiae CNCM I-1007. Reproduction and Nutrition Development 41:57-68.

Chaucheyras, F., G. Fonty, G. Bertin, and P. Gouet. 1995. In Vitro H@ utilization by a ruminal acetogenic bacterium cultivated alone or in association with an archaea methanogen is stimulated by a probiotic strain Saccharomyces cerevisiae . Applied Environment Microbiology 61:3466-3467.

Chow, C. K. 1979. Nutritional influence on cellular antioxidant defense systems. American Journal of Clinical Nutrition 32:1066-1081.

Chung, Y. H., N. D. Walker, S. M. McGinn, and K. A. Beauchemin. 2011. Differing effects of 2 active dried yeasr (Saccharomyces cerevisiae ) strains on ruminal acidosis and methan production in nonlactating dairy cows. Journal of Dairy Science 94(5):2431-2439.

Collier, R. J., G. E. Dahl, and M. J. VanBaale. 2006. Major advances asociated with environmental effects on dairy cattle. Journal of Dairy Science 89(4):1244-1253.

Curtis, C. R., H. N. Erb, C. J. Sniffen, R. D. Smith, P. A. Powers, M. C. Smith, M. E. White, R. B. Hillman, and E. J. Pearson. 1983. Association of parturient hypocalcemia with eight periparturient disorders in Holstein cows. Journal of American Veterinary Medicine Association 183(5):559-561.

Dann, H. M., J. K. Drackley, G. C. McCow, M. F. Hutjens, and J. E. Garrett. 2000. Effects of yeast culture (Saccharomyces cerevisiae ) on prepartum intake and 
postpartum intake and milk production of Jersey cows. Journal of Dairy Science 83(1):123-127.

de Vries, M. J. and R. F. Veerkamp. 2000. Energy balance of dairy cattle in relation to milk production variable and fertility. Journal of Dairy Science 83(1):62-69.

Dillion, P., D. P. Berry, R. D. Evans, F. Buckley, and B. Horan. 2006. Consequences of genetic selection for increased milk production in European seasonal pasture based systems of milk production. Livestock Science. 99(2-3):141-158.

Domecq, J. J., A. L. Skidmore, J. W. Lloyd, and J. B. Kaneene. 1997. Relationship between body condition scores and milk yield in a large dairy herd of high yielging holstein cows. Journal of Dairy Science 80(1):101-112.

Drackley, J. K. 1999. ADSA Foundation Scholar Award. Biology of dairy cows during the transition period: the fianl frontier? Journal of Dairy Science 82(11):22592273.

Drackley, J. K., S. S. Donkin, and C. K. Reynolds. 2006. Major advances in fundamental dairy cattle nutrition. Journal of Dairy Science 89(4):1324-1336.

Drackley, J. K., T. R. Overton, and G. N. Douglas. 2001. Adaptations of glucose and long-chain fatty acid metabolism in liver of dairy cows during the periparturient period. Journal of Dairy Science 84, Supplement (0):E100-E112.

Edmonson, A. J., I. J. Lean, L. D. Weaver, T. Farver, and G. Webster. 1989. A body condition scoring chart for Holstein dairy cows. Journal of Diary Science 72(1):68-78.

Emery, R. S. and L. D. Brown. 1961. Effects of feeding sodium and potassium bicarboate on milk fat, rumen $\mathrm{pH}$, and volatile fatty acid production. Journal of Dairy Science 44(10):1899-1902.

Erasmus, L. J., P. M. Botha, and A. Kistner. 1992. Effect of yeast culture supplement on production, rumen fermentation, and duodenal nitrogen flow in dairy cows. Journal of Diary Science 75(11):3056-3065.

Erasmus, L. J., P. H. Robinson, A. Ahmadi, R. Hinders, and J. E. Garrett. 2005. Influence of prepartum and postpartum supplementation of yeast culture and monensin, or both, on ruminal fermentation and performance of multiparous dairy cows. Animal Feed Science and Technology 122(3-4):219-239.

Erdman, R. A., R. L. Botts, R. W. Hemken, and L. S. Bull. 1980. Effect of dietary sodium bicarbonate and magnesium oxide on production and physiology in early lactation. Journal of Dairy Science 63(6):923-930.

Ferguson, J. D., D. J. Tomlinson, and M. T. Socha. 2004. Effects of inorganic and organic (40PlexR) trace mineral supplementation on milk production and reproduction. Journal of Dairy Science 87 (Suppl. 1):117(abstract). 
Formigoni, A., S. Emanuele, C. J. Sniffen, G. Biagi, and M. Fustini. 2009. The influence of feeding chelated trace minerals on diary cattle performance and colostrum quality. Journal of Animal Science 87(Suppl.2):472-473.

Formigoni, A., M. Fustini, L. Archetti, S. Emanuele, C. Sniffen, and G. Biagi. 2011. Effects of an organic source of copper, manganese and zinc on dairy cattle productive performance, health status and fertility. Animal Feed Science and Technology 164(3-4):191-198.

Fox, D. G. L. O. Tedeschi, T. P. Tylutki, J. B. Russell, M. E. Van Amburgh, L. E. Chase, A. N. Pell, and T. R. Overton. 2004. The Cornell Net Carbohydrate and Protein System model for evaluating herd nutrition and nutrient excretion. Animal Feed Science and Technology 112(1-4):29-78.

French, P. D. 2006. Dry matter intake and blood paraeters of nonlactating Holstein and Jersey cows in late gestation. Journal of Dairy Science 89(3):1057-1061.

Garnsworthy, P. C. and G. P. Jones. 1987. The influence of body condition at calving and dietary protein supply on voluntary food intake and performance in dairy cows. Journal of Animal Science 44(03):347-353.

Garnsworthy, P. C. and J. H. Topps. 1982. The effect of body condition of dairy cows at calving on their food intake and performance when given complete diets. Journal of Animcal Science 35(01):113-119.

Gerloff, B. J., T. H. Herdt, R. S. Emery, and W. W. Wells. 1984. Inositol as a liptropic agent in dairy cattle diets. Journal of Animal Science 59:806-812.

Gillund, P., O. Reksen, Y. T. Grohn, and K. Karlberg. 2001. Body condition relatied to ketosis and reproductive performance in Norwegian dairy cows. Journal of Dairy Science 84(6):1390-1396.

Girard, C. L. and J. J. Matte. 1998. Dietary supplements of folic acid during lactation: Effects on the performance of dairy cows. Journal of Dairy Science 81(5):14121419.

Girard, C. L., J. J. Matte, and G. F. Tremblay. 1995. Gestation and lactation of dairy cows: A role for folic acid? Journal of Dairy Science 78(2):404-411.

Gitto, R. , R. J. Reiter, M. Karbownik, D. X. Tan, P. Gitto, S. Barberi, and I. Barberi. 2002. Causes of oxidative stress in the pre- and perinatal period. Biology of Neonate 81:146-157.

Goff, J. P. and R. L. Horst. 1997. Physiologyical changes at parturition and their relationship to metabolic disorders. Journal of Dairy Science 80(7):1260-1268.

Golombeski, G. L. 2011. The effect of dietary trace minerals during late gestation on health and performance of the dam and progeny. PhD Dissertation. University of Minnesota. 
Grant, R. J. and J. L. Albright. 1995. Feeding behavior and management factors during the transition period in dairy cattle. Journal of Animal Science 73(9):2791-2803.

Grummer, R. R. 1993. Etiology of Lipid-related metabolic disorders in periparturient dairy cows. Journal of Dairy Science 76(12):3882-3896.

Grummer, R. R. 1995. Impact of changes in organic nutrient metabolis on feeding the trasition dairy cow. Journal of Animal Science 73(9):2820-2833.

Grummer, R. R. 2006. Optimization of transition period energy status for improved health and reproduction. World Buiatrics Congress.

Haaland, G. L. and H. Tyrrell, F. 1982. Effects of limestone on sodium bicarbonate buffers on rumen measurements and rate of passage in cattle. Journal of Animal Science 55:935-942.

Hayirli, A., R. R. Grummer, E. V. Nordheim, and P. M. Crump. 2002. Animal and dietatyr factors affecting feed intake during the prefresh transition period in Holsteins. Journal of Dairy Science 85(12):3430-3443.

Herdt, T. H. 200. Ruminant adaptation to negative energy balance: Influences on the etiology of ketosis and fatty liver. Veterinary Clinic of North American Food Animal Practice 16(2):215-230.

Herdt, T. H., T. Wensing, H. P. Haagsman, L. M. van Golde, and H. J. Breukink. 1988. Hepatic triacyglycerol synthesis during a period of fatty liver development in sheep. Journal of Animal Science 66(8):1997-2013.

Heuer, C., Y. H. Schukken, and P. Dobbelaar. 1999. Postpartum body condition score and results from the first test day milk as predictors of disease, ferrtility, yield, and culling in commercial dairy herds. Journal of Dairy Science 82(2):2+95-304.

Hippen, A. R., D. J. Schingoethe, K. F. Kalscheur, P. Linkel, K. Gross, D. Rennich, and I. Yoon. 2007. Interactions of yeast culture and dried distillers grains plus solubles in diets of lactating dairy cows. Journal of Dairy Science 90(Suppl.1):452 (abstract).

Ingvartsen, K. L., R. J. Dewhurst, and N. C. Friggens. 2003. On the relationship between lactational performance and health: is it yield or metabolic imbalance that causes production diseases in dairy cattle? A position paper. Livestock Production Science 83(2-3):277-308.

Irvine, L. D., M. j. Freeman, D. J. Donaghy, I. Yoon, G. Lee, and J. R. Roche. 2011. Short communication: Responses to supplemental Saccharomyces cerevisiae fermentation product and triticale grain in dairy cows grazing high-quality pasture in ealy lactation. Journal of Dairy Science 94(6):3119-3123.

Jones, C. A. 1995. Effect of zinc source on zinc retention and animal health. Masters Thesis. University of Missouri-Columbia. 
Kaps, M. and W. Lamberson. 2004. Biostatistics for animal science. CABI Publishing, 875 Massechusetts Avenue, Cambridge, MA 02139.

Kellogg, D. W., M. T. Socha, and D. J. Tomlinson. 2003. Review: Effects of feeding cobalt glucoheptonate and metal specific amino acid complexes of zinc, manganses, ad copper on lactation and reproductive performance of dairy cows. Professional Animal Sciecne 19:1-9.

Kelton, D. F., K. D. Lissemore, and R. E. Martin. 1998. Recommendations for recording and calculationg the incidence of selected clinical diseases of dairy cattle. Journal of Dairy Science 81(9):2502-2509.

Kimura, K. T. A. Reinhardt, and J. P. Goff. 2006. Parturition and hypocalcemia blunts calcium signals in immune cells of dairy cattle. Journal of Dairy Science 89(7):2588-2595.

Kinal, S., A. Korniewicz, A. Razasa, D. Korniewicz, K. Bialon, and B. Lubojemska. 2007. Effect of Saccharomyces cerevisiae yeast metaolies on colostrum quality and passice immunity transfer in claves. Bulletin of the Veterinary Institute of Pulawy.

Kincaid, R. L. and M. T. Socha. 2004. Inorganic versus complexed trace mineral supplements on performace of dairy cow. Professional Animal Science 20:66-73.

Kunz, P. L., J. W. Blum, I. C. Hart, H. Bickel, and J. Landis. 1985. Effects of different energy intakes before ad after calving on food intake, performance and blood hormones and metabolites in dairy cows. Journal of Animal Science 40(02):219231.

LeBlanc, S. J., K. E. Leslie, and T. F. Duffield. 2005. Metabolic predictors of displaced abomasum in dairy cattle. Journal of Dairy Science 88(1):159-170.

Lehloenya, K. V., D. R. Stein, D. T. Allen, G. E. Selk, D. A. Jones, M. M. Aleman, T. G. Rehberger, K. J. Mertz, and L. J. Spicer. 2008. Effects of feeding yeast and propionibacteria to dairy cows on milk yield and components, and reproduction. Journal of Anaimal Physiology and Animal Nutrition 92(2):190-202.

Linn, J. G., M. L. Raeth-Knight, and G. L. Golombeski. 2001. Trace minerals in the dry period: Boosting cow and calf health. WCDS Advaces in Dairy Technology 23:271-286.

Littell, R. C., P. R. Henry, ad C. B. Ammerman. 1998. Statstical analysis of repeated measures data using SAS procedures. Journal of Animal Science 76(4):12161231.

Lynch, H. A. and S. A. Martin. 2002. Effects of Saccharomyces cerevisiae live cells on In Vitro mixed ruminal microorganism fermentation. Journal of Dairy Science 85(10):2603-2608. 
Macciotta, N. P. P., D. Vicario, C. Di Mauro, and A. Cappio-Borlino. 2004. A multivariate approach to modeling shapes of individual lactation curves in cattle. Journal of Dairy Science 87(4):1092-1098.

Majee, D. N., E. C. Schwab, S. J. Bertics, W. M. Seymour, and R. D. Shaver. 2003. Lactation performance by dairy cows fed supplemental biotin and a B-vitamin blend. Journal of Dairy Science 86:2106-2112.

Mallard, B. A., J. C. Dekkers, M1. J. Ireland, K.e. Leslie, S. Sharif, C. Lacey Vankampen, L. Wagter, and B.N. Wilkie, 1998. Aleration in immune responsiveness during the peripartum period and its ramification on dairy cow and calf health. Journal of Dairy Science 81(2):585-595.

Marquardt, J. P., R. L. Horst, and N. A. Jorgensen. 1977. Effect of parity on dry matter intake at perturition in dairy cattle. Journal of Dairy Science 60(6):929-934.

McArt, J. A. A., D. V. Nydam, and G. R. Oetzel. 2012. A field trial on the effect of propylene glycol on displaced abomasum, removal from herd, and reproduction in fresh cows diagnosed with subclinical ketosis. Journal of Dairy Science 95(5):2505-2512.

McGuffey, R. K., L. F. Richardson, and J. I. D. Wilkinson. 2001. Ionophores for dairy cattle: Current status and future outlook. Journal of Dairy Science 84, Supplement (0):E194-E203.

Miller-Webster, T., W. H. Hoover, M. Holt, and J. E. Nocek. 20020. Influence of yeast culture on ruminal microbial metabolism in continuous culture. Journal of Dairy Science 85(8):2009-2014.

Mulligan, F. J. and M. L. Doherty. 2008. Production diseases of the transition cow. Veterinary Journal 176(1):3-9.

Mulligan, F. J., L O’Grady, D. A. Rice, and M. L. Doherty. 2006. A herd health approach to dairy cow nutirion and prodution diseases of the transition cow. Animal Reproduction Science 96(3-4):331-353.

Newbold, C. J., R. J. Wallace, and F. M. McIntosh. 1996. Mode of action of the yeast Saccharomyces cerevisiae as a feed additive for ruminants. British Journal of Nutrition 76:249-261.

Nocek, J. E., M. T. Socha, and D. J. Tomlinson. 2006. The effect of trace mineral fortification level and source on performance of dairy cattle. Journal of Dairy Science 89(7):2679-2693.

Nutrient Requirments of Dairy Cattle: Seventh Revised Edition. 2001. The National Academies Press.

Oetzel, G. R. and McGuirk. 2008. Evaluation of hand-held meter for cowside evaluation of blood betahydroxybutyrate and glucose concentrations in dairy cows. Page 234 in Proceedings of American Association of Bovine Practitioners. 
Overton, T. R. and M. R. Waldron. 2004. Nutritional minagement of transistion dairy cows: Strategies to optimize metabolic health. Journal of Dairy Science 87, Supplement (0):E105-E119.

Poppy, G. D., A. R. Rabiee, I. J. Lean, W. K. Sanchez, K. L. Dorton, and P. S. Morley. 2012. A meta-analysis of the effects of feeding yeast culture produced by anaerobic fermentation of Saccharomyces cerevisiae on milk production of lactating dairy cow. Journal of Dairy Science 95(10):6027-6041.

Pryce, J. E., M. P. Coffey, and G. Simm. 2001. The relationship between body condition score and reproductive performance. Journal of Dairy Science 84(6):1508-1515.

Putnam, D. E., C. G. Schwab, M. T. Socha, N. L. Whitehouse, N. A. Kierstead, and B. D. Garthwaite. 1997. Effect of yeast culture in the diets of early lactation dairy cows on ruminal fermentation and passage of nitrogen fractions and amino acids to the small intestine. Journal of Dairy Science 80(2):374-384.

Rabiee, A. R., I. J. Lean, M. A. Stevenson, and M. T. Socha. 2010. Effects of feeding organic trace minerals on milk production and reproductive performance in lactating dairy cows: A meta-analysis. Journal of Dairy Science 93(9):4239-4251.

Ramsing, E. M., J. A. Davidson, P. D. French, I. Yoon, M. Keller, and H. PetersFleckenstein. 2009. Effects of yeast culture on Peripartum intake and milk production of primiparous and multiparous Holstein cows. Professional Animal Science 25(4):487-495.

Rastani, R. R., R. R. Grummer, S. J. Bertics, A. Gumen, M. C. Wiltbank, D. G. Mashek, and M. C. Schwab. 2005. Reducing dry period length to simplify fedding transition cows: Milk production, energy balance, and metabolic profiles. Journal of Dairy Science 88(3):1004-1014.

Rekik, B. and A. B. Gara. 2004. Factors affecting the occurrence of atypical lactations for Holstein-Friesian cows. Livestock Production Science 87(2-3):245-250.

Revelo, X. S. 2012. Function and gene expression of circulating neutrophils in dairy cows impact of micronutrient supplementation. PhD Dissertation. University of Missouri-Columbia.

Reynolds, C. K., P. C. Aikman, B. Lupoli, D. J. Humphries, and D. E. Beever. 2003. Splanchnic metabolis of dairy cows during the transition from late gestation through early lactation. Journal of Dairy Science 86(4):1201-1217.

Robinson, P. H. 1997. Effects of yeast culture (Saccharomyces cerevisiae) on adaptation of cows to diets postpartum. Journal of Dairy Science 80(6):1119-1125.

Robinson, P. H. and J. E. Garrent. 1999. Effect of yeast culture (Saccharomyces cerevisiae ) on adaptations of cows to postpartum diets and on lactation performance. Journal of Animal Science 77:988-999. 
Roche, J. R., N. C. Friggens, J. K. Kay, M. W. Fisher, K. J. Stafford, and D. P. Berry. 2009. Invited review: Body condition score and its association with dairy cow productivity, health, and welfare. Journal of Dairy Science 92(12):5769-5801.

Rukkwamsuk, T., M. J. H. Geelen, T. A M. Kruip, and T. Wensing. 2000. Interrelation of fatty acid composition in adipose tissue, serum, and liver of dairy cows during the deveopment of fatty liver postpartum. Journal of Dairy Science 83(1):52-59.

Sacadura, F. C. , P. H. Robinson, E. Evans, and M. Lordelo. 2008. Effects of a ruminally protected B-vitamin supplement on milk yield and composition of lactating dairy cows. Animal Feed Science and Technology 144(1-2):111-124.

Santschi, D. E., R. Berthiaume, J. J. Matte, A. F. Mustafa, and C. L. Girard. 2005a. Fate of supplementary B-vitamins in the gastrointestinal tract of dairy cows. Journal of Dairy Science 88(6):2043-2054.

Santschi, D. E., J. Chiquette, R. Berthiaumen, R. Martineau, J. J. Matte, A. F. Mustafa, and C. L. Girard. 2005b. Effects of the forage to concentrate ratio on B-vitamin concentration in different ruminal fractions of dairy cows. Canadian Journal of Animal Science 85:389-399.

Schingoethe, D. J., K. N. Linke, K. F. Kalscheur, A. R. Hippen, D. R. Rennich, and I. Yoon. 2004. Feed efficiency of mid-lactation dairy cows fest yeast culture during summer. Journal of Dairy Science 87(12):4178-4181.

Schwab, E. C., C. G. Schwab, R. D. Shaver, C. L. Girard, D. E. Putnam, and N. L. Whitehouse. 2006. Dietary forage and nonfiber carbohydrate contents influence B-vitamin intake, duodenal flow, and apparent ruminal synthesis in lactating dairy cows. Journal of Dairy Science 89(1):174-187.

Seal, C. J. and C. K. Reynolds. 1993. Nutritional implications of gastrointestinal and liver metabolism in ruminants. Nutrition Resource Review 6:185-208.

Sharma, N., N. K. Singh, O. P. Singh, V. Pandey, and P. K. Verma. 2011. Oxidative stress and antioxidant status during transition period in dairy cows. AsianAustrian Journal of Animal Science 24(4):479-484.

Shave, R. D. and M. A. Bal. 2000. Effect of dietary thiamin supplementation on milk production by dairy cows. Journal of Dairy Science 83(10):2335-2340.

Shaver, R. D. and J. E. Garrett. 1997. Effect of dietary yeast culture on milk yield, composition, and component yields at commercial dairies. Professional Animal Science 13:204-207.

Siciliano-Jones, J. L, M. T. Socha, D. J. Tomlinson, and J. M. DeFrain. 2008. Effect of trace mineral source on lactation performance, claw integrity, and fertility of dairy cattle. Journal of Dairy Science 91(5):1985-1995. 
Silvestre, A. M., A. M. Martins, V. A. Santos, M. M. Ginja, and J. A. Colaco. 2009. Lactation curves for milk, fat and protein in dairy cows: A full approach. Livestock Science 122(2-3):308-313.

Skaar, T. C., R. R. Grummer, M. R. Dentine, and R. H. Stauffacher. 1989. Seasonal effects of prepartum and postpartum fat and niacin feeding on lactation performace and lipid metabolism. Journal of Dairy Science 72:2028-2038.

Sordillo, L. M. and S. L. Aitken. 2009. Impact of oxidative stress on the health and immune function of dairy cattle. Veterinary Immunology and Immunopathology 128(1-3):104-109.

Spain, J. C., C. A. Jones, C. J. Rapp, M. T. Socha, and D. J. Tomlinson. 2005. The effect of complexed zinc on keratin synthesis in the teat canal and the establishment and severity of experimentally induced E. coli mastitis in dairy cows. Mastitis in Dairy Production pg.948.

Spears, J. W. 2000. Micronutrients and immune function in cattle. Proceedings of Nutritional Society 59(4):587-589.

Spears, J. W. 2003. Trace mineral bioavailability in ruminants. Journal of Nutrition 133(5):1506s-1509s.

Spears, J. W. and W. P. Weiss. 2008. Role of antioxidants and trace elements in health and immunity of transition dairy cows. The Veterinary Journal 176(1):70-76.

Sprecher, D. J., D.E. Hostetler, and J. B. Kaneene. 1197. Locomotion scoring of dairy cattle. Theriogenology 47:1178-1187.

Stella, A. V., R. Paratte, L. Valnegri, G. Cigalino, G. Soncini, E. Chevaux, V. Dell'Orto, and G. Savoini. 2007. Effect of administration of live Saccharomyces cerevisiae on milk production, milk composition, blood metabolites, and faecal flora in early lactating dairy goats. Small Ruminant Research 67(1):7-13.

Sullivan, H. M. and S. A. Martin. 1999. Effects of Saccharomyces cerevisiae culture on In Vitro mixed ruminal microorganism fermentation. Journal of Dairy Science 82(9):2011-2016.

Tekerli, M., Z. Akinci, I. Dogan, and A. Akcan, 2000. Factors affecting the shape of lactation curves of Holstein cows from the Balikesir province of Turkey. Journal of Dairy Science 83(6):1381-1386.

Thrune, M., A. Bach, M. Ruiz-Moreno, M. D. Stern, and J. G. Linn. 2009. Effects of Saccharomyces cerevisiae on ruminal $\mathrm{pH}$ and microbial fermentation in dairy cows: Yeast supplementation on rumen fermentation. Livestock Science 124(13):261-265.

Togashi, K. and C. Y. Lin. 2003. Modifying the lactation curve to improve lactation milk and persistency. Journal of Dairy Sciecne 86(4):1487-1493. 
Toni, F., L. Grigoletto, C. J. Rapp, M. T. Socha, and D. J. Tomlinson. 2007. Effect of replacing inorganic forms of zinc, manganese, and copper with complexed sources on lactation and reproductive performance of dairy cows. Professional Animal Science 23:409-416.

Trevisan, M., R. Browne, M. Ram, P. Muti, J. Freudenheim, A. M. Carosella, and D. Armstron. 2001. Coorelates of markers of oxidative status I the general population. American Journal of Epidemiology 154(4):348-356.

Uchida, K., P. Mandebvu, C. S. Ballard, C. J. Sniffen, and M. P. Carter. 2001. Effect of feeding a combination of zinc, manganese and copper amino acid complexes, and cobalt glucoheptonate on performance of early lactation high producing dairy cows. Animal Feed Science and Technology 93(3-4):193-203.

Val-Arreola, D., E. Kebrab, J. Dijkstra, and J. France. 2004. Study of the lactation curve in dairy cattle on farms in Central Mexico. Journal of Dairy Science 87(11):37893799.

Vizcarra, J. A., R. P. Wettemann, J. C. Spitzer, and D. G. Morrison. 1998. Body condition at parturition and postpartum weight gain influence luteal activity and concentrations of glucose, insulin, and nonesterified fatty acids in plasm of primiparous beef cows. Journal of Animal Science 76:927-936.

Wallace, R. J. 1994. Ruminal microbiology, biotechnology, and ruminant nutrition: Progress and problems. Journal of Animal Science 72:2992-3003.

Wang, Y., S. Puntenney, J. L. Burton, and N. Forsberg. 2007. Ability of commercial feed additive to modulate expression of inate immunity in sheep immunosuppressed with dexamethasone. Animal 1:945-951.

Wang, Y. Q., S. B. Puntenney, J. L. Burton, and N. E. Forsberg. 2009. Use of gene profiling to evaluate the effects of a feed additive on immune function in periparturient dairy cattle. Journal of Animal Physiology and Animal Nutrition 93(1):66-75.

Watts, D. L. 1990. Nutrient interrelationships minerals-vitamins-endocrines. Journal of Orthomology Medicine. 5:11-19.

Wiedmeier, R. D., M. J. Arambel, and J. L. Walters. 1987. Effects of yeast culture and Aspergillus oryzae fermentation extract on ruminal characteristics and nutrient digestibility. Journal of Dairy Science 70(10):2063-2068.

Williams, P. E., G. M. Tair, G. M. Innes, and C. J. Newbold. 1991. Effects of the inclusion of yeast culture (Saccharomyces cerevisiae plus growth medium) in the diet of dairy cows on milk yield and forage degradation and fermentation patterns in the rumen of steers. Journal of Animal Science 69:3016-3026. 
Young, C. W., V. R. Eidman, and J. K. Reneau. 1985. Animal health and management and their impact on economic efficiency. Journal of Dairy Science 68(6):15931602.

Zaracula, S., H. Cernescu, C. Mircu, C. Tulcan, A. Morvay, S. Baul, and D. Popovici. 2010. Influence of breed, parity and food intake on chemical composition of first colostrum in cow. Animal Science and Biotechnologies 43(1):154-157.

Zimmerly, C. A. and W. O. Weiss. 2001. Effects of supplemental dietary biotin on performance of Holstein cows during early lactation. Journal of Dairy Science 84:498-506. 


\section{VITA}

Nicole Barkley was born in Aurora, Colorado and raised in the state of Alaska.

She received her B.S. in Animal Science: Pre-veterinary Science and Dairy Science (honors) from the University of Idaho in Moscow, Idaho in 2006. She attended the University of Missouri in Columbia, Missouri where she received her M.S. in Animal Science: Reproductive Physiology in 2008 and will receive her Ph.D. in Animal Science: Nutrition Physiology in 2013. 